UNIVERSIDADE DE BRASÍLIA - UNB

FACULDADE DE EDUCAÇÃO FÍSICA

PROGRAMA DE PÓS-GRADUAÇÃO STRICTO SENSU EM EDUCAÇÃO FÍSICA

\title{
EFEITOS DE DOIS TIPOS DE TREINAMENTO RESISTIDO DE FORÇA MUSCULAR E DESEMPENHO FUNCIONAL E IDOSOS DA COMUNIDADE
}

Gerson Aparecido de Souza Junior

BRASÍLIA

2015 


\title{
EFEITOS DE DOIS TIPOS DE TREINAMENTO RESISTIDO NA FORÇA, MASSA MUSCULAR E DESEMPENHO FUNCIONAL EM MULHERES IDOSAS
}

GERSON APARECIDO DE SOUZA JUNIOR

\begin{abstract}
Dissertação apresentada ao Programa de Mestrado em Educação Física da Universidade de Brasília como requisito para obtenção do grau de Mestre em Educação Física.
\end{abstract}




\section{DEDICATÓRIA}

Dedico este trabalho aos meus pais (Divina

e Gerson) e minha amada Gabriella. 


\section{AGRADECIMENTOS}

Aos meus pais, Gerson Aparecido de Souza e Divina de Fátima Gonçalves de Souza pelo apoio e fortaleza, não apenas durante a realização deste trabalho, mas desde o inicio de minha existência. Seu suporte, carinho, dedicação e cobrança, me trouxeram até aqui. Por isso, e muito mais, muito obrigada.

A minha amada, Gabriella Costa Amaral pelo amor, companheirismo, pela paciência, atenção e amizade durante todos os nossos momentos vividos e maiores ainda nesses últimos anos.

A minha orientadora e meu exemplo, Prof. Dra . Marisete Peralta Safons, pela orientação, por todo apoio e incentivo, pelos conhecimentos, por sua ajuda no estudo sempre que possível, críticas e principalmente as "Catracadas", por sua dedicação e disponibilidade demonstradas ao longo deste trabalho. Sem a sua dedicação não teria sido possível a realização do mesmo.

As amigas e companheiras, Karina e Milene, viver cada etapa ao lado de vocês foi muito especial. Comer bastante, trocar idéias, "ir ao pancadão", ouvir conselhos, dividir tarefas, superar etapas difíceis, vocês me ajudaram a crescer como pesquisador e como pessoa. Muito Obrigado!!

Ao professor Dr. Wagner Rodrigues Martins por todos os conhecimentos partilhados, pelas idéias, pela ajuda e por sempre estar disponível a ajudar.

Aos também amigos estagiários, em especial ao Tito, Anderson, More, Carlos, Wanessa e Gustavo, obrigado pelo respeito e dedicação demonstrados, obrigado pela ajuda nas coletas e intervenções e por tantos momentos de aprendizado. Aprendi muito com vocês.

Aos pesquisadores do Grupo de Estudos e Pesquisas sobre Atividade Física para Idosos (GEPAFI), que de maneira direta ou indireta contribuíram para a realização do trabalho. Obrigado pelos conselhos, discussão de artigos e momentos de descontração.

Às voluntárias da pesquisa a minha eterna gratidão, vocês contribuíram para o meu crescimento pessoal e profissional. Obrigado, pelo empenho, pelos deliciosos lanchinhos, pelo imenso afeto e carinho demonstrados para mim. Serei eternamente grato a vocês. Por fim, agradeço a todos os professores, funcionários da instituição e colegas por todos os momentos de convivência. 


\section{SUMÁRIO}

LISTA DE TABELAS.............................................................................. I

LISTA DE FIGURAS..................................................................................... II

LISTA DE SIGLAS, ABREVIATURAS E SÍMBOLOS.......................... IV

RESUMO_.......................................................................................................

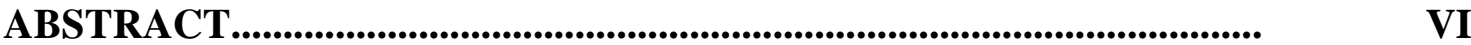

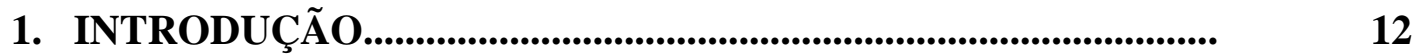

2. OBJETIVOS.......................................................................................

3. HIPÓTESES............................................................................... 16

4. REVISÃO DA LITERATURA...................................................... 17

4.1.Envelhecimento: Uma Visão Epidemiológica................................. 17

4.2.Alterações Fisiológicas no Envelhecimento........................................ 19

4.2.1. Força e Massa Muscular no Envelhecimento............................... 19

4.2.2. Envelhecimento e Desempenho Funcional................................ 22

4.3.Exercício Físico e Envelhecimento..................................................... 24

4.3.1. Treinamento Muscular no Envelhecimento................................ 24

4.3.2. Treinamento com Resistência Elástica para Idosos....................... $\quad 27$

5. MATERIAIS E MÉTODOS........................................................................ 31

5.1.Delineamento do Estudo................................................................. 31

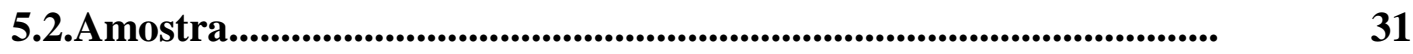

5.2.1. Critérios de Inclusão e Exclusão............................................... 32

5.2.2. Triagem da Amostra.................................................................

5.3. Instrumentos e Avaliações............................................................. 33

5.3.1. Entrevistas........................................................................... 
5.3.2. Avaliações Antropométricas....................................................... 34

5.3.3. Avaliação da Força Muscular Isocinética........................................ 34

5.3.4. Avaliação da Massa Muscular............................................................. 36

5.3.5. Avaliação da Funcionalidade..................................................... 37

5.3.6. Equipamentos de Resistência .............................................................. 38

5.4.Procedimentos Experimentais......................................................... 40

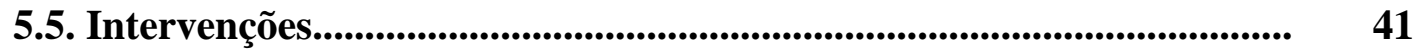

5.6.Análise Estatística................................................................................... 49

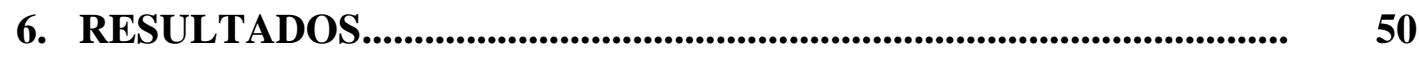

7. DISCUSSÃ

7.1.Efeitos sobre a Força Muscular......................................................................... 53

7.2.Efeitos sobre a Massa Muscular................................................................. $\quad 56$

7.3.Efeitos sobre o Desempenho Funcional........................................................ 58

7.4.Limitações do Estudo.....................................................................

7.5.Aplicações Práticas...................................................................... 61

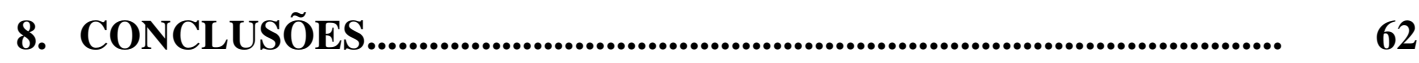

9. REFERENCIAS BIBLIOGRÁFICAS................................................... 63

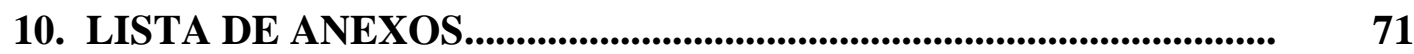




\section{LISTA DE TABELA E QUADROS}

Tabela 1- Características da amostra por grupo no início do estudo........................ 49

Tabela 2- Características das variáveis dependentes por grupo no início do estudo. $\quad \mathbf{5 0}$

Tabela 3 - Mudanças Pré e Pós das variáveis dependentes.................................... 51

Tabela 4 - Critérios de referencia para a manutenção da independência física.......... 58

Quadro 1 - Exercícios realizados durante o período de treinamento........................ 42

Quadro 2 - Variáveis agudas do treinamento.........................................................42 


\section{LISTA DE FIGURAS}

Figura 1- Causas e conseqüências da sarcopenia......................................... 20

Figura 2- Fluxograma da seleção da amostra e delineamento experimental. 33

Figura 3- Mensuração da força isocinética no membro inferior e superior... 35

Figura 4- Avaliação da massa muscular no DEXA..................................... 36

Figura 5- Teste de sentar e levantar da cadeira............................................ 37

Figura 6- Teste flexão de cotovelo............................................................ 38

Figura 7- Níveis de resistência elástica e acessórios para fixação................ 39

Figura 8- Valores de força e alongamento em cada um dos 7 níveis de 39 resistência.....

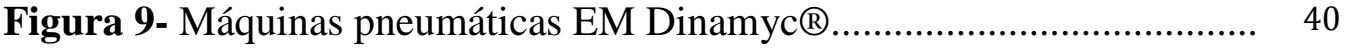

Figura 10-Equiparação do exercício remada.............................................. 43

Figura 11-Equiparação do exercício supino............................................ 43

Figura 12-Equiparação do exercício puxada alta.................................... 44

Figura 13-Equiparação do exercício tríceps................................................ 44

Figura 14-Equiparação do exercício flexão de joelho.................................. 45

Figura 15-Equiparação do exercício extensão de joelho............................. 45

Figura 16-Equiparação do exercício abdução de quadril............................ 46

Figura 17-Equiparação do exercício extensão de quadril............................. 46

Figura 18-Equiparação do exercício abdução de quadril............................. 47

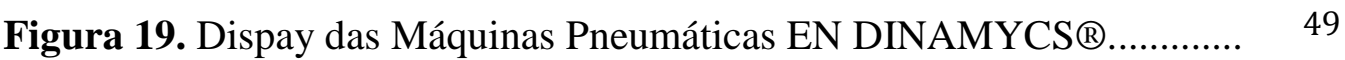




\section{LISTA DE SIGLAS, ABREVEATURAS E SÍMBOLOS}

$\mathrm{TF}=$ Treinamento de Força

$\mathrm{TR}=$ Treinamento Resistido

AVDs = Atividades da Vida Diária

CID = Classificação Internacional de Doenças

DNCT = Doenças Crônicas não Transmissíveis

$\mathrm{PT}=$ Pico de Torque

PTEJ = Pico de Torque de Extensão de Joelho

PTFC $=$ Pico de Torque de Flexão de Cotovelo

MLG $=$ Massa Livre de Gordura

MLGI = Massa Livre de Gordura Membros Inferiores

MLGS = Massa Livre de Gordura Membros Superiores

MLGT = Massa Livre de Gordura Membros Total

IMC = Índice de Massa Corporal

OMS = Organização Mundial da Saúde

IBGE $=$ Instituto Brasileiro de Geografia e Estatística

GEPAFI $=$ Grupo de Estudos e Pesquisas sobre Atividades Física para Idosos

$\mathrm{AF}=$ Atividade Física

DEXA = Absormetria de Raio-X de Dupla Energia

$\mathrm{RM}=$ Repetição Máxima

$\mathrm{GE}=$ Grupo Experimental

GM= Grupo Máquina

TSL $=$ Teste de Sentar e Levantar

$\mathrm{FC}=$ Teste Flexão de Cotovelo

TCLE $=$ Termo de Consentimento Livre Esclarecido

UnB = Universidade de Brasília

FCE $=$ Faculdade da Ceilândia

FEF = Faculdade de Educação Física

PRÉ = Avaliação pré intervenção

PÓS = Avaliação pós intervenção

Rep $=$ Repetições 


\section{RESUMO}

A redução da força e da massa muscular associada ao envelhecimento são considerados fatores preditores para o desenvolvimento de incapacidades físicas e funcionais. Dentre as estratégias consideradas positivas para o incremento da força e da massa muscular encontra-se o treinamento resistido (TR). Uma possibilidade simples, prática e de baixo custo para praticar o TR é a utilização de dispositivos elásticos. OBJETIVO: Verificar os efeitos de doze semanas de dois tipos de TR na força, massa muscular e desempenho funcional em mulheres idosas. MÉTODOS: Um total de 44 mulheres idosas completou este ensaio clínico, divididas em dois grupos de intervenção: Grupo Elástico (GE; n=18; idade=67,55 $\pm 5,2$ anos) e Grupo Máquina (GM; n=26; idade=69,34 $\pm 5,37$ anos). O GE e GM praticaram as intervenções em sessões de 60 minutos, duas vezes por semana durante 12 semanas com nove exercícios equiparados para ambos os grupos. A força muscular foi avaliada através do pico de torque isocinético (PT) de extensão do joelho (PTEJ) e flexão de cotovelo (PTFC) dominante nas velocidades 60 e $180 \%$ s. A massa muscular foi avaliada pelo DXA com medida de massa livre de gordura membros superiores(MLGS), massa livre de gordura membros inferiores(MLGI) e massa livre de gordura total (MLGT). O desempenho funcional foi avaliado através dos testes de Levantar da cadeira (TSL) e Flexão do Cotovelo (FC). Todas as avaliações foram realizadas antes e após o período de intervenção. Utilizou-se estatística descritiva e verificou-se a normalidade dos dados através do teste de Shapiro-Wilk. Para comparar as variáveis dependentes entre os grupos e entre os momentos pré e pós-intervenção a análise de variância mista, testes t pareado e independente, Wilcoxon e U-Mann-Whitney foram aplicados. Os cálculos foram realizados no programa SPSS, para um índice de significância de $p \leq 0,05$. No início do estudo os grupos eram equivalentes em termos de idade, medidas antropométricas e variáveis dependentes ( $>>0,05)$.RESULTADOS:O GE obteve melhora no PTEJ60\%(9,6\%), PTEJ180 $(11,4 \%), \quad \operatorname{PTFC}^{\circ}(11,3 \%), \quad \operatorname{PTFC} 180^{\circ}(9,2 \%), \quad \operatorname{MLGS}(0,5 \%), \quad \operatorname{MLGI}(3,3 \%)$, MLGT $(1,5 \%), \operatorname{TSL}(41,4 \%)$ e FC(56,3\%). O GM obteve melhora no PTEJ60(14,4\%), PTEJ180 $(14,1 \%), \quad \operatorname{PTFC60}(18,9 \%), \quad \operatorname{PTFC} 180^{\circ}(19,6 \%), \operatorname{MLGS}(2,9 \%), \operatorname{MLGI}(2,6 \%)$, MLGT $(1,3 \%), T S L(38,4 \%)$ e FC(51,6\%). Não foram observadas diferenças "entre" os grupos nos deltas (PÓS-PRÉ) em todas as variáveis dependentes. CONCLUSÃO: Concluise que ambos os tipos de TR foram capazes de melhorar a força a massa muscular e o desempenho funcional de mulheres idosas.

Palavras-chave: Envelhecimento, treinamento resistido, força muscular, massa muscular, desempenho funcional. 


\begin{abstract}
The reduction of muscle mass and strength associated with aging are considered as predictors for the development of physical and functional disabilities. Among the strategies considered positive for the increase of strength and muscle mass is resistance training (RT). A simple possibility, practical and inexpensive to practice TR is the use of elastic devices. To assess the effects of twelve weeks of two types of TR in strength, muscle mass and functional performance in elderly women. METHODS: A total of 44 elderly women completed this clinical trial, divided into two distinct groups: Elastic Group $(\mathrm{GE}, \mathrm{n}=18$; age $=67.55 \pm 5.2$ years $)$ and Machine Group $(\mathrm{CG}, \mathrm{n}=26$; age $=$ $69.34 \pm 5.37$ years). GE and GM practiced interventions in 60 minute sessions, twice a week for 12 weeks treated with nine years for both groups. Muscle strength was evaluated by the isokinetic peak torque (PT) knee extension (PTKE) and elbow flexion (PTEF) dominant at speeds 60 to $180^{\circ} / \mathrm{s}$. Muscle mass was assessed by DXA with free mass as fat upper limbs (FFUL), lower fat free mass members (FFML) and total fat-free mass (FFMT). Functional performance was evaluated by the Lift Chair tests (TLC) and elbow flexion (EF). All evaluations were performed before and after the intervention period. We used descriptive statistics and verified the data normality by the ShapiroWilk test. To compare the dependent variables between groups and between pre- and post-intervention analysis of mixed variance, paired t tests and independent, Wilcoxon and U-Mann-Whitney were applied. The calculations were performed using SPSS for a $p \leq 0,05$ significance index. At baseline the groups were similar in terms of age, anthropometric measurements and dependent variables $(\mathrm{p}>0.05)$. RESULTS: GE obtained improved PTKE60 ${ }^{\circ}$ (9.6\%), PTKE180 $(11.4 \%)$, PTEF60 ${ }^{\circ}(11.3 \%)$, PTEF180 (9.2\%), FFUL (0.5\%), FFML (3.3\%), FFMT (1.5\%), TLC (41.4\%) and EF (56, 3\%). The obtained improvement in GM PTKE60 ${ }^{\circ}(14.4 \%)$, PTKE180 ${ }^{\circ}(14.1 \%)$, PTEF60 ${ }^{\circ}$ (18.9\%), PTEF180 (19.6\%), FFUL (2.9\%), FFML (2.6\%) FFMT (1.3\%), TLC $(38.4 \%)$ and EF (51.6\%). There were no differences "between" groups in the deltas (POST-PRE) on all dependent variables. CONCLUSION: We conclude that both types of TR were able to improve the strength muscle mass and functional performance in elderly women.
\end{abstract}

Key words: Aging, resistance training, muscle strength, muscle mass, functional performance. 


\section{INTRODUÇÃO}

O envelhecimento é um processo natural e multifatorial, caracterizado por intensas mudanças na estrutura e funcionamento dos diversos sistemas fisiológicos, mesmo na ausência de doenças. Essas alterações no organismo podem comprometer variáveis antropométricas e neuromusculares ampliando o declínio na qualidade e na quantidade das atividades da vida diária (AVDs), como fazer compras, cuidar do jardim, vestir-se, deslocar-se de um local a outro, podendo ocasionar uma redução da independência física do idoso (FARINATTI, 2008; ACMS, 2009).

Uma das alterações fisiológicas consideradas mais importantes com o avançar da idade é a diminuição da força muscular. Este declínio contribui diretamente para a fragilidade e incapacidade funcional do idoso aumentando as chances de quedas, morbidades e mortalidade (HARTHOLT et al., 2011; OLSSON et al., 2012). Outra alteração importante, ocorrida com o envelhecimento é a composição corporal, resultando no aumento na massa de gordura corporal, especialmente com acúmulos na cavidade abdominal e uma diminuição na massa magra corporal (LANDI et al., 2014). Além disso, existe uma significativa relação entre a força muscular reduzida, desempenho funcional e perda da massa muscular (KARIKANTA et al., 2010).

O termo sarcopenia foi proposto por Rosenberg (1989) para descrever, inicialmente o declínio da massa muscular, contemplando posteriormente, aspectos relacionados à redução da função muscular. Em estudo recente de revisão Santilli et al. (2014) afirmou que o termo sarcopenia, ainda não aceitou uma definição clínica de consenso na Classificação Internacional de Doenças em sua 9a revisão (CID-9). Porém, existem convergências na definição operacional, caracterizada pela perda progressiva e generalizada de força e massa muscular esquelética com risco de resultados adversos, tais como deficiência física, diminuição da qualidade de vida e morte (GOODPASTER et al., 2006; DELMONIACO et al., 2007).

A literatura relata nas últimas revisões e posicionamentos sobre os benefícios do treinamento resistido (TR) ou também denominado treinamento de força (TF) para a população idosa, trazendo algumas orientações sobre a utilização deste método como possibilidade não farmacológica de minimizar os efeitos deletérios do processo de envelhecimento nos sistemas fisiológicos, aumentando a expectativa de vida, autonomia e limitar a progressão de Doenças Crônicas não Transmissíveis (DCNT) (ACMS, 2009; STEIB et al., 2010; SILVA et al., 2014). 
O último posicionamento do Colégio Americano de Medicina Esportiva (ACSM, 2009) sobre a progressão do treinamento resistido para a população idosa, recomenda iniciar um programa de treino usando máquinas e pesos livres. Porém, em muitos casos, não é possível acessar estes equipamentos, devido à falta de instalações ou recursos financeiros. Além disso, a taxa média de abandono em programas de exercícios como estes equipamentos é de aproximadamente $50 \%$ durante o primeiro ano de prática (DISHMAN et al., 2004). Diante disso, parece importante propor alternativas ao treinamento resistido que podem ser convenientes para certos grupos, tais como a população idosa.

Outra possibilidade de praticar o treinamento resistido ocorre com a utilização de resistência elástica, que é realizado com auxílio de materiais elásticos em forma de banda ou tubo, juntamente com acessórios, estes materiais apresentam diferentes níveis de progressão da intensidade (COLADO et al., 2010; MARTINS et al., 2013). Estes equipamentos são práticos, portáteis e permitem sua utilização em praticamente qualquer local, além de apresentar baixo custo (SAKANOUE, 2007). Existem no mercado, equipamentos que possuem ergonomia que permitem tornar os exercícios mais versáteis, possibilitando movimentos mais funcionais.

No estudo transversal de Jakobsen et al. (2014) a ativação muscular dos músculos isquiotibiais foi comparada através de eletromiografia de superfície durante um exercício de flexão do joelho utilizando máquina de musculação e dispositivo elástico. Os resultados do estudo demonstraram semelhança na ativação entre os dois tipos de dispositivos, chegando a valores acima de $80 \%$ no dispositivo elástico.

Os ensaios clínicos que investigaram os efeitos do treinamento resistido com resistência elástica em idosos têm demonstrando eficácia na força muscular isométrica, isocinética e isotônica (RIBEIRO et al., 2009; CHEUG et al., 2009 e WEBBER et al., 2010). Porém, não foram encontrados estudos que avaliaram força muscular isocinética para membros superiores. Em relação á massa muscular, estudos que investigaram este tipo de intervenção sobre esta variável são escassos. Os que tivemos acesso trabalharam com idosas obesas (KNOW et al., 2010), com doença pulmonar obstrutiva (RAMOS et al., 2014) e mulheres pós-menopausa saudáveis média de idade 53,5 anos (COLADO et al., 2012), necessitando de mais estudos para verificar a eficácia deste tipo de dispositivo sobre esta variável em mulheres idosas que vivem na comunidade. Pois já existem evidencias, inclusive com meta analise para a efetividade do treinamento 
resistido com treinamento com pesos livres e máquinas de musculação (PETERSON et al., 2011).

Sendo assim, se faz necessário identificar novas estratégias de treinamento físico no sentido de ampliar as possibilidades de intervenção com a população idosa, buscando contribuir para melhorar o desempenho nas suas atividades de vida diária, na prevenção dos declínios naturais do envelhecimento, repercutindo positivamente na melhora da qualidade de vida de idosos. 


\section{OBJETIVO}

Verificar e comparar os efeitos de dois tipos de treinamento resistido (Máquinas Pneumáticas e Resistência Elástica Progressiva) na força, massa muscular e desempenho funcional em mulheres idosas. 


\section{HIPÓTESES}

I Haverá diferença significativa na força, massa muscular e desempenho funcional “intra - grupo" após o Treinamento Resistido.

II Não haverá diferença significativa na força, massa muscular e desempenho funcional "entre - grupos" após o Treinamento Resistido. 


\section{REFERENCIAL TEÓRICO}

\subsection{Envelhecimento: Uma Visão Epidemiológica}

Segundo a Organização Mundial da Saúde (OMS, 2012), o envelhecimento populacional é um fenômeno global que ocorre em diferentes proporções, de acordo com aspectos sociais e econômicos, tendo no momento atual um destaque maior nos países em desenvolvimento. Uma das explicações para este fenômeno está na interação entre a queda da taxa de natalidade, ocasionada por diversos fatores (planejamento familiar e controle das mulheres sobre sua fertilidade) e o aumento da expectativa de vida (avanço da medicina e do acesso aos cuidados com a saúde) (BAPTISTA et al., 2006).

Na metade do século XX, existia, no mundo, aproximadamente 14 milhões de pessoas com idade superior a 80 anos, tendo projeção para este número alcançar os 400 milhões em 2050 (OMS, 2012). No Brasil, a população tem passado por uma grande transição nas ultimas décadas, em 2000 os idosos representavam 8,6 \% e em 2025 chegará a 13\% (IBGE, 2010). Segundo Freitas et al. (2011), atualmente o Brasil possui cerca de 21 milhões de idosos e as estimativas sobre essa população apontam para superar os 33 milhões em 2025, tornando nosso país o sexto maior percentual de idosos no mundo.

Diante desta realidade, a preocupação com problemas associados á saúde do idoso, tende a ser ampliado pelos diversos setores da sociedade, uma vez que, com o avanço da idade, há um aumento da incidência de doenças que acometem esta população. Neste sentido, o perfil de mortalidade por doenças infectocontagiosas típico da população jovem, tende a ser alterado para doenças crônicas não transmissíveis (DCNT), necessitando de investimentos de recursos nos serviços de saúde, visto que, aumenta o número de internações hospitalares, gasto com exames, medicamentos e o tempo de ocupação dos leitos (VERAS et al., 2003; IBGE, 2009).

De acordo com dados do Instituto Brasileiro de Geografia e Estatística (IBGE, 2009), 64,4\% da população idosa é acometida por uma ou mais DCNT. As mais prevalentes são a hipertensão, diabetes e obesidade, ocasionadas principalmente pelo estilo de vida do indivíduo. A pesquisa sobre vigilância de fatores de risco e proteção para DCNT por inquérito telefônico, realizada nas 26 capitais e no Distrito Federal 
(VIGITEL, 2015) destaca que 24.4\% dos idosos são diabéticos, 59.9\% hipertensos, $19.9 \%$ obesos e $57.8 \%$ estão acima do peso.

Em relação à prática de atividades físicas $(\mathrm{AF})$ no trabalho, deslocamento ou lazer, os dados são preocupantes. Esta mesma pesquisa relata que apenas 22,8\% dos entrevistados realizam pelo menos 150 minutos de AF moderada semanalmente, $72,5 \%$ não alcançaram este gasto somando todas as suas atividades diárias e 38,2\% são fisicamente inativos. A pesquisa Vigitel (2015) classifica como fisicamente inativos todos os indivíduos que relataram não ter praticado qualquer AF no tempo livre nos últimos três meses e que não realizaram esforços físicos relevantes no trabalho, não se deslocaram para o trabalho ou para a escola caminhando ou pedalando (perfazendo um mínimo de 10 minutos por trajeto) e que não participaram da limpeza pesada de suas casas.

Com o avançar da idade, ocorrem grandes alterações na composição corporal dos indivíduos como a redução da força e da massa muscular. Essa diminuição ocorre basicamente como resultado das perdas da massa muscular esquelética, denominada sarcopenia (CARDOSO et al., 2008). A sarcopenia é mais evidente em indivíduos fisicamente inativos, mas também é vista em sujeitos que permanecem ativos ao longo de suas vidas, com isso corroboram fatores pertinentes à saúde pública (PÍCOLI et al., 2011).

Segundo Santilli et al. (2014) a sarcopenia afeta, atualmente, mais de 50 milhões de pessoa e as projeções mais conservadoras é que este número se aproxime dos 200 milhões em 40 anos. O impacto da sarcopenia em idosos é de grande alcance; suas ferramentas substanciais são medidas em termos de morbidade, incapacidade, altos custos nos cuidados com a saúde e mortalidade (MORLEY et al., 2008).

A diminuição da massa muscular e da força muscular, juntamente com o aumento da massa de gordura corporal, pode influenciar na autonomia, no bem estar e na qualidade de vida dos idosos (CARDOSO et al., 2008).

A ampliação do número de idosos e a maior utilização do sistema de saúde, conseqüências de uma maior expectativa de vida e das múltiplas patologias que acometem a população idosa, configuram-se como grande desafio para pesquisadores e para a iniciativa governamental. Desta forma, pesquisas das alterações fisiológicas decorrentes do envelhecimento podem propiciar uma melhor compreensão dos mecanismos que regem este processo, possibilitando intervenções preventivas e terapêuticas 


\subsection{Alterações fisiológicas no envelhecimento}

\subsubsection{Força e massa muscular no envelhecimento}

A força muscular diminui com o avançar da idade, indivíduos com 80 anos apresentam cerca de $40 \%$ menos força comparados com indivíduos de 20 anos (DOHERTY, 2003). Estas reduções são mais evidentes em mulheres do que em homens, mais prevalentes nos membros superiores que nos inferiores e grande parte desta diminuição está relacionada á atrofia muscular e nas alterações ocorridas no tecido muscular (ROSENBERG, 1989; FRONTERA et al. 2000; SANTILLI et al., 2014).

O tecido muscular armazena $60 \%$ das reservas de proteínas do corpo. A perda deste tecido é uma alteração muito relevante para o idoso, sendo diretamente responsável por prejuízo funcional, aumento da probabilidade de quedas e perda da autonomia (JANSEN, 2004). Esta perda pode ser considerada a mais importante alteração em níveis clínicos e funcionais (VALENTE et al., 2011). A perda de massa muscular, denominada sarcopenia, também está relacionada á diminuição de força muscular, velocidade de contração muscular e da função muscular (ROSENBERG, 1989).

O termo sarcopenia foi proposto inicialmente por Rosenberg (1989) ("sarx"=carne+ "penia"=perda) trazendo do grego a definição para este processo relacionado à idade. As causas da sarcopenia são multifatoriais, sendo relacionado a alterações endócrinas, metabolismo muscular, falta de atividade física, ingestão calórica, síntese de proteínas, medidores inflamatórios, fatores genéticos entre outros, conforme Figura 1. (DOROTY, 2003; CRUZ-JENTOFT et al., 2010). 


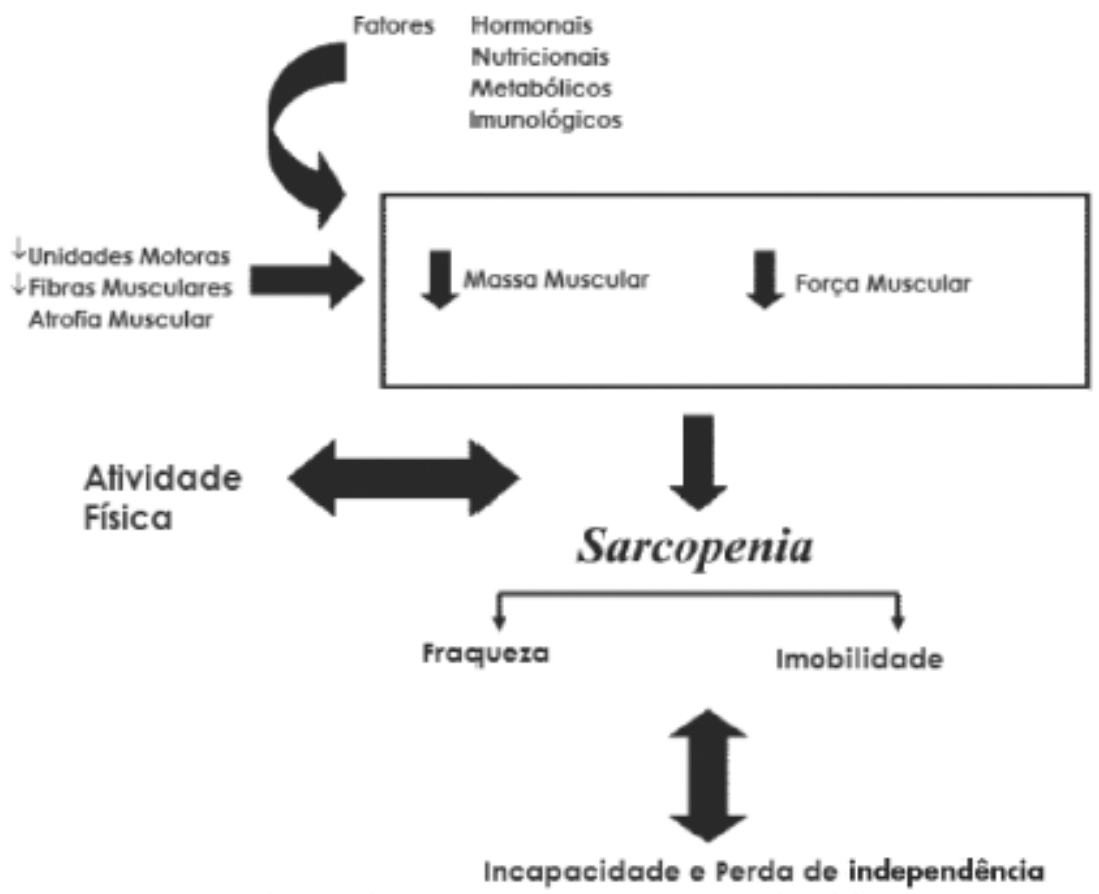

Figura 1: Causas e consequências da sarcopenia.

Fonte: Doroty, 2003.

A revisão de Walrand et al. (2011), chama a atenção sobre as interações entre fatores intrínseco e extrínseco na ocorrência da sarcopenia. Os autores identificaram que as mudanças no tecido muscular e sistema nervoso central estão diretamente relacionados com fatores humorais e estilo de vida.

O processo de declínio da força e da massa muscular pode ocorrer inicialmente na quarta ou quinta décadas de vida, demonstrando, a partir destes momentos, níveis de regressões diferentes (SCOTT et al., 2011). O estudo longitudinal de Frontera et al. (2000) pesquisou sobre alterações no tecido muscular esquelético de nove homens, evidenciando que a cada ano o declínio da força muscular variou de $1 \%$ a $4 \%$ avaliados nas velocidades 60,180 e $240 \%$ no dinamômetro isocinético e a massa muscular $0.5 \%$ a $1.0 \%$ avaliada com tomografia computadorizada. Assim, percebe-se que a força muscular diminua a cada ano de duas a cinco vezes mais que a massa muscular (HUGHES et al. 2001).

Visser et al.(2011) acompanharam as modificações da composição corporal de 2.040 mulheres e homens idosos saudáveis, utilizando como instrumento de avaliação a absormetria de raios-X de dupla energia (DEXA). A massa muscular diminuiu em média $1.1 \%$ e a gordura corporal aumentou em média $2.0 \%$ sendo observada uma perda maior de massa muscular nos homens em dois anos de acompanhamento. $\mathrm{O}$ estudo 
Raguso et al.(2006) avaliou a composição corporal com DEXA e a atividade física feitas no tempo livre por um questionário específico 143 mulheres e homens idosos. Após três anos de acompanhamento foi observado manutenção do peso total dos indivíduos, porém, houve redução da massa muscular em média $(-0.2 \pm 2.2 \mathrm{~kg}, \mathrm{p}<0,001)$ e aumento da massa gorda $(0,6 \pm 2,2 \mathrm{~kg}, \mathrm{p}<0,0001)$. Os autores concluíram que um nível maior de atividade física está associado com maior massa muscular e menor acúmulo de gordura corporal.

A diminuição da massa muscular afeta diretamente a estrutura e a função muscular, pois com a redução do ângulo de penação, redução da proporção das fibras tipo II, do comprimento do fascículo muscular e do conteúdo de proteínas contráteis, a força muscular e a velocidade de contração tornam-se limitadas (PILLARD et al., 2011).

Em relação à comparação entre características musculares entre jovens e idosos, o estudo realizado por Lexell \& Taylor (1991) foi muito explicativo. O estudo foi avaliado com análise direta da área de secção transversal de fibras do tipo I e II do músculo vasto lateral de cadáveres. Os resultados demonstraram não haver diferença entre jovens e idosos na comparação da área transversal das fibras tipo I. Porém, a área transversal das fibras do tipo II foi menor nos idosos. Outro achado importante deste estudo foi a verificação de uma hipertrofia das fibras do tipo I, como possível mecanismo de compensação pela diminuição do total de fibras acorridas com o avançar da idade.

Os declínios da força e da massa muscular podem trazer grandes prejuízos na saúde do idoso como: a redução da mobilidade, deficiência física, diminuição da qualidade de vida e mortalidade. Ocasionando grandes impactos no sistema de saúde (GEIRSDOTTIR et al., 2012).

Alguns estudos associam diretamente a diminuição da massa muscular a limitações funcionais, diminuição da força muscular e perda de autonomia (JANSEN et al., 2002; VALENTE et al., 2011). Porém, outros estudos sugerem que esta variável não seja a principal responsável por estas perdas (HUGLES et al., 2001; AUYEUNG et al, 2014). Assim, o conceito de qualidade muscular tem recebido uma grande atenção dos pesquisadores. Ainda não há consenso em relação ao conceito de qualidade muscular, sendo esta, definida como a capacidade de gerar força muscular por unidade de massa muscular. Em recente revisão sistemática McGregor et al. (2014) discutiu os fatores que influenciam a qualidade muscular dentre eles o tamanho do músculo, tipo de fibra, 
arquitetura, capacidade aeróbia, tecido adiposo intramuscular, fibrose e ativação neuromuscular. Os autores sugerem que intervenções no estilo de vida com foco na função muscular devem ser adotadas pelos idosos para que esta função possa ser preservada.

Baseado nas evidências citadas é bem aceito que o funcionamento limitado do tecido muscular, tendo como preditor principal à diminuição da força muscular, aumenta o risco de declínio funcional, quedas e mortalidade. Estes dados são importantes para construção de estratégias de treinamentos para a prevenção do declínio da força e da massa muscular contribuindo para a qualidade muscular.

\subsubsection{Envelhecimento e desempenho funcional}

O processo de envelhecimento provoca diversas alterações nos sistemas fisiológicos dos idosos, estas alterações favorecem o declínio funcional, chegando a reduções entre 10 a $15 \%$ trazendo grandes impactos nos componentes da aptidão física (MACALUSO e DE VITO, 2004). Como componentes da aptidão física podem citar a força muscular, a resistência muscular, a capacidade aeróbia, flexibilidade e a composição corporal. Estas aptidões também denominadas como capacidade ou desempenho funcional são de extrema importância para a realização das AVDs. (RIKLI \& JONES, 2013; MATSUDO et al., 2010).

A funcionalidade do indivíduo é a interação de múltiplos fatores entre os estados de saúde, fatores pessoais, demográficos, sociais, econômicos, comportamentais e ambientais. A capacidade ou desempenho funcional é um importante preditor de um envelhecimento bem sucedido, funcionalidade e da qualidade de vida dos idosos. Diversos são os problemas associados à redução deste desempenho: dependência física, fragilidade muscular, institucionalização, diminuição da mobilidade e morte. (BALOH et al. 2003; RIBOM et. al., 2011; RIKLI \& JONES, 2013).

No estudo longitudinal de Baloh et al. (2003) foi avaliado as alterações ocorridas anualmente no sistema visual, na marcha e no equilíbrio de 59 homens e mulheres idosas (idade 78,5 \pm 3,7 anos) em 10 anos de acompanhamento. Marcha e equilíbrio foram avaliados pela escala de Tinett que apresentou decréscimos médios em seu escore de 0,50 a cada avaliação anual, demonstrando redução no desempenho destas funções.

O estudo de Ribom et al. (2011) avaliaram a força de preensão manual e testes funcionais ( teste de sentar e levantar da cadeira e caminhada de 6 minutos )de 999 
homens idosos com idade entre 70 e 80 anos. Houve redução de 10 a $18 \%$ nos testes funcionais com a avançar da idade, a força de preensão manual também foi bem evidenciada.

Compreendendo a importância do desempenho funcional para a independência e funcionalidade dos idosos, alguns ensaios clínicos têm realizado diversas intervenções para melhorar estas condições, e os resultados tem sugerido melhoras significativas com o treinamento de força (COLADO et al, 2008; SO et al., 2013; MATSUDO et al., 2010).

Colado et al.(2008) avaliaram as alterações decorrentes de 10 semanas de TF comparando com um grupo controle, realizadas duas vezes por semana no desempenho funcional de 42 mulheres idosas saudáveis. Foi realizado para avaliar a força indireta dos membros superiores, o teste de flexão de braço com joelhos apoiados e para os membros inferiores, $\mathrm{o}$ teste de agachamento. Os resultados $(\mathrm{p}<0,05$ e $\mathrm{p}<0,01$ respectivamente) foram estatisticamente significativos após o período de intervenção para o grupo que realizou o treinamento, demonstrando melhoras no desempenho funcional.

So et al. (2013) examinaram os efeitos de 12 semanas de TF sobre o desempenho funcional de 40 homens e mulheres idosas ( $\mathrm{GE}=18 ; \mathrm{GC}=22)$. $\mathrm{O}$ estudo foi conduzido em três encontros semanais, com exercícios para membros superiores, inferiores e tronco. Os participantes realizaram 2 a 3 séries de 15 a 25 repetições em cada exercício. O desempenho funcional da força indireta de membros superiores e inferiores foram avaliados através dos testes de sentar e levantar da cadeira, e flexão de cotovelo e demonstraram incremento no GE de 20,5\% ( $p=0,001)$ e $15 \%(p=0,001)$ respectivamente.

No estudo de revisão de Mahant \& Stacy (2001) sugerem que a perda do desempenho funcional pode ser específica a tarefa e determinado de forma seletiva pelo desuso das funções sensório-motoras. Em contrapartida, as funções que continuam a serem realizadas com o avançar da idade tendem a se manter em boas condições. Diante do exposto, a compreensão do declínio funcional com o avançar da idade, torna-se uma oportunidade para a construção de propostas de intervenção para que esta condição possa ser preservada ao máximo. 


\subsection{Exercício Físico e envelhecimento}

Já está bem estabelecido na literatura que a prática de exercício físico regular, em todas as idades, pode proporcionar melhoras na força, resistência, massa e potência muscular, além de ajudar na prevenção da perda óssea, quedas e função articular (ACSM \& AHA, 2008; WHO, 2010; BEAUCHAMP et al.,2015). A adoção deste hábito regular pode ainda, diminuir os fatores de risco para doenças coronarianas, metabólicas e alguns tipos de câncer, promovem bem-estar, melhora do sono e ainda apresentam benefícios de inclusão social (PATERSON et al., 2007).

\subsubsection{Treinamento Muscular no Envelhecimento}

Apesar dos decréscimos relacionados com avançar da idade, estudos demonstram que o músculo esquelético do idoso pode sofrer adaptações morfológicas e fisiológicas com a prática sistematizada de TR. O aumento da força muscular é uma delas, sendo recrutado um número maior de unidades motoras, aumento na área transversa do músculo e adaptações metabólicas. Outra importante adaptação é o aumento da massa muscular, conhecida também como hipertrofia, caracterizada como aumento volumétrico das células e constituintes musculares (HUNTER \& BAMMAN 2004; BOTTARO et al., 2009).

Nos últimos anos, o número de pesquisas e publicações com TF para idosos tem aumentado consideravelmente. O estudo de Fronteira et al.(1988), analisou os efeitos de doze semanas de TF realizado três vezes por semana na força e massa muscular de idosos destreinados. Neste estudo, todos os grupos musculares exercitados ampliaram a força dinâmica, aferida pelo teste de uma repetição máxima (1RM), sendo 116,7\% para os músculos extensores do joelho e $226,7 \%$ para os flexores do joelho. Na avaliação isocinética extensão do joelho os ganhos foram de $8.5 \%$ e $10 \%$ no lado direito e esquerdo, respectivamente. Em relação à hipertrofia muscular, foi aumentada entre $10 \mathrm{a}$ $11 \%$ a área transversa total dos idosos, avaliada por tomografia computadorizada.

Em estudo clássico, Fiatarone et al. (1990) demonstraram que nove indivíduos acima de 90 anos, residentes em casa de longa permanência,conseguiram resultados positivos nas adaptações fisiológicas e morfológicas com o TF de alta intensidade. $\mathrm{O}$ treinamento foi realizado em oito semanas, e o ganho de força muscular de extensão de joelho aumentou em média $174 \%$ e a área de secção transversa do quadríceps em média 
9\%. Estes resultados sugerem que o TF provoca ganhos significativos na força muscular e massa muscular, mesmo em poucas semanas de treinamento.

Kalapotharakos et al. (2004) investigaram os efeitos de doze semanas de TF na força e massa muscular com intensidades diferentes em 33 idosos destreinados. Os indivíduos foram divididos em três grupos; grupo alta intensidade, grupo moderada intensidade e grupo controle. Após o período de treinamento, foram observados aumentos significativos no PT dos extensores e flexores do joelho e na área de secção transversa do quadríceps em ambas as intensidades treinadas. Porém, o grupo que treinou com intensidade mais elevada, obteve melhores resultados.

Em relação à capacidade de realizar AVDs, Rabelo et al. (2004) examinaram os efeitos de dez semanas de TF no desempenho funcional de mulheres idosas com idade entre 60 a 76 anos. O protocolo de treinamento simulava as AVDs e foram observadas melhoras significativas no aprimoramento na maioria dessas atividades, sugerindo que a intervenção colabora para uma melhor independência física, tornando-os mais ativos e saudáveis.

As respostas do sistema muscular esquelético ao TF são resultados de stress fisiológico ocorridos por contrações musculares impostas ao tecido protéico, resultando em adaptações específicas neste sistema. Desta forma, o TF pode aumentar os níveis de força por adaptações neurais ou morfológicas. As adaptações neurais estão relacionadas a aspectos coordenativos entre o músculo e velocidade de condução de impulsos elétricos advindos do sistema nervoso central. Em relação às adaptações morfológicas o TF provoca uma remodelação dos tecidos musculares e adjacentes, impostas pela sobrecarga mecânica podendo aumentar a síntese de proteínas, provocando um aumento da área de secção transversa (GENTIL et. al., 2006)

A quantidade e os diversos desenhos metodológicos de estudos utilizando o TF para incrementar a força muscular em idosos, influenciaram Steib et al. (2009) a realizar uma revisão sistemática com meta-análise com o objetivo de identificar quais as doses de treinamento eram mais adequadas e produziam melhores benefícios na força muscular de idosos. No total foram incluídos 29 estudos com 1.313 indivíduos com idades entre 65 a 81 anos. As análises foram divididas sobre a intensidade, volume, frequência e tipo de treinamento. Em relação à intensidade de treinamento foram analisados oito estudos, com total de 214 idosos, que demonstrou que o treinamento de alta intensidade resultou maiores ganhos de força máxima em relação a moderada e baixa intensidade, porém, este também apresentaram melhoras significativas na força 
máxima. Em relação ao volume de treinamento os autores analisaram apenas um estudo, com 28 homens e mulheres idosas com idade variando entre 65 a 78 anos, que sugere maiores ganhos de força muscular em maiores volumes de treinamento, considerando limitada esta avaliação. Já em relação ao tipo de treinamento, sete estudos com 140 idosos revelaram não existir diferenças entre o treinamento de potência e o treinamento tradicional para o aumento da força máxima. Além desta análise, a comparação entre os estudos de treinamento progressivo, funcional e isocinético, também não revelou diferenças significativas entre esses tipos de treinamento. Em relação à frequência semanal, o treinamento realizado três vezes na semana foi mais efetivo comparado ao realizado uma vez por semana, porém, não houve diferença significativa comparando três com duas vezes semanais. Já em relação a tempo de intervenção os estudos tiveram duração entre oito semanas a um ano.

A revisão sistemática com meta analise de Liu \& Lathan (2009) analisou 121 estudos com 6.700 idosos. O objetivo deste estudo foi determinar os efeitos do TF na função física de idosos, através de comparações entre TF e sem exercício (controle passivo), ou outra intervenção (controle ativo ex: treinamento aeróbio ou flexibilidade). Foram feitas comparações sobre as variáveis do treinamento (intensidade, frequência, ou velocidade). Nesta revisão, a frequência semanal variou de duas a três vezes por semana, realizado em alta intensidade. O TF resultou em melhora significativa em relação a capacidade física (33 estudos, 2.172 participantes), melhoria da velocidade de marcha (24 estudos, 1.179 participantes) e teste de sentar e levantar da cadeira (11 estudos, 384 participantes). Em relação à força muscular (73 estudos, 3059 participantes, $\mathrm{SMD}=0,84)$. Os autores sugerem que o TF é uma intervenção eficaz para melhorar a função física de homens e mulheres idosos, incluindo força muscular e o desempenho de algumas atividades simples e complexas.

Outra revisão sistemática com meta-análise que investigou a relação dose resposta do TF na população idosa foi a de Silva et al. (2014). O objetivo do estudo foi utilizar a técnica de meta-regressão para investigar a relação dose-resposta de domínios combinados de variáveis de treinamento de força, como a intensidade do treino, frequência semanal de treinamento, numero de séries por exercício e período de intervenção sobre o ganho de força muscular em idosos. Um total de 15 estudos foi analisado na investigação, e os resultados sugerem que as combinações de diferentes variáveis de treinamento (intensidade, numero de grupos musculares, freqüência semanal de treinamento) podem resultar efeitos semelhantes para melhorar a força em 
idosos sedentários, pelo menos na extensão de joelho. No entanto, a única variável que demonstrou diferença dentro da meta-regressão em relação às demais foi a duração do treinamento, indicando que quanto maior o tempo do programa de treinamento maiores serão os ganho de força, independente de combinações de diferentes de intensidade de treinamento, frequência ou numero de séries.

Em relação a composição corporal, Peterson et al. (2011) foi a primeira revisão sistemática com meta análise que investigaram os efeitos de TF sobre a variável massa muscular que tivemos acesso. Foram incluídos neste estudo 49 estudos, com 20.5 semanas de duração em média, com total de 1.328 homens e mulheres idosos saudáveis e destreinados. O aumento da massa muscular na comparação pré e pós intervenção foi média entre $1.1 \mathrm{~kg}(\mathrm{p}<0,001)$, sendo observado que o volume de treinamento de alta intensidade proporcionam maiores ganhos de massa muscular. Em comparação entre sexo, homens apresentam ganhos mais significativos. Neste estudo, foram analisadas algumas variáveis agudas do treinamento resistido. Em relação ao tempo de intervenção, os treinamentos variaram entre 10 a 52 semanas (média $=20.5 \pm 9.1$ ), e a freqüência semanal entre duas e três (média $=2.8 \pm 0.4$ ), a intensidade variou entre $50 \%$ e $80 \%$ de $1 \mathrm{RM}$ (média=74.6 \pm 6.9), o número de séries entre 7 a 39 (média $=20 \pm 7,3$ ), o numero de repetições variou entre 2 a 20 (média $=10$ ), o intervalo de recuperação entre 60 a 360 segundos (média $=110$ s) e o número de exercícios entre 5 a 16(média $=$ $8.3 \pm 2.1$ ). Com os resultados os autores sugerem que o treinamento com alta intensidade é mais efetivo para o incremento da massa muscular, sugerindo um aumento progressivo na carga de treinamento para alcançar melhores resultados.

\subsubsection{Treinamento com Resistência Elástica para Idosos}

O TF utilizando dispositivos elásticos como resistência, parece ser capaz de produzir melhorias na força muscular para a população idosa. O estudo de Mikesky (1994) foi um dos primeiros que utilizaram resistência elástica para aumentar a força muscular em idosos. Foram demonstrados que 12 semanas de treinamento baseado em casa, realizados três vezes por semana com 6 exercícios para membros superiores e 6 inferiores, aumentaram o PT excêntrico da extensão e flexão do joelho em $12 \%$ e $10 \%$ respectivamente. Em seguida, Topp (1996) demonstraram os efeitos de 14 semanas de treinamento em idosos saudáveis. Neste estudo, a intervenção realizada três vezes por semana aumentou o PT concêntrico e excêntrico da flexão dorsal do tornozelo em $16 \%$ 
e 12\%. Em um ensaio clínico randomizado, Krebs et. al.(1998) examinaram os efeitos do treinamento na força muscular isométrica, realizados três vezes por semana nos membros inferiores(extensão de quadril, abdução de quadril e extensão de joelhos), demonstrando aumento de $17.6 \%$ no Grupo experimental (GE, n=54) em relação ao Grupo controle(GC,n=66) após 24 semanas de intervenção.

Os estudos com resistência elástica têm analisado a população idosa em condições com algum comprometimento funcional, patologia diagnosticada ou em indivíduos saudáveis (WEBBER \& POTTER, 2010; CHEUG et al.,2009 e DAMUSH \& DAMUSH, 1999). O aumento da força muscular tem sido destacado nas medidas isométrica, isotônica e isocinética (RIBEIRO et al., 2009; CHEUG,2009; WEBBER \& POTTER, 2010).

Em revisão sistemática com meta-análise, Martins et al.(2013) evidenciaram os efeitos do TF com resistência elástica em idosos. A duração das intervenções variou de 6 a 24 semanas (média $=14.1 \pm 7.0$ ), a freqüência variou de 1 a 5 encontros por semana (média $=3,2 \pm 0.9$ ), a quantidade de exercícios por treino variou de 2 a 11 (média $=7,8$ $\pm 3,2$ ) o numero de séries por exercício variou de 1 a 3 (média $=2,0 \pm 0.8$ ) e o número de repetições variou de 10 a 12 (média $=10,02 \pm 0,7$ ). Foi demonstrado um efeito significativo na força muscular em três subgrupos relacionados com a condição de saúde: idosos saudáveis com três estudos, $\mathrm{n}=152$ idosos homens e mulheres $(\mathrm{SMD}=$ 1.30; 95\% CI, 0.90, 171), idosos com algum comprometimento funcional seis estudos, $\mathrm{n}=591$ idosos homens e mulheres $(\mathrm{SMD}=1.01 ; 95 \% \mathrm{CI}, 0.82,1.19)$ e em idosos que relatavam alguma patologia dois estudos, $\mathrm{n}=91$ idosos homens e mulheres (SMD $=0.54 ; 95 \%$ CI $, 0.12,0.96)$. Tais autores sugerem novos estudos para que as relações dose-resposta de diferentes intensidades de treinamento sobre a força muscular em idosos sejam mais esclarecidas.

Em relação aos efeitos do TF utilizando resistência elástica que avaliaram o desempenho funcional, os estudos demonstram ótimos resultados. Os estudos de Colado et al., 2009 e Colado et al., 2012 analisaram os efeitos do TF no desempenho funcional em mulheres pós-menopausa em diversos testes (Agachamento, Flexão de braços com joelhos apoiados e abdominais). Os resultados dos testes após a intervenção demonstram que o TF foi capaz de melhorar estatisticamente todos os testes analisados, sugerindo que este método pode ser efetivo para incrementar funcionalidade a esta população. 
Egana et al. (2010) avaliaram as alterações decorrentes de 12 semanas de TF, realizadas duas vezes por semana no desempenho funcional em 16 mulheres idosas $(\mathrm{GE}=8 ; \mathrm{GC}=8)$. Foram realizados três testes funcionais para avaliar a força indireta dos membros superiores (Rosca Bíceps em 30s), inferiores (Sentar e Levantar da Cadeira em 30s) e flexibilidade (Alcançar atrás das costas). Neste estudo, foi descrito melhora em todos os testes avaliados após o período de intervenção.

Estudos utilizando TF com resistência elástica para o incremento da massa muscular em idosos são escassos. Know et al. (2010) propuseram uma estratégia de treinamento utilizando baixas intensidades $40 \%$ a $50 \%$ de $1(\mathrm{RM})$ para o aumento da massa muscular,avaliado pelo DEXA em mulheres obesas com diabetes tipo 2 (GE=13; $\mathrm{GC}=15)$. O GE participou da intervenção que teve duração de 12 semanas com frequência de 3 dias por semana, realizando exercícios para os membros superiores, inferiores e tronco durante 60 minutos diários, o GC foi orientado a não realizar exercícios durante o período da intervenção. Após a intervenção, o GE incrementou 5,3 e $4,2 \%$ de tronco e braços respectivamente e $3 \%$ na massa muscular de corpo inteiro.

Colado et al. (2012) compararam três grupos intervenção (Elástico $n=21$; Aquático $n=17$; Máquina+Peso Livre $n=14$ ) e um grupo controle $n=10$ em relação a variáveis morfológicas como: massa livre de gordura e gordura corporal, analisados por bioimpedância elétrica em mulheres pós-menopausa. O treinamento foi equiparado para que ambos os grupos executassem a mesma carga de trabalho durante toda intervenção. Foram conduzidas 10 semanas de treino, duas vezes por semana, executando exercícios para membros superiores e inferiores. Os resultados foram significativos em todos os grupos de intervenção na redução da gordura corporal na análise intra grupo (Pós x Pré). Em relação à massa livre de gordura, houve incremento nos grupos Elástico $(p<0,05) \mathrm{e}$ Máquina+Peso Livre $(p<0,01)$ com diferença entre estes dois grupos $(p<0,05)$ tendo mais efetividade o grupo Máquina+Peso Livre.

So et al. (2013) examinaram os efeitos de 12 semanas de TF sobre a composição corporal de 40 homens e mulheres idosas $(\mathrm{GE}=18 ; \mathrm{GC}=22)$. O estudo foi conduzido em três encontros semanais, com exercícios para membros superiores, inferiores e tronco. Os participantes realizaram 2 a 3 séries de 15 a 25 repetições em cada exercício. A massa muscular foi aferida através de bioimpedância elétrica e demonstraram incremento no $\mathrm{GE}$ de 2,7\% ( $\mathrm{F}=5,7, \mathrm{p}=0,02)$. Em contraste, não houve mudanças significativas no GC. Apesar dos resultados positivos, os autores chamam a atenção para alguns limites, incluindo a carga fixa utilizada durante toda intervenção. 
Ramos et al. (2014) em um ensaio clínico randomizado comparou dois tipos de TF na massa muscular em mulheres e homens idosos com doença pulmonar obstrutiva. Os grupos $(\mathrm{GRE}=22 ; \mathrm{GRT}=23)$ realizaram os mesmos exercícios (extensão e flexão de joelho, abdução de ombro e flexão do cotovelo) durante as 8 semanas de intervenção, as cargas foram equiparadas para que obtivessem o mesmo trabalho em ambos os grupos. O GRE utilizou dispositivos elásticos (Lemgruber ${ }^{\circledR}$ marca, Brasil) e o GRT utilizou aparelhos de musculação (linha Ipiranga ${ }^{\circledR}$ Gym, Brasil). A massa muscular foi avaliada por DEXA e indicou uma tendência a melhora em ambos os grupos $(p=0,05)$. Não houve diferenças entre os grupos em relação à massa muscular nos membros superiores, inferiores e corpo total após as intervenções.

Como se observa, na literatura existe evidencias sobre a efetividade do TF com resistência elástica na força muscular e desempenho funcional, porém, ainda não é possível determinar qual a melhor intensidade de treinamento para alcançar os melhores resultados. No que se referem à massa muscular, os estudos ainda são escassos, não existindo evidencias suficientes para garantir que o uso dos dispositivos elásticos seja efetivo no incremento desta variável. Neste estudo optou-se por analisar o efeito de doze semanas de dois tipos de TF (máquinas pneumáticas e resistência elástica progressiva) na força, massa muscular e desempenho funcional de mulheres idosas. 


\section{MATERIAIS E MÉTODOS}

\subsection{Delineamento do Estudo}

O presente estudo é classificado como ensaio clínico randomizado (EL DIBE, 2007), com número de registro NCT 02253615 aceito no dia 27-09-2014pelo sítio: https://register.clinicaltrials.gov. O objetivo foi verificar os efeitos de dois programas de TF na força, massa muscular e desempenho funcional de idosos da comunidade. As variáveis dependentes consideradas para a análise foram o pico de torque muscular do membro superior e inferior dominate nas velocidades de 60 e $180 \%$, as variáveis da massa muscular foram obtidas de corpo inteiro, membros superiores e membros inferiores e o desempenho funcional foi avaliado com dois testes( Sentar e levantar da cadeira e Flexão do cotovelo). As variáveis independentes foram dois programas de TF, um utilizando resistencia elástica e o outro máquinas pneumáticas.

Os procedimentos desenvolvidos e executados nesse estudo foram aprovados pelo Comitê de Ética da Faculdade de Ciências da Saúde da UnB no dia 21 de julho de 2011, Protocolo 081/11 (ANEXO A), de acordo com a Resolução nº196 / 96 do Conselho Nacional de Saúde que regulamenta as pesquisas com seres humanos. A participação no estudo foi voluntária e ocorreu após esclarecimento dos objetivos, protocolos de intervenção e de avaliações, bem como sobre possíveis riscos do estudo, assim eram convidados a assinarem o Termo de Consentimento Livre e Esclarecido (TCLE) (ANEXO B).

\subsection{Amostra}

Participaram do estudo 44 mulheres idosas, que viviam normalmente na comunidade, sem dispositivos de auxílio para o desempenho de suas atividades diárias, recrutados por conveniência, a partir de convites que foram realizados por mídia impressa distribuídas nas regionais do Núcleo de Atenção Integrada a Saúde do Idoso do Distrito Federal. Foram realizadas 4 palestras explicativasna Faculdade da Ceilândia da UnB com o objetivo de esclarecer com mais detalhes os procedimentos, tempo de duração e local onde aconteceriam as intervenções. 


\subsubsection{Critérios de Inclusão e Exclusão}

Para participar do estudo foi estabelecido que os indivíduos deveriam ser mulheres, ter no mínimo 60 anos de idade e apresentar atestado médico liberando para a prática de exercícios resistidos.

Os critérios de exclusão utilizados no presente estudo foram; (a) Patologias traumato-ortopédicas, neurodegenerativas, reumatológicas, metabólicas ou cardiovasculares; (b) Hipertensão arterial sem controle; (c) uso de marcapasso cardíaco; (d) Artroplastia de quadril ou joelho; (e) Cirurgia traumato-ortopédica nos últimos seis meses; (f) Prática de exercícios resistidos nos últimos seis meses.

\subsubsection{Triagem da Amostra}

Com a divulgação da pesquisa, 113 indivíduos efetivaram contato telefônico ou compareceram na UnB-FCE, apresentando interesse em participar da pesquisa. Porém, apenas 74 compareceram e foram avaliadas para critério de elegibilidade. Dessas, 10 foram excluídas pelos critérios de seleção da amostra e 10 não apresentaram interesse em participar após a explicação dos objetivos da pesquisa. Foram motivos de exclusão: trombose venosa profunda $(n=1)$, prática de treinamento resistido $(n=1)$, insuficiência cardíaca congestiva $(n=1)$, acidente vascular cerebral $(n=2)$, artrite reumatóide $(n=1)$, idade inferior a 60 anos $(n=4)$. Assim, 54 dos indivíduos avaliados para elegibilidade foram selecionados e distribuídos, aleatoriamente, nos dois grupos de pesquisa. Como dez indivíduos não completaram as doze semanas de treinamento, a amostra foi composta por 44 indivíduos, 26 no Grupo Máquina $(\mathrm{GM}=26)$ e 18 no Grupo de Resistência Elástica (GE=18). O fluxo de indivíduos durante as etapas da pesquisa pode ser visto na Figura 2. 


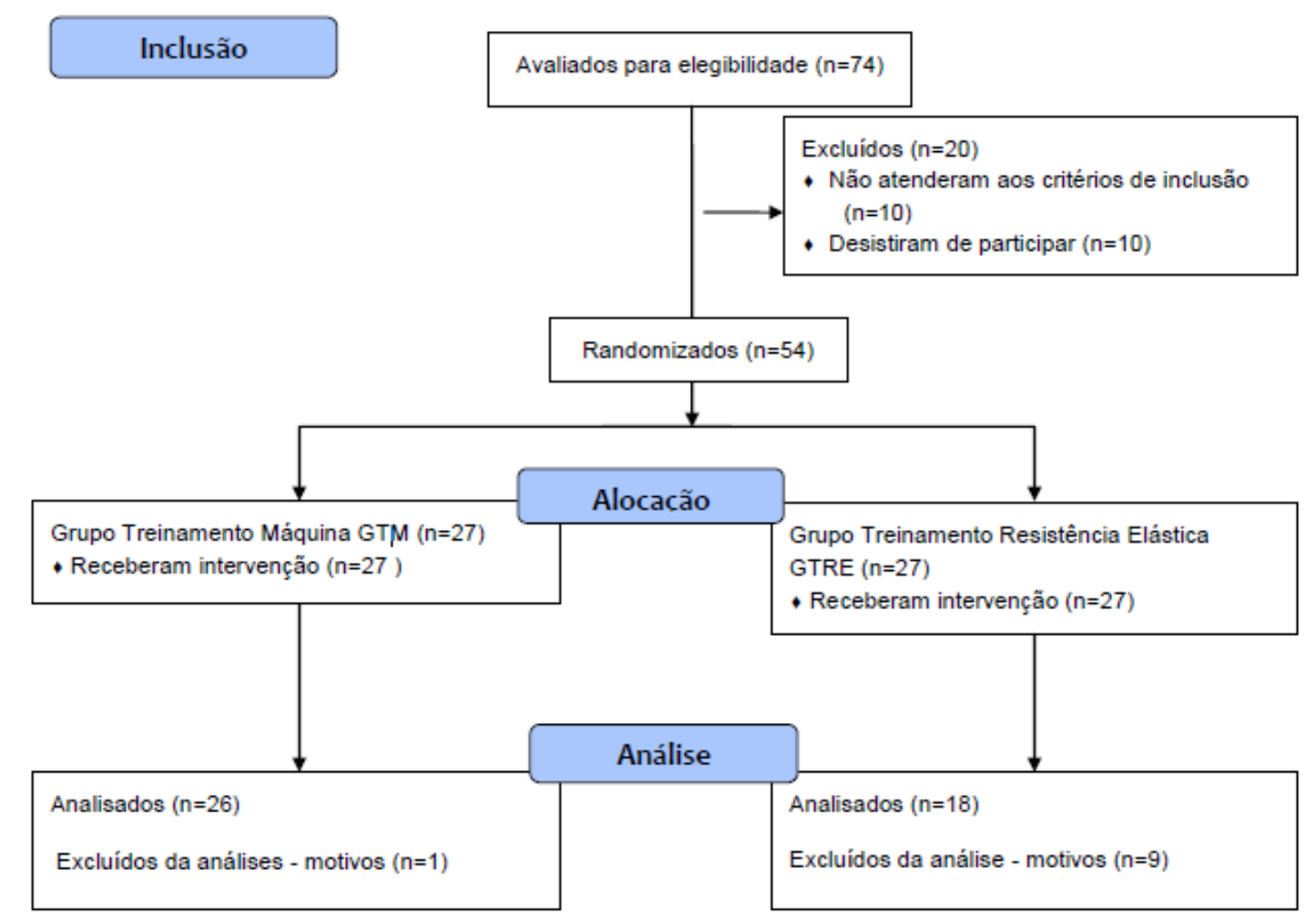

Figura 2: Fluxograma da seleção da amostra e delineamento experimental.

Fonte: Consort, 2010.

As razões para as voluntárias não completarem o treinamento no GE incluíram no a ocorrência de problemas de saúde familiar impedindo o comparecimento nos treinos $(n=2)$, incompatibilidade de horário $(n=1)$, acidente domiciliar com sequela ( $n$ $=3)$, pneumonia $(\mathrm{n}=1)$, cirurgia de vesícula $(\mathrm{n}=1)$ e por motivo de viajem $(\mathrm{n}=1)$ totalizando uma perda amostral de 9 idosas. No GM apenas uma voluntária desistiu por incompatibilidade de horários. Toda a fase de execução da pesquisa ocorreu entre os meses de março e dezembro de 2014.

\subsection{Instrumentos e Avaliações}

O presente estudo foi realizado na Faculdade da Ceilândia da UnB e na Faculdade de Educação Física da UnB. Estes locais ofereceram os laboratórios e demais estruturas físicas para a aplicação das avaliações, palestras de convite e as duas intervenções. Os instrumentos eram calibrados de acordo com as especificações contidas no manual dos fabricantes, antes do primeiro teste do dia. 


\subsubsection{Entrevistas}

Foi realizado com os indivíduos interessados em participar da pesquisa um questionário semiestruturado (ANEXO C). O nível de atividade física foi avaliado por autorrelato sobre a frequência semanal e a duração diária de exercícios físicos e atividades do cotidiano, realizadas na semana anterior, utilizando os itens do Minessota Leisure Time Activity Questionare, validado para a população brasileira (LUSTOSA et al., 2009).

\subsubsection{Avaliações Antropométricas}

As avaliações antropométricas foram realizadas no Laboratório de Cineantropometria no momento pré intervenção para a caracterização inicial dos voluntários. A massa corporal foi mensurada utilizando uma balança digital, com resolução em gramas (modelo 2006pp TOLEDO, Brasil), os voluntários foram orientados a utilizar roupas leves e retirar os sapatos e demais acessórios. A estatura foi aferida utilizando um estadiômetro, com resolução em centímetros(CARDIOMED, Brasil) fixado na parede. O índice de massa corporal (IMC) foi calculado dividindo-se a massa corporal pela estatura ao quadrado $\left(\mathrm{Kg} / \mathrm{m}^{2}\right)$.

\subsubsection{Avaliação da Força Muscular Isocinética}

As avaliações do membro superior e inferior foram realizadas no dinamômetro isocinético (Biodex System $\odot$, modelo III). Este instrumento é considerado padrão ouro pela literatura, tendo uma grande confiabilidade nas medidas, pois o erro humano/fisiológico é considerado pequeno, podendo avaliar as diversas manifestações de força (CARUSO \& TUFANO, 2012). A avaliação isocinética se tornou um método popular de mensuração tanto na rotina clínica como na pesquisa para indivíduos idosos (DROUIN et al., 2004; LIMA et al., 2009).

A força muscular isocinética do membro superior e inferior foram verificados pelo PT de extensão concêntrica do joelho dominante e da flexão concêntrica do cotovelo respectivamente, Figura 3. O membro dominante foi definido pela preferência de escovar os dentes ou escrever e para o membro superior a preferência em chutar uma bola no alvo determinado para o inferior (HARTMANN et al., 2009). Foram 
aleatorizados no momento PRÉ e PÓS, um dos dois protocolos de aferição : $1^{\circ}$ (a) uma série de aquecimento com dez repetições a $300^{\circ} / \mathrm{s}$; (b) duas séries de quatro repetições a $60^{\circ}$; (c) duas séries de quatro repetições a $180^{\circ}$ s ou $2^{\circ}$ uma série de aquecimento com dez repetições a $300^{\circ} / \mathrm{s}$; (b) duas séries de quatro repetições a $180^{\circ}$; (c) duas séries de quatro repetições a $60 \%$ s. O intervalo de recuperação entre as séries foi de um minuto (BOTTARO et al., 2005). O maior PT nas duas velocidades foi utilizado para fins de análise estatística.

Para estabilizar o corpo ao máximo e minimizar movimentos extras, as voluntárias forma posicionados na cadeira do dinamômetro em posição confortável e fixado os cintos de segurança. Os posicionamentos foram regulados de acordo com as instruções contidas no manual do fabricante para o membro superior e inferior. Foram registrados no momento PRÉ para cada indivíduo; (a) altura da cadeira; (b) regulagem do encosto; (c) posição da cadeira; (d) posição do dinamômetro; (e) posição do braço de resistência: (f) altura do suporte para os pés; (g) altura do encosto do braço. Foi utilizado encorajamento verbal e visual para tentar alcançar o nível máximo de esforço.
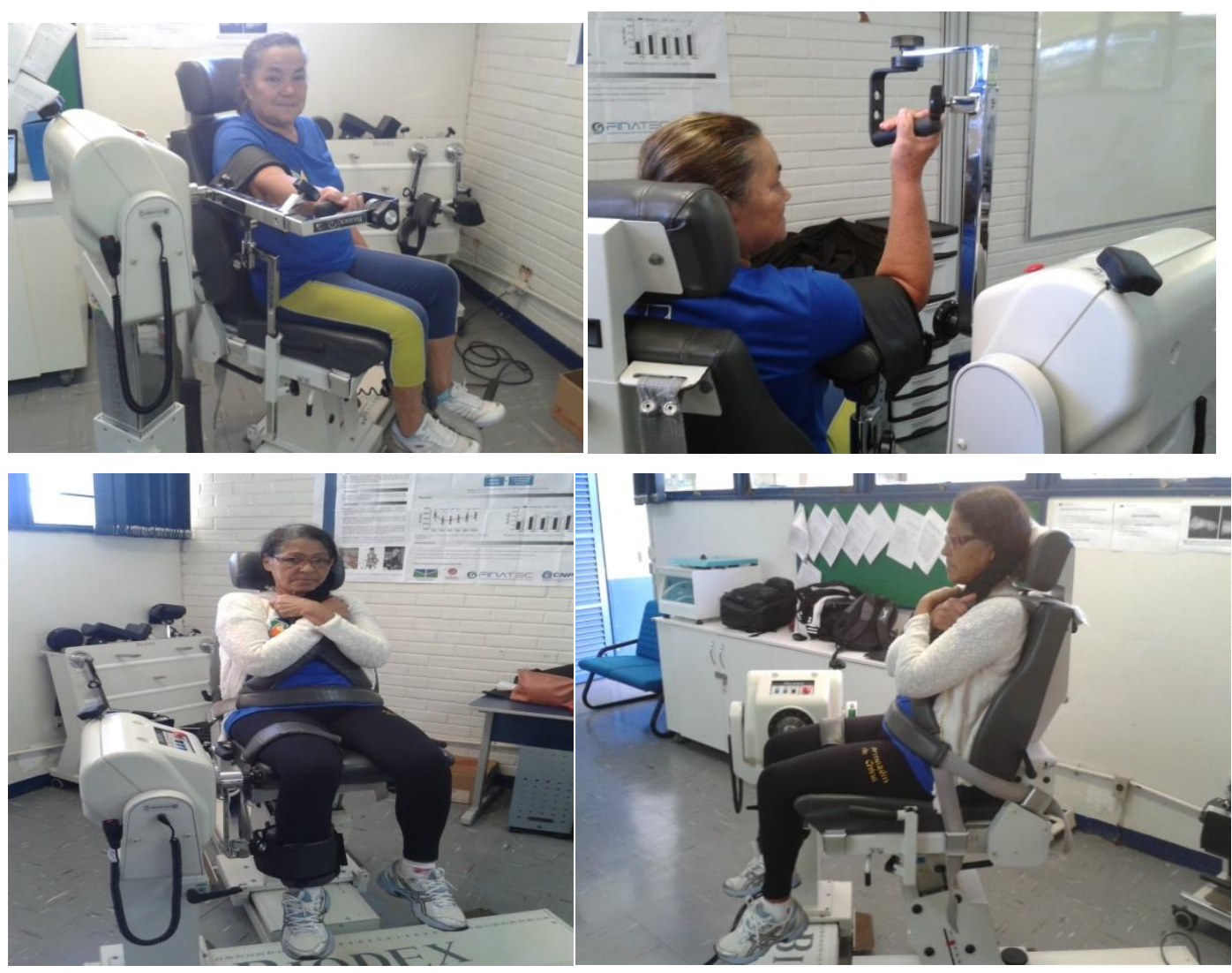

Figura 3: Mensuração da força muscular isocinética de membro superior e inferior 


\subsubsection{Avaliação da Massa Muscular}

Para a avaliação da massa muscular foi utilizado um equipamento de Absormetria de raios-X de dupla energia (DEXA) (GE Eletric Company, modelo Lunar Prodigy). Este instrumento utiliza a Massa Livre de Gordura (MLG) como medida indireta de avaliação da massa muscular. A confiabilidade do protocolo utilizado nesse estudo já foi descrita em outra pesquisa (TOOMBS et al., 2012).

As voluntárias foram posicionadas durante o procedimento de aferição em decúbito dorsal sobre a mesa do equipamento, conforme instruções do Software enCORE® , Figura 4. Os membros inferiores foram colocados próximos em rotação neutra, envolvidos por duas faixas de velcro e os superiores ao longo do corpo. Foi obtida para o exame a medida de corpo inteiro, assim conseguimos obter medidas da composição corporal de regiões específicas. Os registros PRÉ e PÓS foram identificados como corpo inteiro (braços, pernas e troco), braços (membro superior direito e esquerdo) e pernas (membro inferior direito e esquerdo), com escala em gramas. Os indivíduos utilizaram roupas leves e ficaram descalços e foram orientados a retirar todos os acessórios do corpo.

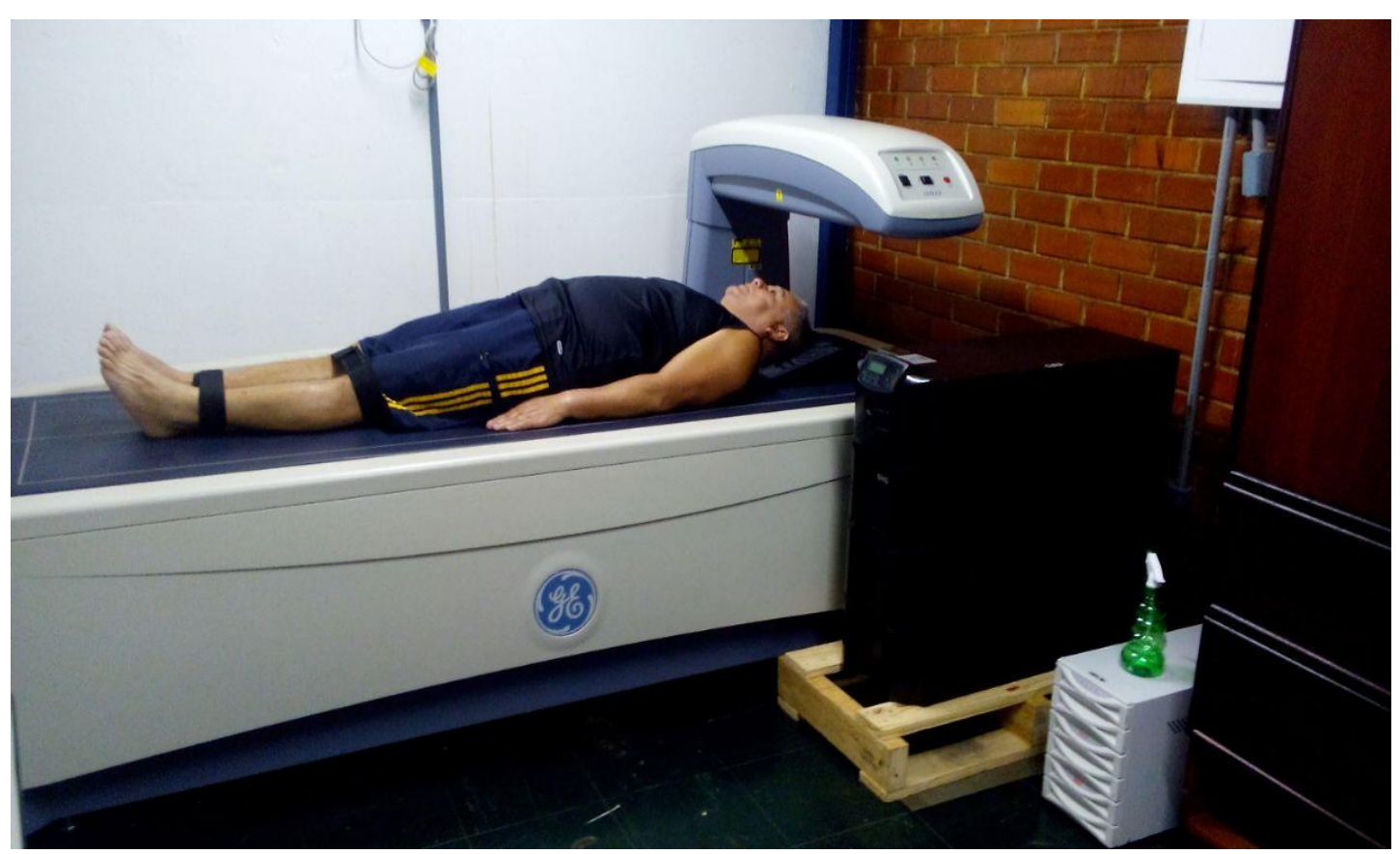

Figura 4: Avaliação da massa muscular no DEXA.

Fonte: Autor, 2014 


\subsubsection{Avaliação da Funcionalidade}

Para a avaliação do desempenho funcional dos membros inferiores e superiores, foram aplicados dois testes propostos por Rikli \& Jones (2008). Para a força indireta dos membros inferiores foi utilizado o Teste de Levantar da cadeira (TSL) Figura 5, no membro superior dominante foi realizado o teste de Flexão de Cotovelo (FC) Figura 6.

\section{Sentar e levantar da cadeira}

No (TSL), o principal objetivo foi avaliar a força indiretados membros inferiores. Foram utilizados cadeira e cronômetro. O teste iniciou com a voluntária sentada na cadeira de $43 \mathrm{~cm}$ de altura (encostada em uma parede por motivos de segurança), as costas apoiadas no encosto, com as plantas dos pés sobre o solo e braços cruzados a região peitoral e mãos sobre os ombros. Ao sinal “Atenção, já!”, a avaliada levantou-se totalmente e retorou a posição inicial repetindo esses movimentos durante 30 segundos. Foi registrado a quantidade máxima de repetições completas realizadas em uma tentativa. A variável a utilizada para análise foi o número de repetições realizadas (RIKLI \& JONES, 2008).
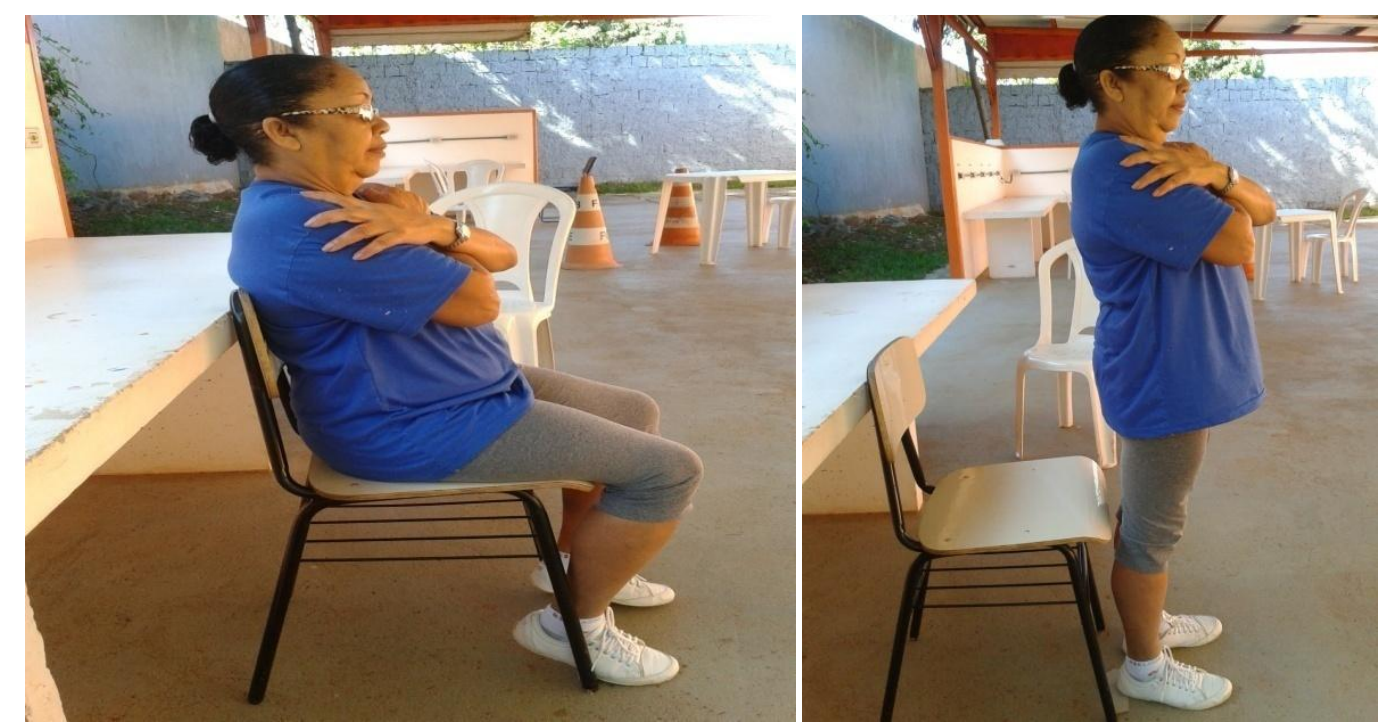

Figura 5: Teste de sentar e levantar da cadeira.

Fonte: Autor, 2014 


\section{Flexão do cotovelo}

No teste de flexão de cotovelo, o principal objetivo foi avaliar a força indireta dos membros superiores. Foram utilizados cadeira, cronometro e halteres de mão de 2 kg. A voluntária sentou em uma cadeira com as costas retas, os pés no chão e o lado dominante do corpo próximo à borda da cadeira. Ela segurou o halter com a mão dominante, utilizando uma empunhadura de aperto de mão. O teste começou com o braço estendido perto da cadeira e perpendicular ao chão. Ao sinal indicativo, a voluntária girou sua palma da mão para cima enquanto flexionou o braço em amplitude total de movimento e então retornou o braço para uma posição completamente estendida. Foi registrada a quantidade máxima de repetições realizadas em 30 segundos. A variável utilizada para análise foi o número de repetições realizadas em uma tentativa (RIKLI \& JONES, 2008).
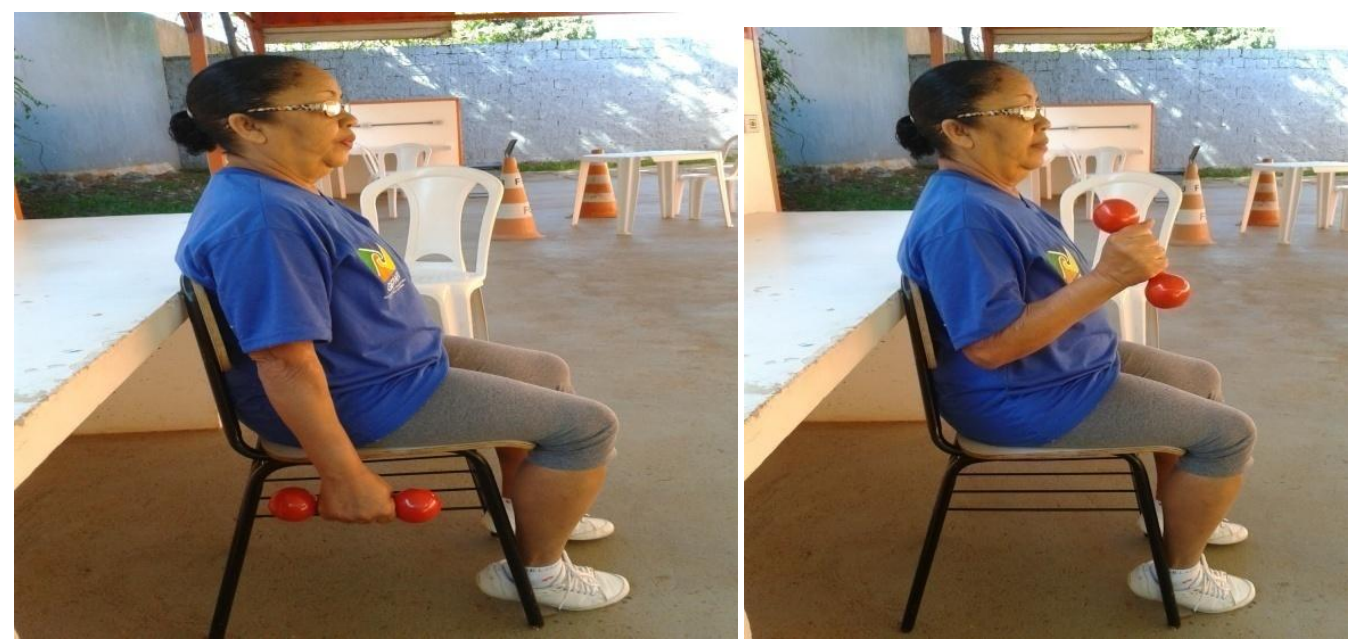

Figura 6: Teste flexão de cotovelo.

Fonte: Autor, 2014.

\subsubsection{Equipamentos de resistência}

\section{Resistência Elástica}

Para a realização dos exercícios propostos neste estudo, foram utilizados equipamentos de resistência elástica para o GE (Elastos®, modelo Krampe), Os elásticos são em forma de tubo, com comprimento de $(50 \mathrm{~cm})$ e ganchos nas extremidades para fixação junto aos acessórios com alças e caneleiras. A intensidade 
dos elásticos é definida por sete níveis identificados por cores que apresentam progressão crescente: amarelo, vermelho, verde, preto, roxo e ouro, Figura 7.

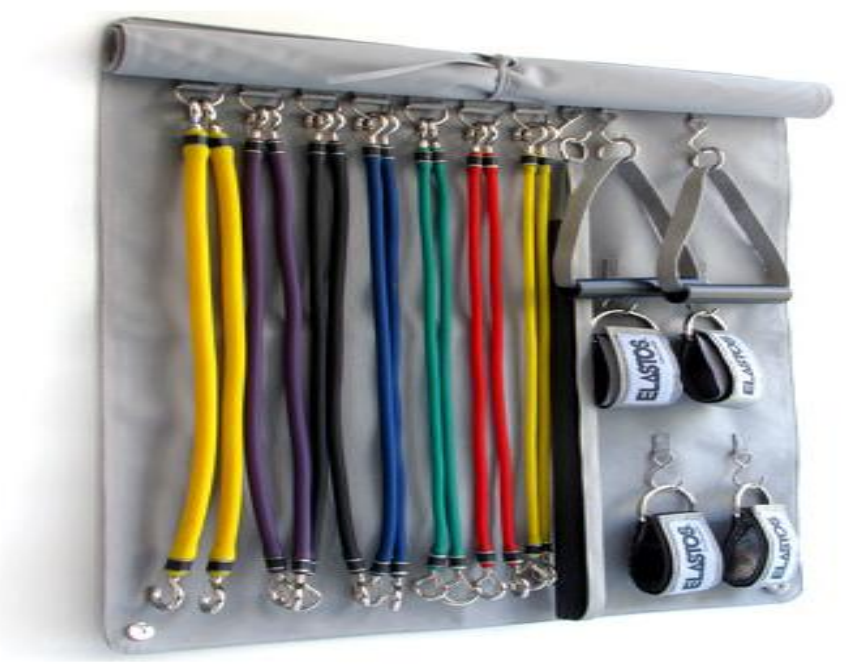

Figura 7: Níveis de resistência elástica e acessórios para fixação.

Fonte: $\underline{w w w . e l a s t o s . c o m . b r}$

Outra possibilidade de controlar a intensidade destes dispositivos é em relação ao percentual de alongamento do tubo. No ensaio mecânico em laboratório conduzido por Martins et al. (2013) foi determinado os valores de força elástica por cor nos percentuais de alongamento $(50 \%, 100 \%, 150 \%$ e $200 \%)$ em ralação ao comprimento inicial dos tubos elástico, Figura 8. Para assegurar que o treinamento era realizado dentro da intensidade desejada e também de maneira progressiva marcações no chão, utilização de cones e réguas de estiramento foram utilizadas para controle de carga.

\begin{tabular}{cccccccc}
\hline \multirow{2}{*}{ Alongamento } & \multicolumn{7}{c}{ Força $(\mathrm{N})$} \\
& Amarelo & Vermelho & Verde & Azul & Preto & Roxo & Ouro \\
& $(\mathrm{n}=15)$ & $(\mathrm{n}=15)$ & $(\mathrm{n}=15)$ & $(\mathrm{n}=15)$ & $(\mathrm{n}=15)$ & $(\mathrm{n}=15)$ & $(\mathrm{n}=15)$ \\
\hline $50 \%$ & $10.6(0.7)$ & $15.8(0.7)$ & $16.6(1.1)$ & $25.9(1.7)$ & $28.8(2.4)$ & $41.7(2.8)$ & $58.1(5.8)$ \\
$100 \%$ & $16.0(0.8)$ & $24.0(0.7)$ & $25.4(1.4)$ & $39.9(1.6)$ & $44.6(2.7)$ & $59.4(1.2)$ & $84.1(5.2)$ \\
$150 \%$ & $20.0(0.9)$ & $30.5(0.7)$ & $32.2(1.7)$ & $50.2(1.3)$ & $56.9(2.6)$ & $78.1(2.8)$ & $105.4(7.2)$ \\
$200 \%$ & $23.8(0.9)$ & $36.7(0.5)$ & $38.6(2.1)$ & $59.9(0.8)$ & $67.7(2,1)$ & $93.8(3.4)$ & $126.4(9.9)$ \\
\hline
\end{tabular}

Valores apresentados em média e desvio padrão.

Figura 8: Valores de força e alongamento em cada um dos 7 níveis de resistência.

Fonte: Martins et al., 2013. 


\section{Resistência Pneumática}

Para a realização dos exercícios o GM utilizou máquinas pneumáticas (EN Dinamyc () Figura 9. As máquinas possuem regulagem manual para encosto e demais ajustes individuais, além de contador de repetições e do intervalo de recuperação. Cada equipamento permite cargas de 0-100 X $10 \mathrm{~N}$ (kgf) mostradas em um dysplay digital em cada máquina. A carga foi fornecida por um compressor do mesmo fabricante do modelo "Jun-Air 6-15 Standard".
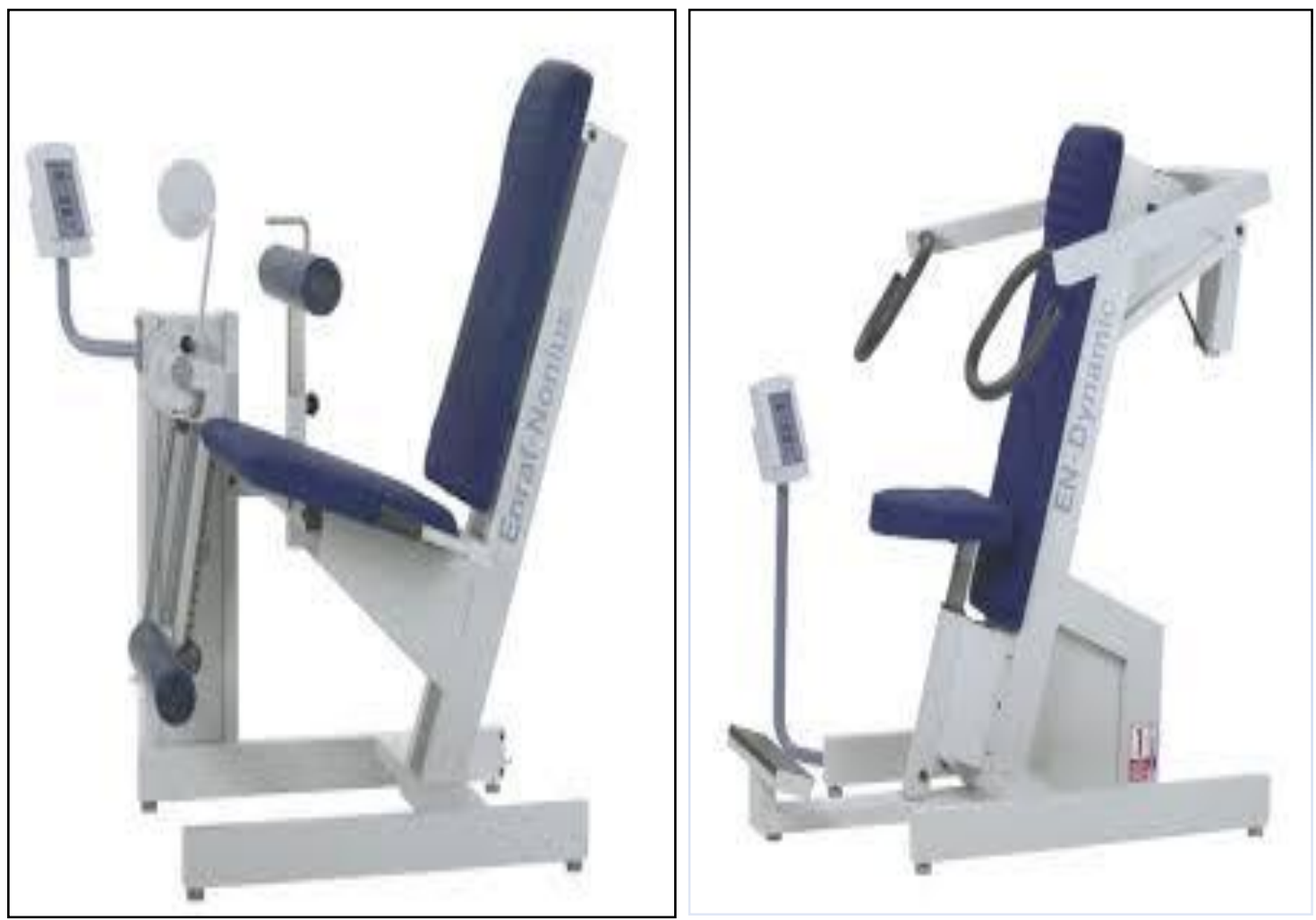

Figura 9: Máquinas pneumáticas EM Dinamyc®.

Fonte: www.google.com

\subsection{Procedimentos Experimentais}

As coletas foram realizadas nos períodos matutinos e vespertinos por uma equipe previamente treinada. As ordens de execução dos testes foram iguais no momento PRÉ e PÓS: 1) Antropometria; 2) Dinamômetro Isocinético; 3) DEXA e 4) Desempenho Funcional. 
Os voluntários compareceram em dois dias para a realização dos testes e foram orientados a utilizar roupas leves e tênis. A primeira parte continha entrevista com cadastro, aplicação do Minessota, mensuração da massa corporal, estatura e avaliação de dominância de membro inferior e superior, em seguida foram realizados os testes isocinéticos. Na segunda parte foram realizados o DEXA e os testes funcionais.

Os procedimentos experimentais foram iniciados com a triagem dos voluntários, após esta etapa, os indivíduos foram divididos, aleatoriamente, em dois grupos de intervenção: GE: $(n=27)$ ou GM: $(n=27)$. A divisão foi realizada pelo método de randomização em blocos (WEBBER \& POTTER, 2010).

Nas três primeiras semanas foram realizadas as coletas pré-intervenção (PRÉ) com todos os voluntários. Após essa etapa, os voluntários foram alocados em uma das três turmas de cada grupo para um melhor acompanhamento, seguindo de três semanas de familiarização, realizando doze semanas de TF, duas vezes por semana. Ao finalizar o período de intervenção, iniciou-se as avaliações pós-intervenção (PÓS), respeitando um tempo mínimo de 48 horas entre o último treinamento e o primeiro teste.

Ambos os grupos foram orientados a não iniciarem outras atividades físicas e a manterem seus hábitos alimentares. Foram explicitadas aos participantes todas as orientações necessárias para a execução correta dos exercícios, os voluntários estavam sempre acompanhados por um professor de educação física e duas fisioterapeutas, além de estagiários de educação física e fisioterapia.

\subsection{Intervenções}

Os testes de Repetições Máximas (RM) e as intervenções ocorreram na Faculdade da Ceilândia-UnB. Após a realização das avaliações PRÉ, os voluntários fizeram em dois dias, os testes de RM para a determinação da carga em ambos os grupos (COLADO et al., 2009). Em seguida, foram conduzidas duas semanas de familiarização com os exercícios, seguindo doze semanas de treinamento, totalizando 32 sessões de treinamento duas vezes por semana, cada sessão durou aproximadamente 60 minutos, iniciada com aquecimento global. Foram propostos treinamentos extras para a reposição para as faltosas e excluídas da análise as que faltaram três vezes consecutivas. Para aproximar ao máximo as duas intervenções, os exercícios foram definidos, para ambos os grupos, os mesmos grupos musculares, conforme Quadro 1. 
Quadro 1: Exercícios realizados durante o período de treinamento.

\begin{tabular}{|c|c|c|c|c|}
\hline \multirow{5}{*}{ 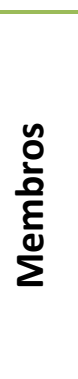 } & \multirow{5}{*}{ 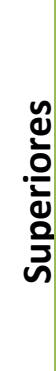 } & № & GRUPO ELÁSTICO & GRUPO MÁQUINA \\
\hline & & 1 & Supino Reto & Supino Reto \\
\hline & & 2 & Puxada Alta & Puxada Alta \\
\hline & & 3 & Tríceps & Tríceps Máquina \\
\hline & & 4 & Remada & Remada Sentado \\
\hline \multirow{5}{*}{ 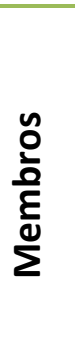 } & \multirow{5}{*}{ 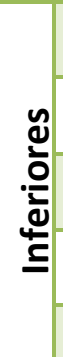 } & 5 & Flexão de Joelhos & Cadeira Flexora \\
\hline & & 6 & Extensão de Joelhos & Cadeira Extensora \\
\hline & & 7 & Abdução de Quadril & Abdução de Quadril (sentado) \\
\hline & & 8 & Extensão de Quadril & Extensão de Quadril \\
\hline & & 9 & Deslocamento Lateral & Abdução de Quadril (em pé) \\
\hline
\end{tabular}

Durante a familiarização, os voluntários realizaram duas séries de 15 a 20 repetições, utilizando um minuto de recuperação e com intensidade leve a moderada, utilizando a carga definida nos testes de RM em todos os exercícios.

As doze semanas de treinamento foram divididas em três meso ciclos (quatro semanas cada), utilizando uma periodização clássica (Linear), Quadro 2. O controle das variáveis agudas do exercício seguiu as recomendações do American Colloge of Sports Medice (ACMS, 2009).

Quadro 2: Variáveis agudas do treinamento.

\begin{tabular}{|c|c|c|c|c|c|c|}
\hline & Semana & № Séries & № Repetições & Recuperação & Ordem & Carga \\
\hline Teste RM & $1^{\mathrm{a}}$ & & & & \multirow{5}{*}{ 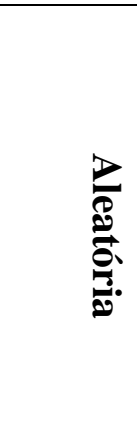 } & \multirow{5}{*}{$\begin{array}{l}0 \\
0 \\
0 \\
0 \\
0 \\
0 \\
0 \\
0 \\
0 \\
0\end{array}$} \\
\hline Familiarização & $2^{a}$ e $3^{a}$ & 2 & $15-20$ & $60 \mathrm{~s}$ & & \\
\hline Mesociclo I & $4^{a}$ a $7^{a}$ & 3 & $12-15$ & $60 \mathrm{~s}$ & & \\
\hline Meso ciclo II & $8^{\mathrm{a}}$ a $11^{\mathrm{a}}$ & 3 & $10-12$ & $60 \mathrm{~s}$ & & \\
\hline Mesociclo II & $12^{\mathrm{a}}$ a $15^{\mathrm{a}}$ & 3 & $10-8$ & $60 \mathrm{~s}$ & & \\
\hline
\end{tabular}

As figuras de 10 a 18 a seguir demonstram os exercícios realizados por cada grupo e a maneira para executá-los com Resistência Elástica Progressiva ou Máquinas Pneumáticas nos distintos grupos. 

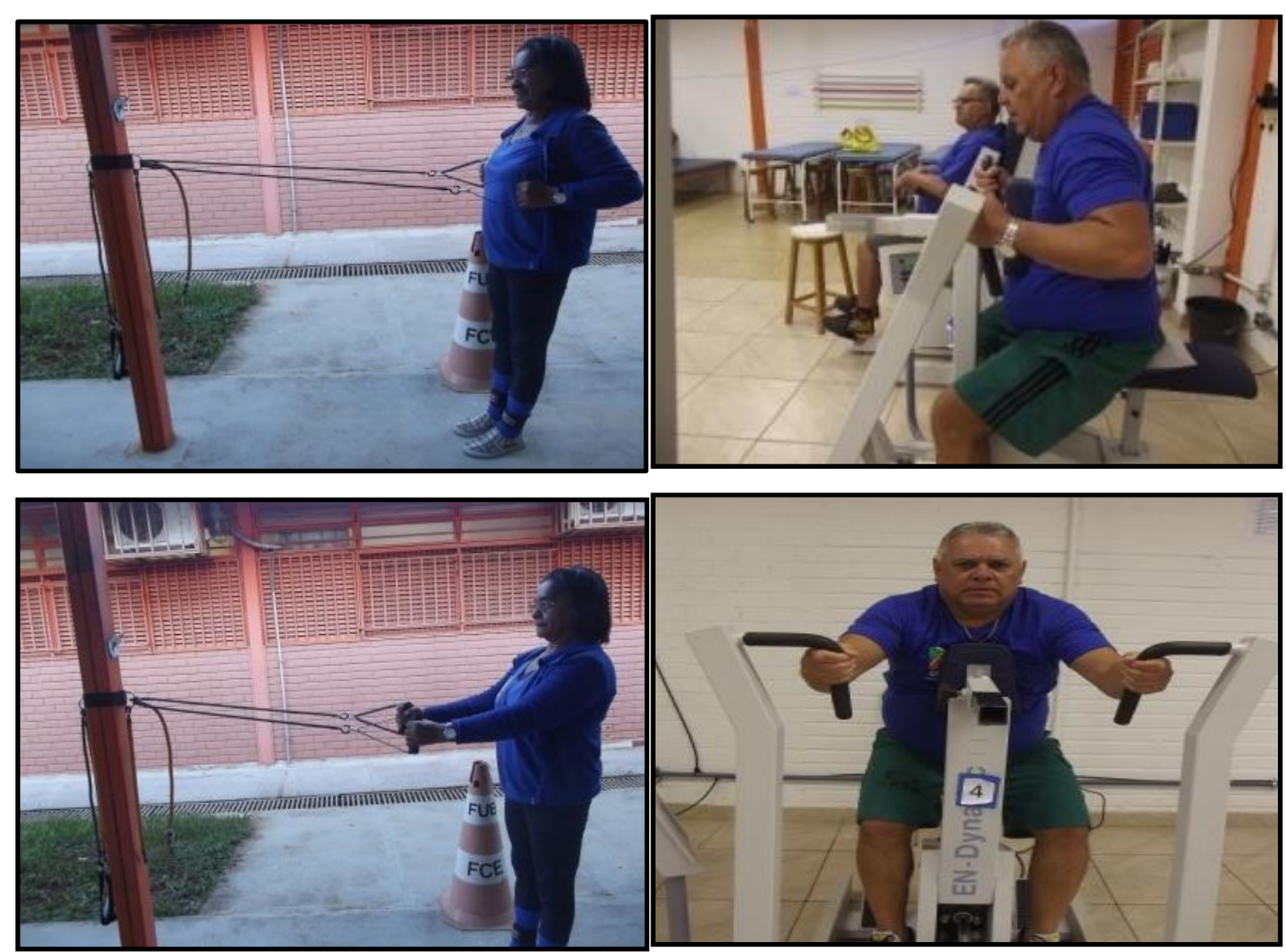

Figura 10: Equiparação do exercício remada.
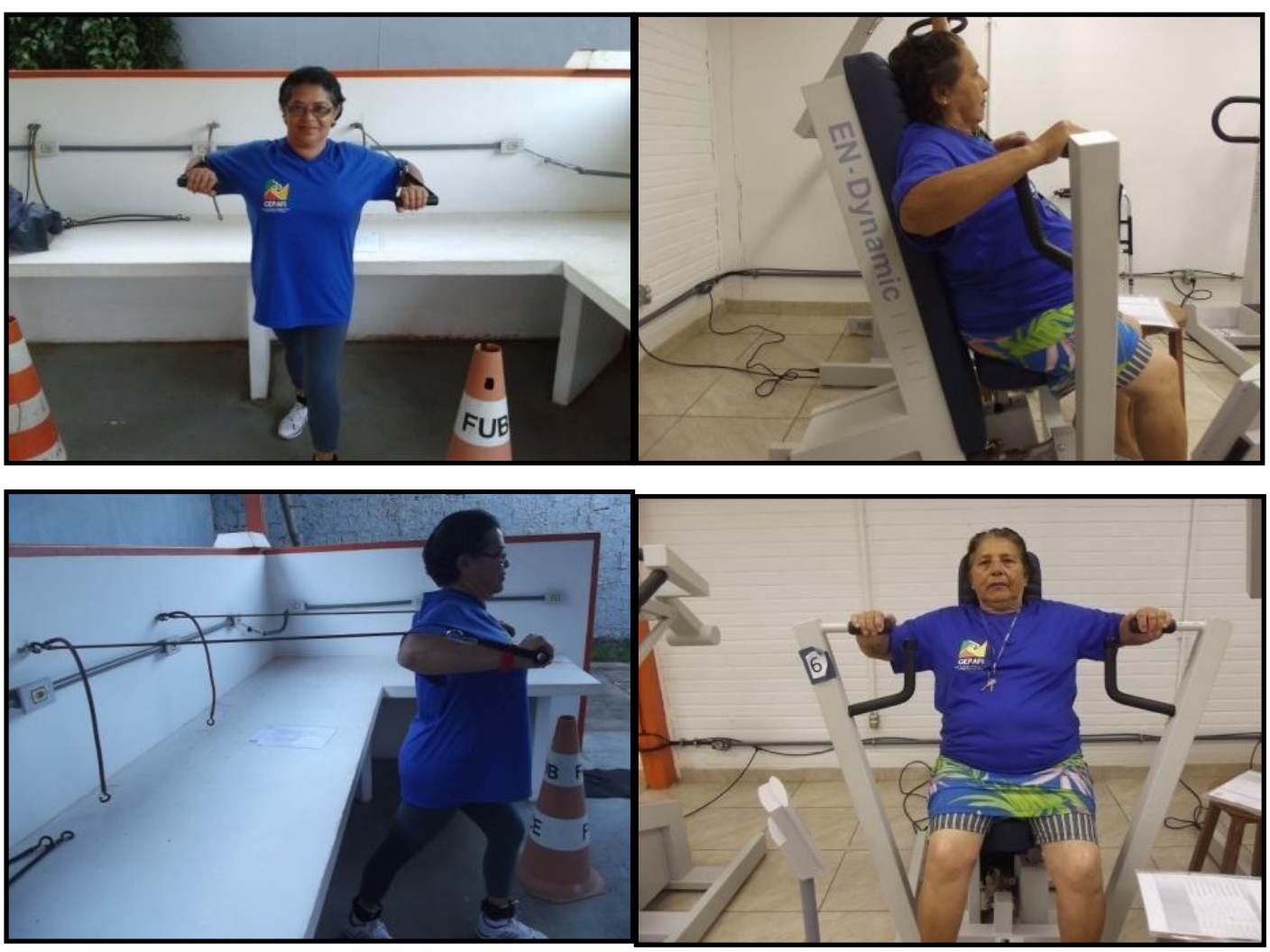

Figura 11: Equiparação do exercício supino. 

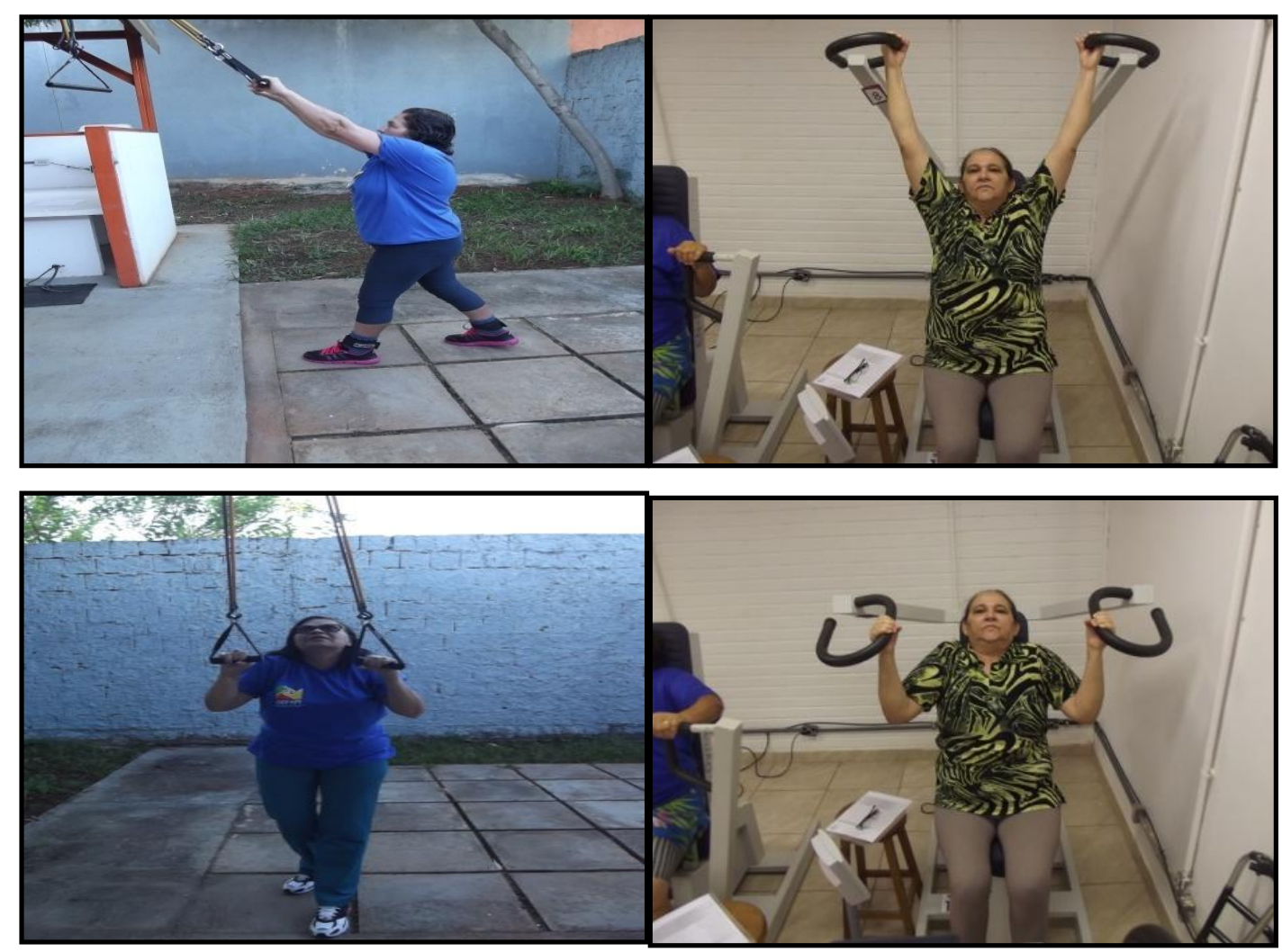

Figura 12: Equiparação do exercício puxada alta.
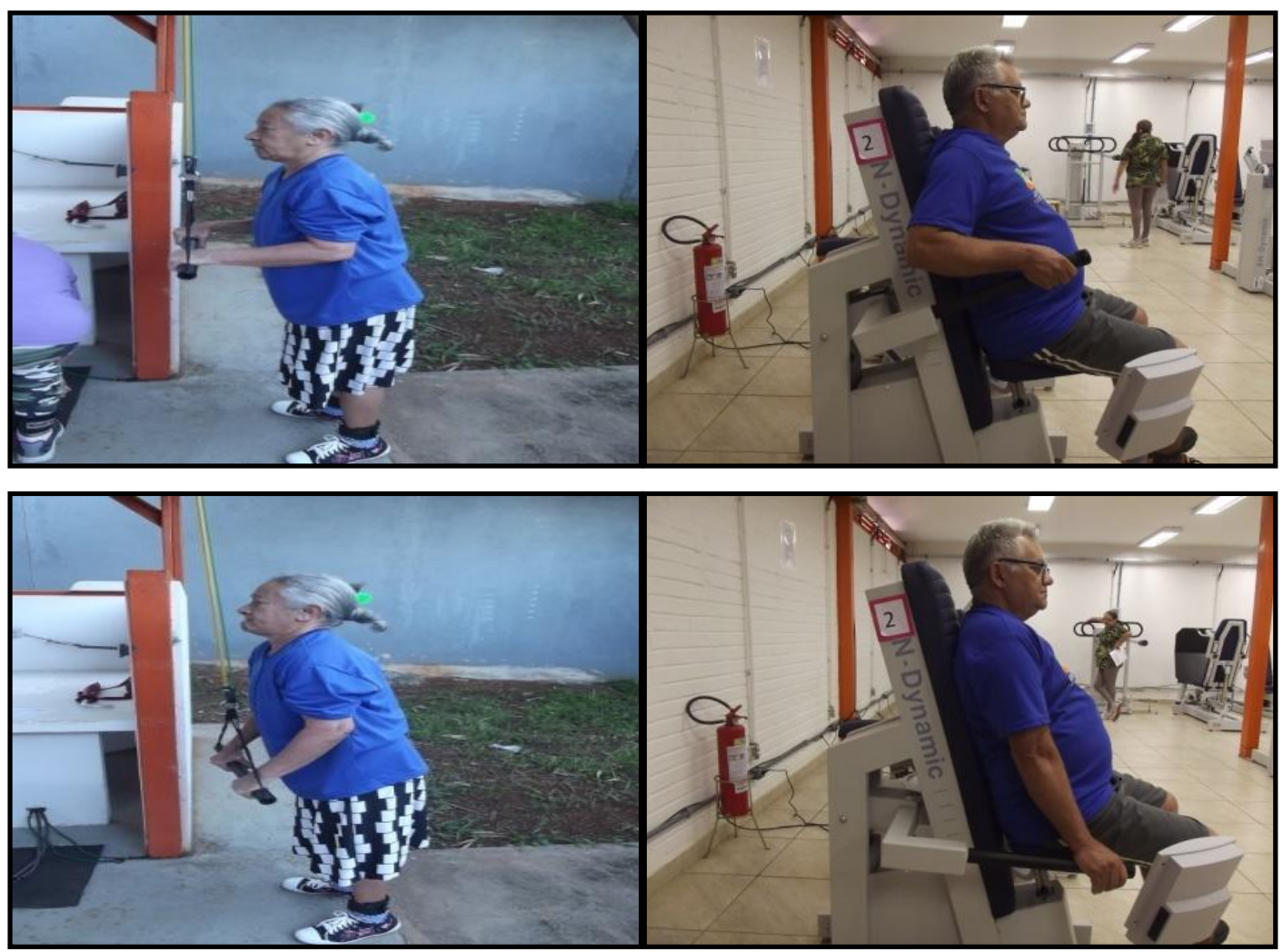

Figura 13: Equiparação do exercício tríceps. 

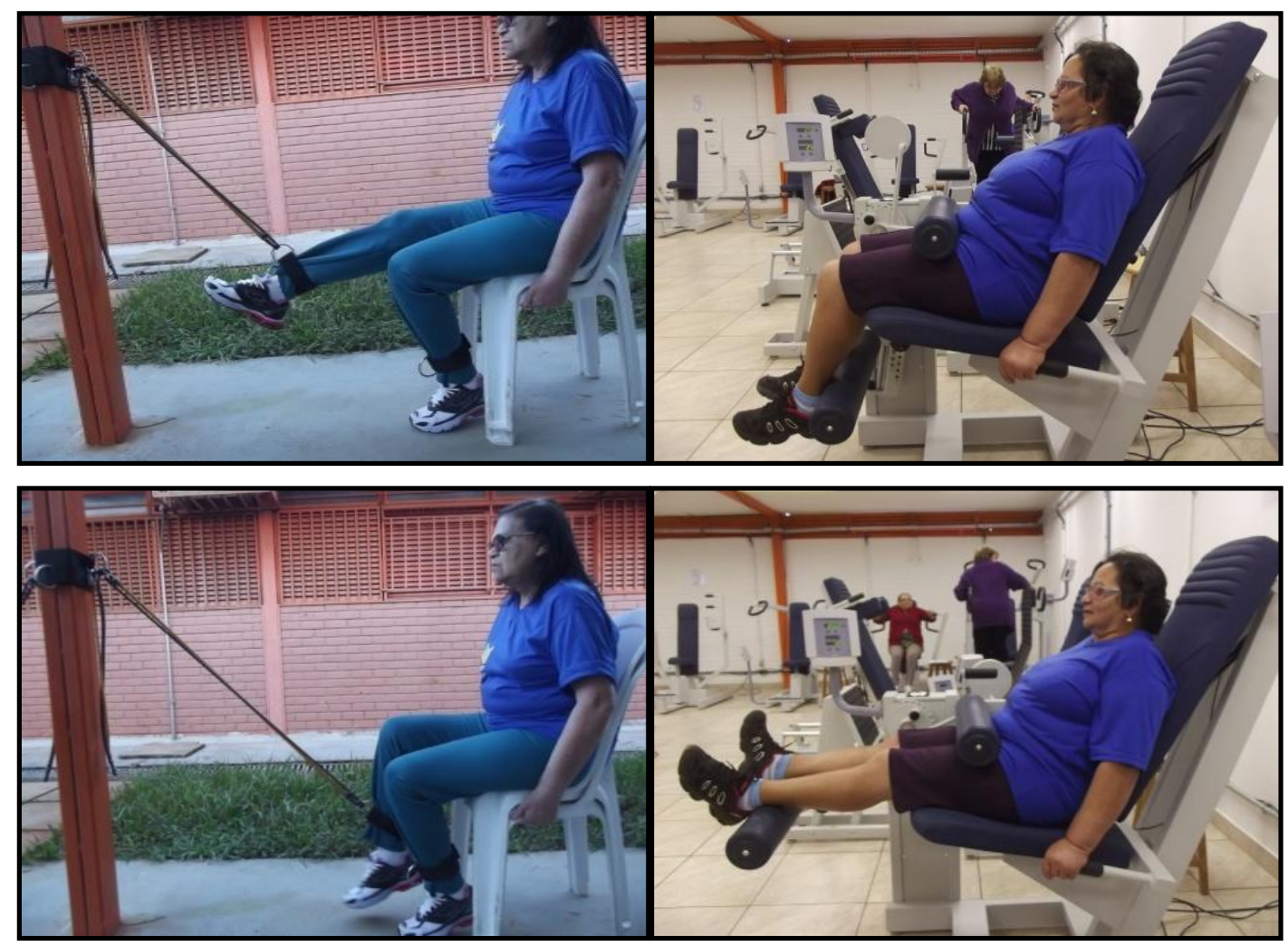

Figura 14: Equiparação do exercício flexão de joelho.
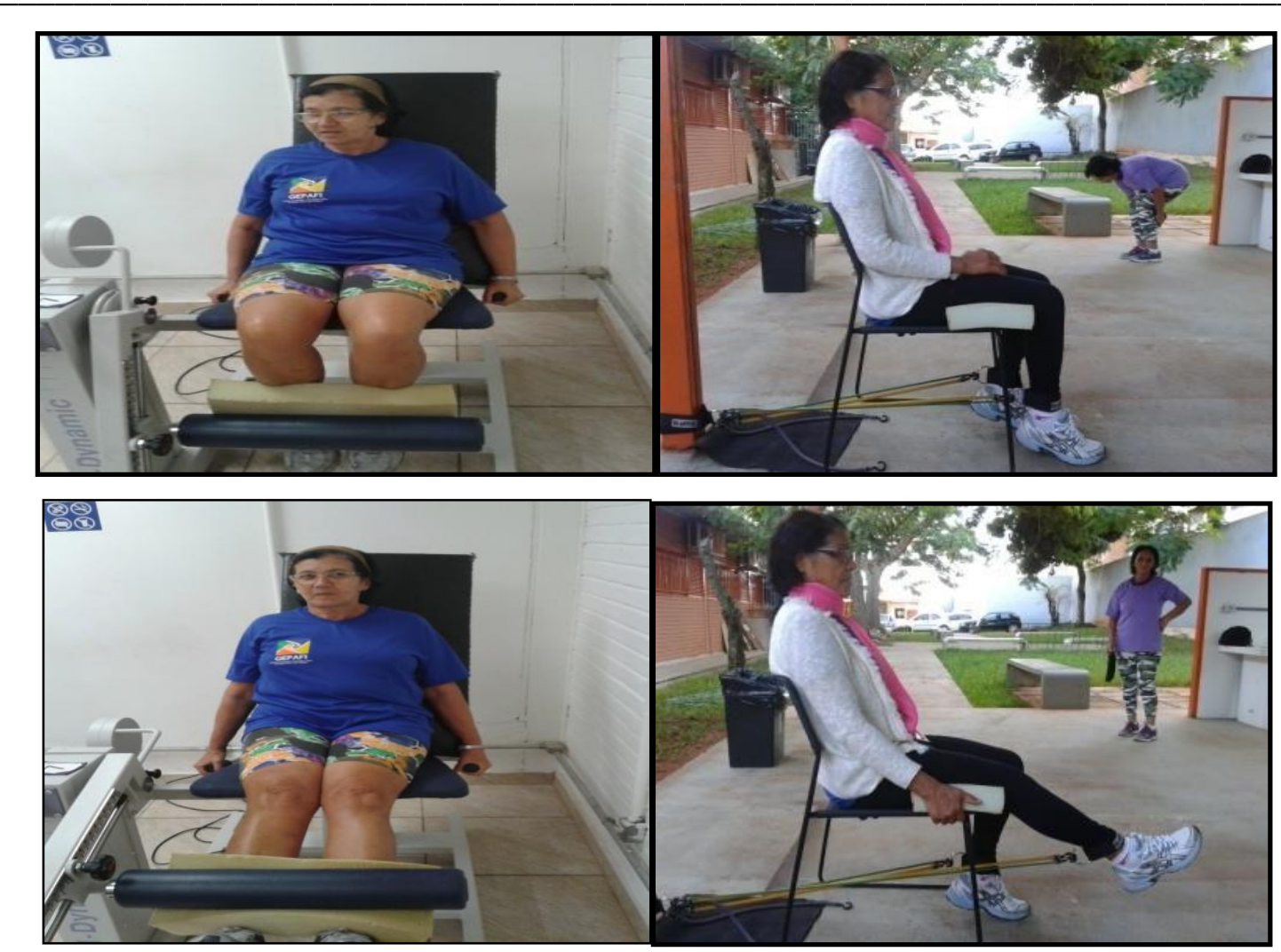

Figura 15: Equiparação do exercício extensão do joelho. 

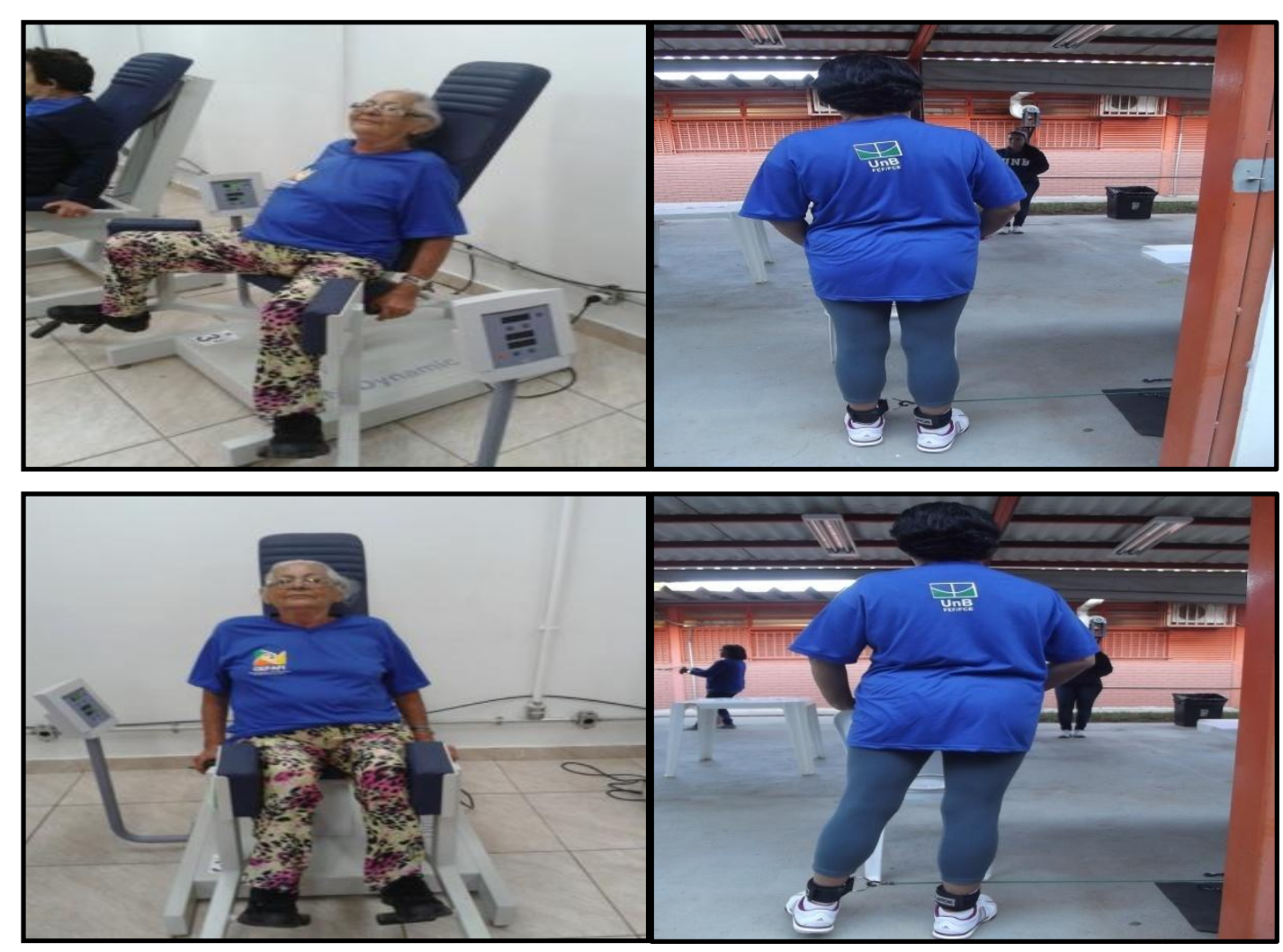

Figura 16: Equiparação do exercício abdução do quadril.
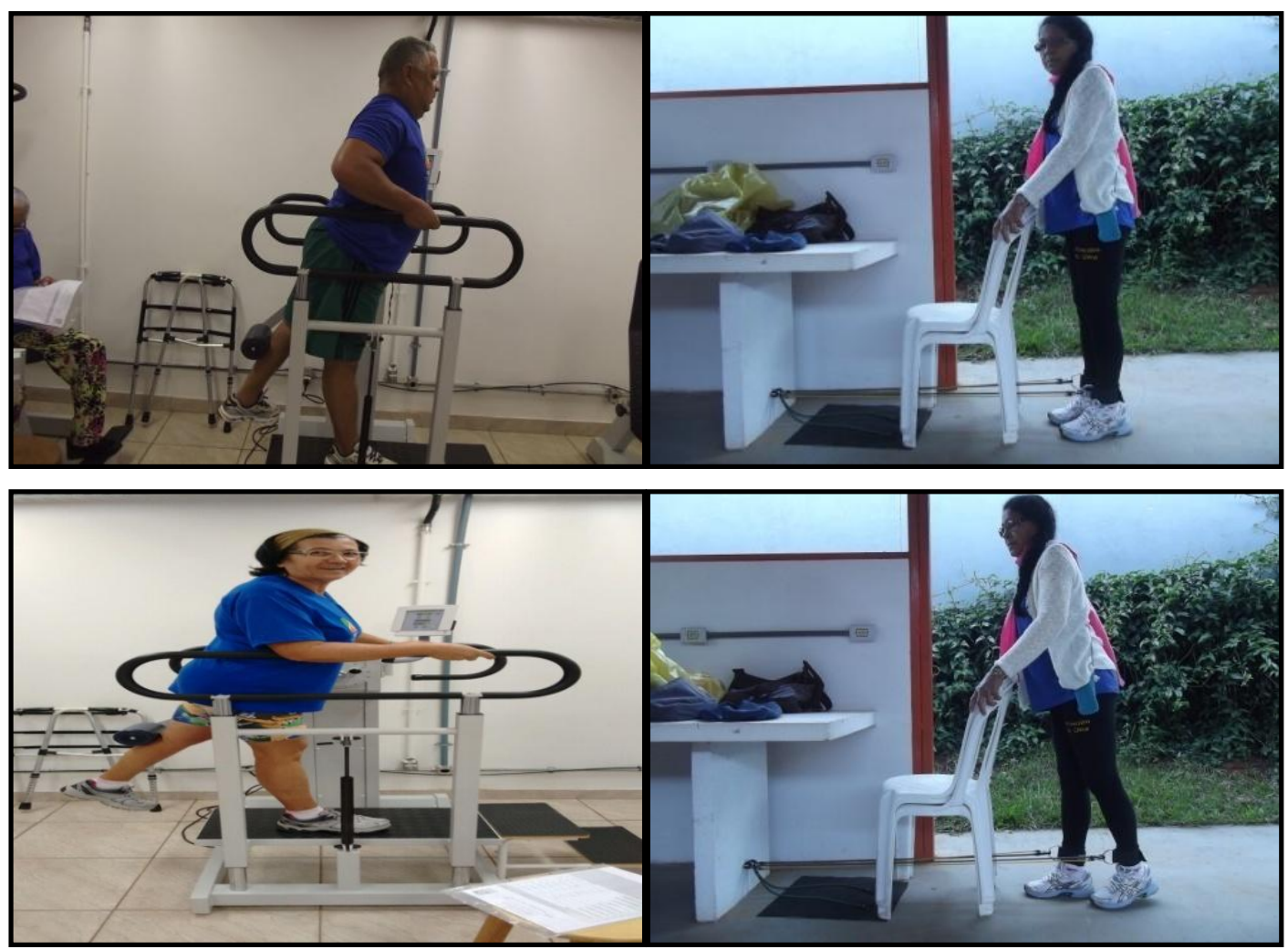

Figura 17: Equiparação do exercício extensão do quadril. 

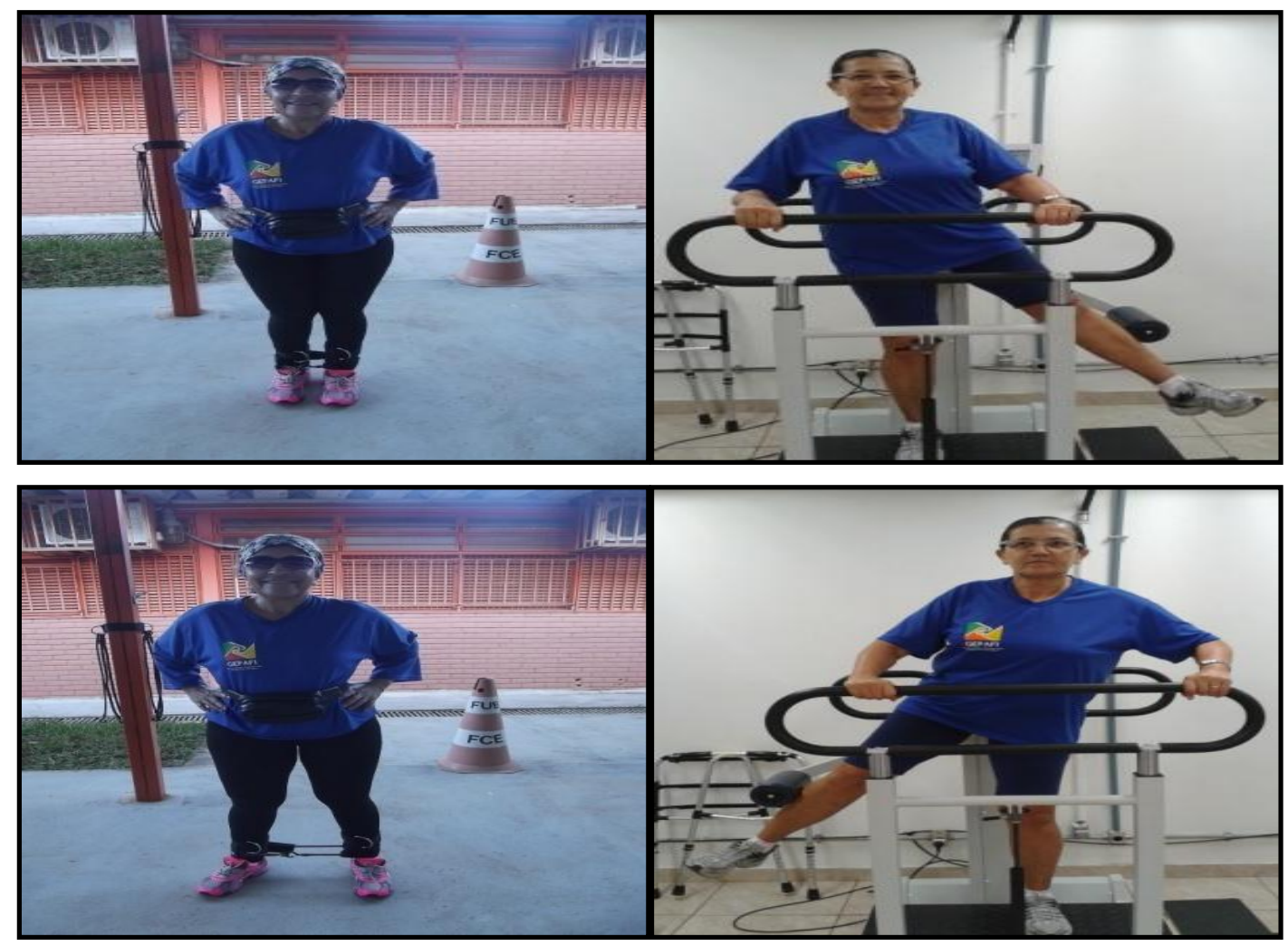

Figura 18: Equiparação do exercício abdução do quadril em pé.

Para que a carga inicial fosse determinada foi feito um controle do número de repetições máximas alvo de $15(15 \mathrm{RM})$. A progressão da carga foi realizada de acordo com o número de RM alvo com a maior carga possível para atingir esse número alvo.

Desta maneira, toda vez que uma voluntária realizasse uma quantidade superior de repetições máximas que fora estipulada para a zona alvo de acordo com a fase de treinamento, uma carga adicional era acrescentada, seja no GE ou no GM.

No GE, a progressão foi feita por meio dos diferentes níveis de carga de acordo com as cores dos componentes elásticos. Por se tratar de uma resistência variável que depende do percentual de estiramento e espessura do tubo, os exercícios foram realizados no momento inicial com $0 \%$ de alongamento e momento final de $150 \%$. Os momentos iniciais e finais dos exercícios foram demarcados com a régua de percentual de estiramento que acompanha o kit do material utilizado no presente estudo e que permite medir quatro diferentes alongamentos dos tubos $(50 \%, 100 \%, 150 \%$ e $200 \%)$. Assim, após determinado o alongamento final de $150 \%$ para os exercícios, marcações foram feitas com cones e hastes e serviram de referências permanentes ao longo do período de treinamento. Desta maneira, as participantes executaram os exercícios até 
atingisse o alongamento de $150 \%$ do componente elástico. Vale ressaltar que a medida de estiramento foi realizada independentemente do acessório exercitador utilizado, sendo que, para mensurar o percentual de estiramento foi considerado o comprimento entre os bulbos do componente elástico que possuem corte padronizado para todas as cores.

No GM, o incremento de carga foi feito diretamente no display das máquinas conforme Figura 19. até que a carga ideal para o número de RM alvo fosse atingido. Para isso, a máquina permitiu um incremento de no mínimo $0,5 \mathrm{~N}$ ou mais até que a voluntária não conseguisse realizar nenhuma repetição a mais do que aquela solicitada para a zona alvo de cada fase de treinamento.

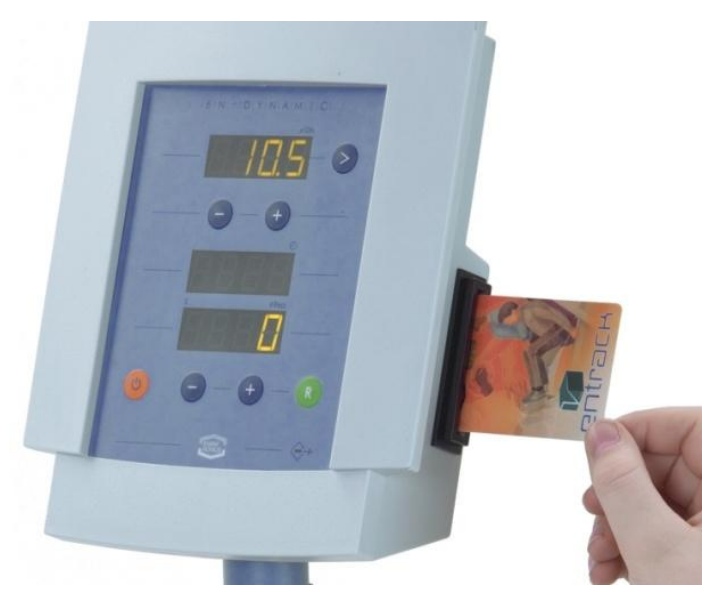

Figura 19. Dispay das Máquinas Pneumáticas EN DINAMYCS®. 


\subsection{Análise Estatística}

Os dados foram apresentados através da estatística descritiva utilizando-se média e desvio padrão para as características da amostra. Inicialmente foi realizada uma análise exploratória para verificar a simetria e a presença de casos extremos nas distribuições das variáveis.

A normalidade da distribuição dos dados foi testada utilizando o teste de Shapiro-Wilk e a homogeneidade de variância foi testada através do teste de Levene. Após estes procedimentos foram aplicados testes de hipóteses específicas para cada variável analisada.

Para verificar possíveis diferenças nas médias entre os grupos, na linha de base do estudo foram utilizados os testes $t$ de student independente e o teste $\mathrm{U}$ de MannWhitney, de acordo com a presença ou não de normalidade dos dados.

Para analisar os efeitos das doze semanas de TF intra-grupo nos momentos (PRÉ x PÓS) foram utilizados os testes $t$ student pareado ou teste de somas de postos de Wilcoxon de acordo com a presença ou não do teste de normalidade. Já para a comparação entre os grupos foi utilizado a análise de variância (ANOVA) ou Kruskalwallis de modelos mistos 2X2 (Grupo [GE e GM] X [PRÉ E PÓS] para cada variável dependente, utilizando o post-hoc de Bonfferroni quando identificada diferença estatisticamente significante.

Inicialmente foi criado um banco de dados no programa Excel ( Microsoft, EUA). Para as análises dos dados foi utilizado o software Statatistical Package for the Social Sciences (SPSS, Chicago, IL) para Windows versão 22.0, e o nível de significância adotado para todas as variáveis foi de $\mathrm{p} \leq 0,05$ (FIELD, 2012). 


\section{RESULTADOS}

\subsection{Caracterização dos Grupos}

As medidas antropométricas, a idade e o nível de atividade física estão representados na Tabela01. Um total de 44 voluntárias finalizou o estudo. No início do estudo não foram observadas diferenças, estatisticamente, significantes entre os grupos na idade $(p=0.277)$, estatura $(p=0.771)$, massa corporal $(p=0.155)$, IMC $(p=0.683)$ e nível de atividade física $(\mathrm{p}=0.063)$.

Tabela 01: Característica da amostra por grupo no início do estudo.

\begin{tabular}{lccc}
\hline & $\begin{array}{c}\text { Grupo Elástico } \\
(\mathrm{n}=18)\end{array}$ & $\begin{array}{c}\text { Grupo Máquina } \\
(\mathrm{n}=26)\end{array}$ & $\mathrm{p}$ \\
\hline Idade (anos) & $67.55 \pm 5.20$ & $69.34 \pm 5.37$ & 0.277 \\
Estatura (cm) & $1.53 \pm 0.47$ & $1.53 \pm 0.64$ & 0.771 \\
Massa Corporal (Kg) & $69.88 \pm 9.10$ & $69.13 \pm 16.38$ & 0.155 \\
IMC $\left(\mathrm{Kg} / \mathrm{m}^{2}\right)$ & $29.73 \pm 3.22$ & $29.16 \pm 5.97$ & 0.683 \\
$\begin{array}{l}\text { MINESOTA } \\
(\text { MET-min/semana) }\end{array}$ & $2167 \pm 1309$ & $4229 \pm 2826$ & 0.063 \\
\hline $\begin{array}{l}\text { IMC: Índice de Massa Corporal; MINESOTA: Minessota Leisure Time Activity Questionare; } \\
\text { MET: taxa metabólica de repouso-minuto por semana. Dados em média e desvio padrão. }\end{array}$
\end{tabular}

Os dados das variáveis dependentes, força, massa muscular e testes funcionais estão representados na Tabela 02. No início do estudo não foram observadas diferenças, estatisticamente, significantes entre os grupos no PTFC60 ${ }^{\circ}(\mathrm{p}=0.298), \mathrm{PTFC}_{180^{\circ}}$

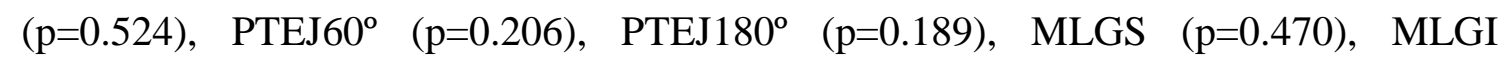
$(p=0.431), \operatorname{MLGT}(p=0.417)$, FC $(p=0.696)$ e TSL (0.384). 
Tabela 02: Características das variáveis dependentes por grupo no início do estudo.

\begin{tabular}{lccc}
\hline Variáveis & $\begin{array}{c}\text { Grupo Elástico } \\
(\mathrm{n}=18)\end{array}$ & $\begin{array}{c}\text { Grupo Máquina } \\
(\mathrm{n}=26)\end{array}$ & $\mathrm{P}$ \\
\hline Força Muscular & & & \\
PTFC $60 \%$ (N.m) & $25.57 \pm 7.90$ & $23.43 \pm 5.38$ & 0.298 \\
PTFC $180 \%$ (N.m) & $22.55 \pm 7.98$ & $21.30 \pm 4.93$ & 0.524 \\
PTEJ 60 \% (N.m) & $91.99 \pm 14.38$ & $84.89 \pm 20.13$ & 0.206 \\
PTEJ 180 \% (N.m) & $60.04 \pm 9.32$ & $55.90 \pm 13.00$ & 0.189 \\
Massa Livre de Gordura & & & 0.470 \\
MLGS (Kg) & $4.00 \pm 0.61$ & $3.85 \pm 0.73$ & 0.431 \\
MLGI (Kg) & $11.09 \pm 1.30$ & $11.16 \pm 1.91$ & 0.417 \\
MLGT (Kg) & $36.41 \pm 3.68$ & $36.62 \pm 5.82$ & \\
Testes Funcionais & & & 0.696 \\
Flexão de Cotovelo (rep) & $16.66 \pm 3.62$ & $16.30 \pm 2.42$ & 0.384 \\
Levantar da Cadeira (rep) & $12.50 \pm 2.00$ & $11.92 \pm 2.22$ & \\
\hline
\end{tabular}

PTFC: pico de torque flexão do cotovelo; PTEJ: pico de torque extensão de joelho; MLGS: massa livre de gordura dos membros superiores; MLGI: massa livre de gordura dos membros inferiores; MLGT: massa livre de gordura total. Dados em média e desvio padrão.

\subsection{Força, Massa Muscular e Desempenho Funcional}

Todos os valores PRÉ e PÓS das variáveis dependentes, os efeitos intra-grupo (tempo) e entre grupos (tempo x grupo) podem ser observados na Tabela 03.

A força muscular exibiu aumento estatístico significativo intra-grupo, nos dois grupos, em todas as velocidades investigadas; PTEJ60 (GE, p=<0.001); GM, $\mathrm{p}=<0.001) \mathrm{PTEJ}_{180^{\circ}}(\mathrm{GE}, \mathrm{p}=<0.001 ; \mathrm{GM}, \mathrm{p}=0.001)$ PTFC60 (GE, p=0.033; GM, $p=<0.001)$, exceto no PTFC $180^{\circ}$ no GE $(p=0.136)$ GM $(p=<0.001)$. Na comparação entre grupos não foram observadas diferenças entre as médias dos deltas (PÓS-PRÉ) em nenhuma das velocidades; PTEJ60 $(p=0.292), \operatorname{PTEJ} 180^{\circ}(p=0.596)$, PTFC60 $^{\circ}(p=0.324)$ e PTFC $180^{\circ}(\mathrm{p}=0.459)$.

Em relação à MLG, houve incremento estatístico significativo intra-grupo na MLGT (GE, p=0.043; GM, p=0.049), MLGI (GE, p=0.01; GM, p=0.034) e na MLGS 
no GM ( $p=0.016)$ e aumento sem diferença significativa no GE $(p=0.749)$. Na comparação entre grupos não foram observadas diferenças entre as médias dos deltas (PÓS-PRÉ) em nenhuma das análises; MLGS ( $p=0.244)$, MLGI ( $p=0.535)$, MLGT $(\mathrm{p}=0.876)$.

Nos testes funcionais, houve melhora estatística significativa na análise intragrupo; no $\mathrm{FC}(\mathrm{GE}=<0.001 ; \mathrm{GM}=<0.001)$ e TSL $(\mathrm{GE}=<0.001 ; \mathrm{GM}=<0.001)$. Na comparação entre grupos não foram observadas diferenças entre as médias dos deltas (PÓS-PRÉ) em nenhum dos testes; TSL ( $\mathrm{p}=0.335)$ e FC ( $\mathrm{p}=0.368)$.

Tabela 03: Mudanças Pré-Pós das variáveis dependentes

\begin{tabular}{|c|c|c|c|c|c|c|}
\hline \multirow{2}{*}{ Variáveis } & \multirow{2}{*}{ Grupo } & \multicolumn{2}{|l|}{ Média } & \multicolumn{3}{|c|}{ Efeito } \\
\hline & & Pré & Pós & $\Delta \%$ & Tempo & $\begin{array}{l}\text { Grupo } x \\
\text { Tempo }\end{array}$ \\
\hline \multicolumn{7}{|l|}{ Força Muscular } \\
\hline PTFC $60 \%$ (N.m) & $\begin{array}{l}\mathrm{GE} \\
\mathrm{GM}\end{array}$ & $\begin{array}{l}25.57 \pm 7.90 \\
23.46 \pm 5.38\end{array}$ & $\begin{array}{l}28.46 \pm 6.83 \\
27.90 \pm 6.81\end{array}$ & $\begin{array}{l}11.3 \\
18.9\end{array}$ & $\begin{array}{l}0.033^{*} \\
<0.001^{*}\end{array}$ & 0.284 \\
\hline PTFC 180 \% (N.m) & $\begin{array}{l}\mathrm{GE} \\
\mathrm{GM}\end{array}$ & $\begin{array}{l}22.55 \pm 7.98 \\
21.30 \pm 4.93\end{array}$ & $\begin{array}{l}24.64 \pm 5.49 \\
25.48 \pm 5.47\end{array}$ & $\begin{array}{l}9.2 \\
19.6\end{array}$ & $\begin{array}{l}0.136 \\
<0.001^{*}\end{array}$ & 0.438 \\
\hline PTEJ $60 \%$ (N.m) & $\begin{array}{l}\mathrm{GE} \\
\mathrm{GM}\end{array}$ & $\begin{array}{l}91.99 \pm 14.38 \\
84.89 \pm 20.13\end{array}$ & $\begin{array}{l}100.76 \pm 16.99 \\
97.15 \pm 2.66\end{array}$ & $\begin{array}{l}9.6 \\
14.4\end{array}$ & $\begin{array}{l}<0.001^{*} \\
<0.001^{*}\end{array}$ & 0.264 \\
\hline PTEJ $180 \%$ (N.m) & $\begin{array}{l}\text { GE } \\
\text { GM }\end{array}$ & $\begin{array}{l}60.04 \pm 9.32 \\
55.90 \pm 13.00\end{array}$ & $\begin{array}{l}66.87 \pm 11.40 \\
63.76 \pm 14.91\end{array}$ & $\begin{array}{l}11.4 \\
14.1\end{array}$ & $\begin{array}{l}<0.001^{*} \\
<0.001^{*}\end{array}$ & 0.459 \\
\hline \multicolumn{7}{|l|}{ Massa Livre de Gordura } \\
\hline $\operatorname{MLGS}(\mathrm{Kg})$ & $\begin{array}{l}\text { GE } \\
\text { GM }\end{array}$ & $\begin{array}{l}4.00 \pm 0.61 \\
3.85 \pm 0.73\end{array}$ & $\begin{array}{l}4.03 \pm 0.62 \\
3.96 \pm 0.72\end{array}$ & $\begin{array}{l}0.5 \\
2.9\end{array}$ & $\begin{array}{l}0.749 \\
0.016^{*}\end{array}$ & 0.284 \\
\hline $\operatorname{MLGI}(\mathrm{Kg})$ & $\begin{array}{l}\mathrm{GE} \\
\mathrm{GM}\end{array}$ & $\begin{array}{l}11.09 \pm 1.30 \\
11.16 \pm 1.91\end{array}$ & $\begin{array}{l}11.45 \pm 1.35 \\
11.41 \pm 2.14\end{array}$ & $\begin{array}{l}3.3 \\
2.6\end{array}$ & $\begin{array}{l}0.01^{*} \\
0.034^{*}\end{array}$ & 0.567 \\
\hline MLGT (kg) & $\begin{array}{l}\mathrm{GE} \\
\mathrm{GM}\end{array}$ & $\begin{array}{l}36.41 \pm 3.68 \\
36.62 \pm 6.06\end{array}$ & $\begin{array}{l}36.92 \pm 3.71 \\
37.08 \pm 6.06\end{array}$ & $\begin{array}{l}1.5 \\
1.3\end{array}$ & $\begin{array}{l}0.043^{*} \\
0.049^{*}\end{array}$ & 0.726 \\
\hline \multicolumn{7}{|l|}{ Testes Funcionais } \\
\hline Flexão de Cotovelo (rep) & $\begin{array}{l}\text { GE } \\
\text { GM }\end{array}$ & $\begin{array}{l}16.66 \pm 3.62 \\
16.30 \pm 2.42\end{array}$ & $\begin{array}{l}26.05 \pm 4.09 \\
24.73 \pm 4.03\end{array}$ & $\begin{array}{l}56.3 \\
51.6\end{array}$ & $\begin{array}{l}<0.001^{*} \\
<0.001^{*}\end{array}$ & 0.343 \\
\hline Levantar da Cadeira (rep) & $\begin{array}{l}\mathrm{GE} \\
\mathrm{GM}\end{array}$ & $\begin{array}{l}12.50 \pm 2.00 \\
11.92 \pm 2.37\end{array}$ & $\begin{array}{l}17.72 \pm 3.12 \\
16.50 \pm 2.51\end{array}$ & $\begin{array}{l}41.4 \\
38.4\end{array}$ & $\begin{array}{l}<0.001^{*} \\
<0.001^{*}\end{array}$ & 0.345 \\
\hline
\end{tabular}




\section{DISCUSSÃO}

Posicionamentos oficiais e revisões recentes afirmam que intervenções envolvendo o TF utilizando máquinas e pesos livres são efetivos no incremento de força, massa muscular e desempenho funcional em idosos (ACMS, 2009; STEIB et al., 2010; SILVA et al., 2014) Porém, são escassos os estudos que utilizam resistência elástica no incremento destas variáveis, não havendo consenso na literatura.

O presente estudo teve como objetivo verificar os efeitos de dois tipos de treinamento resistido na força, massa muscular e desempenho funcional de mulheres idosas da comunidade. O TF foi realizado em doze semanas, duas vezes por semana com nove exercícios para membros superiores e inferiores. O GM treinou utilizando máquinas pneumáticas e o GE utilizou resistência elástica progressiva.

As intervenções foram equiparadas quanto às variáveis agudas do TF e quanto aos exercícios propostos para que ambas estimulassem os mesmos grupos musculares. O estudo de Jokobsen et al. (2014) demonstrou semelhança entre máquina de musculação e dispositivo elástico na ativação muscular dos músculos isquiotibiais durante a execução do exercício de flexão do joelho, avaliado por eletromiografia de superfície.

A amostra do presente estudo foi de conveniência, composta por mulheres idosas saudáveis, com sobre peso e independentes fisicamente, que embora praticassem atividade física não orientada, não possuíam familiaridade com a prática regular e sistematizada de exercícios resistidos. Esse fato é observado em outros estudos com intervenções semelhantes (RABELO et al, 2004; BOTTARO et al, 2007). Cabe ressaltar que amostras de conveniência são geralmente mais saudáveis e apresentam níveis mais altos de funcionalidade do que a população como um todo (RIKLI \& JONES, 2008).

\subsection{Efeitos na Força Muscular Isocinética}

No presente estudo foi observado melhora significativa "intra-grupo" no $\mathrm{PTFC}^{\circ} 0^{\circ}$ de $18,9 \%$ e 11,3\% no GM e GE, respectivamente. Na comparação "entre grupos" não foi observado diferenças entre as médias dos deltas (PÓS-PRÉ) desta variável $(\mathrm{p}=0,324)$. Em relação ao PTFC180 houve melhora significativa de 19,6\% no GM, no GE houve melhora em relação ao momento PRÉ 9,2 \%, porém, sem diferença estatística significativa, na comparação “entre-grupos" não foram observadas diferenças 
( $\mathrm{p}=0,459)$. Já em relação PTEJ60 foi observado melhora significativa de 9,6\% no GE e de 14,4 \% no GM, e não foram encontradas diferenças na comparação "entre-grupos" ( $p=0,292)$. Em relação ao PTEJ180º GE melhorou 11,4\% e o GM 14,1\%, sem diferença "entre-grupos". Os resultados observados com os dois tipos de TF, nas variáveis de força muscular analisadas sugerem que ambos os dispositivos utilizados foram capazes de incrementar esta variável, corroborando com nossa hipótese do estudo.

Neste estudo doze semanas de TF foram suficientes para aumentar de forma significativa o PT isocinético no membro superior e inferior nas velocidades investigadas. Tal fato pode ser explicado devido ao aumento volumétrico das fibras musculares, às adaptações neurais ao treinamento com maior inervação e ativação das fibras musculares e uma melhor coordenação intra e intermuscular (FLECK \& KRAEMER, 2006). A quantidade de resistência empregada é provavelmente um dos fatores chave em qualquer programa de treinamento de força, sendo o principal estímulo relacionado ás alterações observadas nas mensurações de força (PETERSON et al., 2010). Segundo Flecker et al. (2006) o método de repetições máximas (RMs) é provavelmente a forma mais fácil para determinação de uma resistência. De acordo com este autor, o treinamento com cargas correspondentes a faixa de 1 a 6 RM e até mesmo de 8 a 12 RM são efetivos no incremento da força muscular, o presente estudo utilizou o número alvo de 8 a 15 RM.

O desempenho muscular dos membros superiores é fundamental para a realização das atividades da vida diária incluindo carregar compras, arrastar objetos e cuidar do jardim. Os efeitos do TF na força muscular dos membros superiores foram evidenciados no estudo de Brown et al. (1990) que demonstrou após 12 semanas de treinamento com pesos, melhora de $48 \%$ no teste de (1RM) e de $8,8 \%$ no PT isocinético em 14 idosos destreinados. Os autores concluem que os idosos conseguem manter potencial para aumento do desempenho muscular em resposta a sobrecarga do treinamento mesmo com o avançar da idade.

Não foram encontrados na literatura estudos que analisaram os efeitos do $\mathrm{TF}$ com resistência elástica na força muscular isocinética de membros superiores. Porém, o presente estudo observou melhora significativa no GE PTFC60 $(\mathrm{p}<0,033)$ e aumento no PTFC $180^{\circ}$ sem diferença estatística $(\mathrm{p}<0,136)$, uma das possíveis explicações para não obter um ganho estatístico significativo é o fato de três exercícios para membros superiores (remada, supino e puxada alta) realizados no GE eram multiarticulares e 
executados em pé. Exercícios multiarticulares requerem coordenação neural entre os músculos, pois promovem o uso de diversos grupos musculares. Além da coordenação motora, os exercícios feitos em pé necessitam constantemente de um adequado equilíbrio estático e de ajustamentos posturais importantes para promover uma estabilidade corporal necessária para ação dos músculos agonistas. Segundo Fleck et al. (2006) exercícios multiarticulares requerem uma fase neural e de aprendizagem inicial mais longa que em relação aos exercícios monoarticulares. Assim, levantamos a hipótese de que essas adaptações motoras específicas tenham se estendido além do período de familiarização no GE, pois observamos em diversos momentos da intervenção desequilíbrios posturais e dificuldades de coordenação motora durante algumas semanas do treinamento o que pode ter retardado o ganho de força muscular.

$\mathrm{O}$ aumento do torque dos membros inferiores tem sido descrito como importante para a melhora funcional, visto que adultos sadios executam suas atividades diárias perto de suas capacidades máximas de torque, especialmente ao redor da articulação do joelho (HORTOBAGYI et al., 2003).

Os benefícios do TF são evidenciados na literatura em diversos tipos de treino, frequência, intensidade, número de exercícios e repetições (SILVA et al., 2014). Kamen \& Karsh (2004) demonstraram que três séries de dez repetições de extensão de joelho com carga de $85 \%$ de 1 RM, realizadas, aumentaram em $49 \%$ a força muscular do quadríceps de 7 idosos entre 67 e 81 anos. Henwood \& Taaffe (2006) demonstraram que oito semanas de exercícios com carga de $75 \%$ de 1RM aumentaram em $21 \%$ a força de membros inferiores de 22 idosos entre 65 e 84 anos.

Fiatarone et al (1990) demonstrou que 8 semanas de TF com carga média $80 \%$ de 1RM foi capaz de aumentar a força muscular em 174\% do músculo quadríceps de 10 idosos entre 86 e 96 anos. No caso a condição inicial dos sujeitos precisa ser considerada, visto que indivíduos com baixos níveis de aptidão podem apresentar elevados ganhos de força (ORR e at., 2006). Por outro lado, estudos que envolveram idosos fisicamente ativos sem experiência com TF apresentaram ganhos similares aos do presente estudo, como os achados de FERRI et al. (2003) e IVEY et al. (2000) que encontraram aumentos médios de $17 \%$ e $23 \%$.

Em relação ao TF com resistência elástica podemos destacar alguns estudos que avaliaram a força de membros inferiores. Mikesky et al. (1994) demonstraram um aumento de $12 \%$ no PT excêntrico de extensão de joelho e na velocidade de $60^{\circ}$ após 12 semanas de treinamento baseado em casa com 62 idosos (GE, $\mathrm{n}=31 ; \mathrm{GC}, \mathrm{n}=31$ ) 
média de idade (71,2 anos), este valor foi similar ao ganho do presente estudo que foi de 9,6\% e tempo de intervenção igual. Topp et al. (1996) demonstraram em 14 semanas de treinamento em 42 homens e mulheres idosos com idade média (78.3) (GE, n=21; GC $\mathrm{n}=21$ ) um aumento de $16 \%$ no PT concêntrico de extensão do tornozelo e de $12 \%$ no PT excêntrico de extensão de tornozelo na velocidade de $30^{\circ}$. Krebs et al. (1998) demonstraram um ganho total da força muscular isométrica em membros inferiores (extensão de quadril, abdução de quadril e extensão de joelho) de $17,6 \%$ no GE(n=56 após 24 semanas de treinamento. Jette et al. (1999) demonstraram ganho $12 \%$ na força muscular excêntrica dos membros inferiores de 108 idosos após 24 semanas de treinamento.

A literatura demonstra grandes benefícios do TF para a população idosa no incremento da força muscular em suas diversas manifestações. Os resultados aqui apresentados corroboram com os dados encontrados em outros estudos. Assim, reforça a necessidade da variável força ser analisada de forma mais abrangente, uma vez que as atividades da vida diária exigem formas variadas de desempenho desta capacidade.

\subsection{Efeitos na Massa Livre de Gordura}

No presente estudo foi observado melhora significativa "intra-grupo" na MLGS no GM 2,5\%, no GE houve melhora em relação ao momento PRÉ 0,5 \%, porém, sem diferença estatística significativa, na comparação "entre grupos" não foi observado diferenças entre as médias dos deltas (PÓS-PRÉ) desta variável $(\mathrm{p}=0,244)$. Em relação à MLGI houve melhora significativa de 3,3\% e 2,6\% no GE e GM respectivamente, sem diferença "entre-grupos" ( $p=0,535)$. Já em relação à MLGT foi observado melhora significativa de $1,5 \%$ no GE e de 1,3\% no GM, e não foram encontradas diferenças na comparação "entre-grupos" ( $\mathrm{p}=0,876)$. Os achados observados com os dois tipos de TF, nas variáveis de MLG analisadas sugerem que ambos os dispositivos utilizados foram capazes de incrementar esta variável, corroborando com nossa hipótese do estudo.

O TF como método para aumento da massa muscular utilizando pesos livres e máquinas já foi evidenciado na revisão com meta análise de Peterson et al. (2010). O incremento significante da massa muscular pode começar a ocorrer a partir da nona semana de treinamento (HUNTER \& BAMMAN, 2004). Porém, segundo Flecker, (2006) apontam que este fenômeno pode acontecer em programas de curta duração. Em idosos, o TF tende a ser mais efetivo quando uma alta carga de treinamento é imposta 
(PETERSON et al., 2010). As estratégias para a prevenção ou reversão das perdas de massa muscular associadas à idade tem recebido boa atenção. Porém, em relação aos estudos de TF com resistência elástica em idosos que avaliam esta variável são escassos.

Fronteira et. al. (1988) já haviam demonstrado a efetividade do TF em incrementar massa muscular em homens idosos destreinados (faixa etária 60-72 anos) que completaram um programa de TF por doze semanas (3 séries, 8 repetições 3 vezes por semana) a $80 \%$ de 1RM. A massa muscular foi aferida através de tomografia computadorizada e demonstrou aumento da área total da coxa de 4,8\% e da área total do corpo de 11,4\% $(\mathrm{p}<0,01)$. No estudo de Fiatarone et al. (1990) foi demonstrada a efetividade do TF de alta intensidade no incremento da massa muscular em homens idosos institucionalizados com idade acima de 90 anos. A área muscular da coxa aumentou em média $9,0 \%$.

Outros estudos podem ser destacados por incrementar a massa muscular após o TF em idosos. Geirsdottir et al. (2012) demonstraram que doze semanas de treinamento (3 séries, 3 vezes por semana, 6-8 repetições a 75-80\% de 1RM) foram capazes de aumentar (média 0,8 Kg p<0,01) a MLG total de 237 idosos entre 65-92 anos de idade, sendo avaliada pelo DEXA. Lovell et al.(2010) também utilizaram o DEXA para demonstrar que 16 semanas de $\operatorname{TF}$ ( 3 séries, 8 repetições a 50-90\% de 1RM) foram suficientes para aumentar a MLG $(\mathrm{p}<0,05)$ dos membros superiores de 12 idosos com idade média de 72 anos. Karavita et al. (2008). demonstraram que 21 semanas de treinamento periodizado (2-4 séries, 5-10 repetições a 40-85\% de 1RM) aumentaram a área de secção transversa do músculo vasto lateral, aferida por biópsia, de 25 idosos.

Em relação ao TF utilizando resistência elástica para incremento da massa muscular em idosos. Knwo et al. (2010) avaliou a efetividade de 12 semanas de TF na massa muscular de mulheres idosas obesas com diabetes tipo 2, a analise realizada pelo DEXA relatou incremento de 4,2 \% no membro inferior e $3 \%$ na medida de corpo inteiro. Estes achados corroboram com nossos resultados, onde obtivemos incremento no GE de 3,3\% na MLGI e 1,2\% na MLGT. Porém, as nossas voluntárias em média não eram obesas e eram fisicamente ativas. Colado et al. (2012) avaliaram por bioimpedância elétrica os efeitos de dez semanas de treinamento em mulheres pós menopausa comparando três grupos de intervenção (GE=Elástico $n=21$; GA=Aquático $\mathrm{n}=17$; GMP=Máquina+Peso Livre $\mathrm{n}=14$ ). Foram conduzidas 10 semanas de treinamento, duas vezes por semana, obtiveram incremento da MLG no GE $(p<0,05)$ e 
GMP $(p<0,01)$ com diferença entre os grupos, sendo mais efetivo o GMP. Em nosso estudo foram observadas estas diferenças intra-grupos, porém, na comparação entre os grupos os nossos achados se diferenciam deste estudo, onde não obtivemos diferenças entre os grupos.

Outros dois estudos podem ser destacados. No primeiro So et al. (2013) examinaram os efeitos de 12 semanas de TF sobre a composição corporal de 40 homens e mulheres idosas $(\mathrm{GE}=18 ; \mathrm{GC}=22)$. O estudo foi conduzido em três encontros semanais. Os participantes realizaram 2 a 3 séries de 15 a 25 repetições em cada exercício. A massa muscular foi aferida através de bioimpedância elétrica e demonstraram incremento no $\mathrm{GE}$ de 2,7\% ( $\mathrm{F}=5,7, \mathrm{p}=0,02)$. Em contraste, não houve mudanças significativas no GC. No segundo Ramos et al. (2014) compararam dois tipos de TF na massa muscular em mulheres e homens idosos com doença pulmonar obstrutiva. Os grupos $(\mathrm{GRE}=22 ; \mathrm{GRT}=23)$ realizaram os mesmos exercícios (extensão e flexão de joelho, abdução de ombro e flexão do cotovelo) durante as 8 semanas de intervenção. A massa muscular foi avaliada por DEXA e indicou uma tendência a melhora em ambos os grupos $(p=0,05)$. Não houve diferenças entre os grupos em relação à massa muscular nos membros superiores, inferiores e corpo total após as intervenções. Apesar de não encontrarem diferença estatisticamente significativa houve uma melhora em relação a momento pré intervenção, os autores sugerem que o período de 8 semanas não foi suficiente para obter resultados .

Considerando as evidências supracitadas e as características do treinamento utilizado no presente estudo, podemos interpretar que ambas as intervenções foram capazes de melhorar a MLG, não havendo diferença entre os grupos, corroborando com nossa hipótese do estudo.

\subsection{Efeitos no desempenho funcional}

No presente estudo foram utilizadas avaliações do desempenho funcional nos teste Levantar da cadeira e Flexão de cotovelo. A força indireta do membro superior avaliada pelo teste de FC demonstrou diferenças significativas de 56,3\% e 51,6\% no GE e GM respectivamente, sem diferenças entre os grupos $(\mathrm{p}=0.368)$. Já a força indireta de membros inferiores avaliada pelo TSL demonstrou melhora significativa de 41,4\% e $38.4 \%$ no GE e GM respectivamente, sem diferença entre os grupos ( $\mathrm{p}=0.335)$. 
O estudo de Rikli \& Jones (2013) buscou normatizar padrões clinicamente relevantes para a manutenção da independência física. Os pontos de corte do desempenho funcional estão descritos na Tabela 4. No início do estudo o desempenho na FC foi em média de $(\mathrm{GE}=16,66 \pm 3,62$ e $\mathrm{GM}=16,30 \pm 2,42)$ sendo acima do ponto de corte quando comparado média da faixa etária do presente estudo $(68,44$ anos) com o quadro. Em relação ao TSL, o desempenho foi em média $(\mathrm{GE}=12,50 \pm 2,00$ e $\mathrm{GM}=11,92 \pm 2,37)$ sendo abaixo do ponto de corte. Porém, este fato foi modificado quando analisamos o efeito do TF nesta variável, em ambos os grupos, em média ( $\mathrm{GE}=16,30 \pm 2,42$ e $\mathrm{GM}=16,50 \pm 2,51)$ sugerindo a efetividade das intervenções na melhora da funcionalidade.

Tabela 4- Critérios de referência para a manutenção da independência física de mulheres idosas.

\begin{tabular}{l|c|c|c|c|c|c|c}
\hline & \multicolumn{7}{c}{ Grupos por idade (anos) } \\
\cline { 2 - 8 } & $60-64$ & $65-69$ & $70-74$ & $75-79$ & $80-84$ & $85-89$ & $90-94$ \\
\hline $\begin{array}{l}\text { Força de Membro inferior } \\
\text { (Levantar e sentar de uma cadeira em } \\
\text { 30s; repetições) }\end{array}$ & 14 & 14 & 13 & 13 & 12 & 11 & 9 \\
\hline $\begin{array}{l}\text { Força de Membro Superior } \\
\text { (Realizar flexão de cotovelo com } \\
\text { halteres de 2kg em 30s; repetições) }\end{array}$ & 15 & 15 & 14 & 14 & 13 & 12 & 11 \\
\hline
\end{tabular}

Adaptado de Rikli e Jones 2013.

A melhora no teste FC é consistente com resultado de estudo prévio que aplicou intervenções com máquinas e dispositivos elásticos (COLADO et al., 2008). A melhora no estudo supracitado foi menor do que observado no trabalho em discussão $(30,7 \%$ versus $\mathrm{GE}=56,3 \%$ e $\mathrm{GM}=51,6 \%$ ), o que pode ser explicado, em parte, pelo uso de amostras diferentes em termos de nível de atividade física e no tempo de intervenção (sedentárias x ativas e 8 semanas x 12 semanas). No estudo de Egana et al. (2010) também foi observada melhora neste teste em $140 \%$ com 12 semanas de intervenção com TF com dispositivos elásticos, realizadas duas vezes por semana com 16 mulheres idosas pós menopausa. Ambos os estudo utilizaram em suas intervenções exercícios que estimularam grupos musculares essenciais para a realização do movimento de flexão do cotovelo, fato que pode explicar a melhora significativa.

Em relação ao TSL, o já citado estudo de Egana et al. (2010) demonstrou eficácia do TF no incremento de $129 \%$ nesta variável, este fato ocorreu também no presente estudo em 41,4\% e 38.4\% no GE e GM respectivamente. O estudo de SO et al. (2013) observaram melhora de $20,5 \%$ no TSL como efeito de 12 semanas de TF com dispositivos elásticos, realizados três vezes por semana, 2 a 3 séries de 15 a 25 
repetições. Na revisão sistemática com meta analise de Liu \& Lathan (2009) analisou os efeitos do TF em 11 estudos com 384 participantes no desempenho do TSL, demonstrando uma melhora significativa, moderada de grande efeito para esta tarefa $(\mathrm{SMD}=0,94,95 \% \mathrm{CI}-1,49$ para $-0,38)$.

Alguns estudos avaliaram a funcionalidade utilizando outros testes (knee-pushup, squat e abdominal crunch), e observaram melhoras significativas em ambos os testes, sugerindo que o desempenho funcional pode ser melhorado com a prática regular do TF, seja com máquinas, pesos livre, exercícios aquáticos ou resistência elástica (COLADO et al.; 2008; COLADO et al., 2009; COLADO et al., 2012).

No presente estudo, os dois grupos, apresentaram antes do treinamento, valores semelhantes em todas as variáveis do desempenho funcional analisadas. Os achados corroboram com a literatura discutida e reforçam a eficácia do TF no incremento da funcionalidade para mulheres idosas.

\subsection{Limitações do Estudo}

As limitações do presente estudo são reconhecidas. Não houve controle das atividades externas realizadas pelas participantes, apenas foi solicitado as idosas que não realizassem nenhum tipo de treinamento resistido além do realizado na pesquisa e que mantivessem as atividades corriqueiras da vida diária. O número amostral da pesquisa foi menor no grupo que treinou com resistência elástica por motivos de desistência das participantes. Uma outra limitação foi não ter sido possível realizar o cegamento dos avaliadores da pesquisa por questões de logística.

\subsection{Aplicações Práticas}

De forma importante, os resultados observados no presente estudo fornecem evidencias de que o TF com resistência elástica podem alterar, assim como máquinas e pesos livres, favoravelmente a força, massa muscular e desempenho funcional. Os resultados aqui apresentados ajudam a suportar essa outra possibilidade de praticar o TF utilizando a resistência elástica, que é realizado com auxílio de materiais elásticos em forma de banda ou tubo. Juntamente com acessórios, estes materiais conseguem apresentar diferentes níveis de progressão da intensidade. Estes equipamentos são práticos, portáteis e permitem sua utilização em praticamente qualquer local, além de 
apresentar baixo custo, e possuir ergonomia que permitem tornar os exercícios mais versáteis, possibilitando movimentos mais funcionais, podendo ser mais acessível para a população idosa.

Em conjunto, as observações aqui apresentadas agregam evidencias, as quais indicam que TF deve ser contemplado em programas de atividade física direcionados a indivíduos idosos. 


\section{CONCLUSÕES}

Os resultados encontrados na presente investigação sugerem que o TF realizado com máquinas pneumáticas ou com equipamentos de resistência elástica aplicados por um período de 12 semanas produz melhoras na força, massa muscular e desempenho funcional de mulheres idosas da comunidade. Estes achados constituem importante recurso para atenuar os efeitos degenerativos associados ao envelhecimento. Sendo assim, as hipóteses previamente propostas nessa pesquisa foram corroboradas. Porém, as generalizações dos resultados devem ser vistos com cautela. 


\section{REFERÊNCIAS BIBLIOGRÁFICAS}

ACSM - American College of Sports Medicine. Exercise and Physical Activity for older adults - Position Stand. Medicine \& Science in Sports \& Exercise, 2009.

ACSM \& AHA - American College of Sports Medicine \& American Heart Association. Physical Activity and Public Health in Older Adults. Circulation, 2007.

ACSM \& AHA - American College of Sports Medicine \& American Heart Association. Physical activity guidelines for Americans: Be Active, Healthy and Happy, 2008. Alegre, 2006.

AUYEUNG, T. W. et al. Age-associated decline of muscle mass, grip strength and gait speed: a 4-year longitudinal study of 3018 community-dwelling older Chinese. Geriatr Gerontol Int 2014, 14(Suppl 1):76-84.

BALOH, R. W.; YING, S. H. \& JACOBSON, K. M. A longitudinal study of gait and balance dysfunction in normal older people. Archives of Neurology, v.60, 2003.

BAPTISTA, M. N. et. al. Correlação entre sintomatologia depressiva e prática de atividades sociais em idosos. Avaliação Psicológica, v. 5, n. 1, p. 77-85, 2006.

BEAUCHAMP M. R. et. al. GrOup based physical Activity for oLder adults (GOAL) randomized controlled trial: study protocol. BMC Public Health (2015) 15:592 DOI $10.1186 / \mathrm{s} 12889-015-1909-9$

BOTTARO, M. et al. Effect of high versus low-velocity resistance training on muscular fitness and functional performance in older men. Eur J Appl Physiol, v. 99, p. 257264, 2007.

BOTTARO, M. et al. Effects of rest duration between sets of resistance training on acute hormonal responses in trained women. Journal of Science and Medicine in Sport, v. 12, p. 73- 78, 2009.

BOTTARO, M.; RUSSO, A.F.; OLIVEIRA, R.J. The effects of rest interval on quadriceps torque during an isokinetic testing protocol in elderly. Journal of Sports Science and Medicine, v.4, p.285-290, 2005.

BROWN AB, MCCARTNEY N, SALE DG. Positive adaptations to weight-lifting training in the elderly. J Appl Physiol. 1990; 69:1725-33.

CAMPOS G.E. et al. Muscular adaptations in response to 3 different resistance-training regimens: specifi city of repetition maximum training zones . Eur J Appl Physiol 2002; $88: 50-60$

CARDOSO, R.M. et al., Exercício resistido frente à sarcopenia: uma alternativa eficaz para a qualidade de vida do idoso. XI Encontro Latino Americano de PósGraduação- Universidade do Vale do Paraíba. 2008. 
CARUSO J.F BL, TUFANO JJ. The reproducibility of isokinetic dynamometry Isokinetics. Exercise Science. 2012;20:239-59.

CHEUNG N.W. et. al. A pilot randomised controlled trial of resistance exercise banda in the management of sedentary subjects with type 2 diabetes. Diabetes research and clinical practice. 2009;83(3):e68-71. Epub 2009/01/23.

COLADO J.C, et al. A comparison of elastic tubing and isotonic resistance exercises. International journal of sports medicine. 2010;31(11):810-7. Epub 2010/08/13

COLADO J.C. et al. Effects of Aquatic and Dry Land Resistance Training Devices on Body Composition and Physical Capacity in Postmenopausal Women. Journal of Human Kinetics volume 32/2012, 185-195 DOI:10.2478/v10078-012-0035-3

COLADO J.C., TRIPLETT N.T. Effects of a short-term resistance program using elastic banda versus weight machines for sedentary middle-aged women. Journal of strength and conditioning research / National Strength \& Conditioning Association. 2008;22(5):1441-8. Epub 2008/08/21.

CRUZ-JENTOFT J.A. et al. Sarcopenia: European consensus on definition and diagnosis. Age and Ageing 2010; 39: 412-423 doi: 10.1093/ageing/afq034

DAMUSH T.M, DAMUSH J.G, Jr. The effects of strength training on strength and health-related quality of life in older adult women. The Gerontologist. 1999;39(6):70510. Epub 2000/01/29.

DELMONICO M.J, et al. Alternative definitions of sarcopenia, lower extremity performance, and functional impairment with aging in older men and women. J Am Geriatr Soc. 2007;55:769-74.

DISHMAN R.K. et al.. Physical Activity Epidemiology . Champaign, IL: Human Kinetics ; 2004

DOHERTY, T. J. Invited Review: Aging and sarcopenia. Jounal of Applied Physics, v.95, n. 4, p. 1717-1727, 2003.

DREYER H.C, VOLPI E. Role of protein and amino acids in the pathophysiology and treatment of sarcopenia. J Am Coll Nutr. 2005;24(2):140S-45S.

DROUIN, J. M. et al. Reliability and validity of the Biodex system 3 pro isokinetic dynamometer velocity, torque and position measurements. European Journal of Applied Physiology, v.91, p.22-29, 2004.

EGANA, M., R.. et al. Effect of elastic-band-based resistance training on leg blood flow in elderly women Randomized Controlled Trial. Applied Physiology, Nutrition, and Metabolism, 35, 763-772 http://dx.doi.org/10.1139/H10-071.

El DIB, R. P. Como praticar a medicina baseada em evidências. J Vasc Bras 2007;6(1):1-4. 
FARINATTI, P. T. V. Envelhecimento, promoção da saúde e exercício: bases teóricas e metodológicas. v. 1, 2008. 512p.

FERRI, A. et al. Strength and power changes of the human plantar flexors and knee extensors in response to resistance training in old age. Acta Physiologica Scandinavica, v.177, p.69-78, 2003.

FIATARONE M.A, et. al Highintensity strength training in nonagenarians. Effects on skeletal muscle. the journal of the American Medical Association. 1990;263(22):3029-34. Epub 1990/06/13.

FIELD, A. Discovering Statistics Using SPSS. SAGE, $3^{\circ}$ ed. 2012, 821p.

FLECK SJ FW. Fundamentos do treinamento de força muscular. $3^{\mathrm{a}}$. ed. Porto Alegre, 2006.

FREITAS EV et. al. Tratado de Geriatria e Gerontologia, $3^{\mathrm{a}}$ ed. Rio de Janeiro, Guanabara- Koogan, 2011.

FRONTERA W.R, et al. Strength conditioning in older men: skeletal muscle hypertrophy and improved function. J Appl Physiol. 1988;64(3):1038-44. Epub 1988/03/01.

FRONTERA, W.R. et al. Skeletal muscle fibre quality in older men and women. Am J Physiol Cell Physiol, v.279, p.611-618, 2000.

GEIRSDOTTIR O.G, et al. Physical function predicts improvement in quality of life in elderly Icelanders after 12 weeks of resistance exercise. The journal of nutrition, health \& aging. 2012;16(1):62-6. Epub 2012/01/13.

GENTIL, P.; OLIVEIRA, E.; BOTTARO, M. Time under tension and blood lactate response during four different resistance training methods. J Physiol Anthropol, v. 25, n. 5, p. 339-44, Sep 2006.

GOODPASTER, B H. et al. The Loss of Skeletal Muscle Strength, Mass, and Quality in Older Adults: The Health, aging and body composition study. The Gerontological Society of America, v. 61A, n.10, p.1059-1064, 2006.

HARTHOLT K.A, et al. Societal consequences of falls in the older population: injuries, healthcare costs, and long-term reduced quality of life. The Journal of trauma. 2011;71(3):748-53. Epub 2010/11/04.

HARTMANN A, et. al. Reproducibility of an isokinetic strength-testing protocol of the knee and ankle in older adults. Gerontology. 2009;55(3):259-68. Epub 2008/11/11.

HENWOOD T.R, TAAFFE D.R. Short-term resistance training and the older adult: the effect of varied programmes for the enhancement of muscle strength and functional performance. Clinical physiology and functional imaging. 2006;26(5):305-13. Epub 2006/08/31. 
HORTOBÁGYI T. et al. P. Older Adults Perform Activities of Daily living near their maximal Capabilities. J. Gerontologi Med. Sciences, v.58A, n.5, p.453-460, 2003.

HUGHES F.W, et. al. Longitudinal muscle strength changes in older adults: influence of muscle mass, physical activity and health. J Gerontol A Biol Sci Med Sci 2001;56(5):209-17..

HUNTER GR MP, BAMMAN. Effects of resistance traning on older adults. Sports Med. 2004;34(5):329-48.

IBGE - Instituto Brasileiro de Geografia e Estatística. Indicadores demográficos e de Saúde no Brasil. Brasil, 2009.

IBGE - Instituto Brasileiro de Geografia e Estatística. Resultado do Universo do Censo Demográfico 2010. População residente, por situação de domicílio e sexo, segundo os grupos de idade - Brasil - 2010. Rio de Janeiro, 2010. Disponível em: http://www.ibge.gov.br. Acesso em: Fevereiro de 2015.

IVEY F.M ,et al. Effects of strength training and detraining on muscle quality: age and gender comparisons. J Gerontol A Biol Sci Med Sci, v.55, p.B152-B157, 2000.

JAKOBSEN M.D, et. al. Effectiveness of hamstring knee rehabilitation exercise performed in training machine vs. elastic resistance: electromyography evaluation study. Am J Phys Med Rehabil .2014 Apr; 93 (4): 320-7. doi: 10,1097 / PHM.0000000000000043.

JANSSEN, I. et al. The health care costs of sarcopenia in the United States. J Am Geriatr Soc, vol. 52, n.1, p.80-5, 2004.

JETTE AMLM, et. al. Exercise It's Never Too Late: The Strong-for-LifeProgram. American journal of public health. 1999;89(1):66-72.

KALAPOTHARAKOS, V. I. et al. The effects of high- and moderate-resistance training on muscle function in the elderly. Journal of Aging and Physical Activity, vol.12, n.2, p.131-43, Apr. 2004.

KAMEN G, KNIGHT C.A. Training-related adaptations in motor unit discharge rate in young and older adults. The journals of gerontology Series A, Biological sciences and medical sciences. 2004;59(12):1334-8. Epub 2005/02/09.

KARAVIRTA L, et al. Effects of combined endurance and strength training on muscle strength, power and hypertrophy in 40-67-year-old men. Scandinavian journal of medicine \& science in sports. 2011;21(3):402-11. Epub 2009/12/25.

KARINKANTA, S. et al. Physical therapy approaches to reduce fall and fracture risk among older adults - Review. Nature, v.6, p.396-407, 2010.

KARSCH U.M. Idosos dependentes: famílias e cuidadores. Caderno de Saúde Pública, Rio de Janeiro, vol. 19, n. 3, p. 861-66, 2003. 
KNOW, H. R. et al. The Effects of Resistance Training on Muscle and Body Fat Mass and Muscle Strength in Type 2 Diabetic Women. Korean Diabetes J 2010;34:101-110 doi: $10.4093 / \mathrm{kdj} .2010 .34 .2 .101$

KRAEMER W.J et. al. . Resistance training combined with bench-step aerobics enhances women's health profi le . Med Sci Sports Exerc $2001 ; 33: 259$ - 269

KREBS D.E, et al. Moderate exercise improves gait stability in disabled elders. Archives of physical medicine and rehabilitation. 1998;79(12):1489- 95. Epub 1998/12/23.

LANDI, F. et. al., Exercise as a remedy for sarcopenia.Curr Opin Clin Nutr Metab Care .2014, 17:25-31 DOI:10.1097/MCO.0000000000000018

LEXELL J., TAYLOR C.C. Variability in muscle fiber areas in whole human quadriceps muscle: Effects of increasing age. J Anat, v. 174, p. 239-249, 1991.

LIMA, R. M. et al. Fat-free mass, strength, and sarcopenia are related to bone mineral density in older women. Journal of Clinical Densitometry, vol.12, p.35-41, 2009.

LIU C.J, LATHAM N.K. Progressive resistance strength training for improving physical function in older adults. Cochrane Database Syst Rev. 2009(3):CD002759. Epub 2009/07/10.

LOVELL D.I, et. al. The effect of strength training and short-term detraining on maximum force and the rate of force development of older men. European journal of applied physiology. 2010;109(3):429-35. Epub 2010/02/09.

LUSTOSA L, et. al. Traducao, adaptação transcultural e analise das propriedades psicometricas do Questionario Minnesota de Atividades Fisicas e de Lazer. . Cadernos de Saude Publica 2009

MACALUSO A, De VITO G. Muscle strength, power and adaptations to resistance training in older people. European journal of applied physiology. 2004;91(4):45072.Epub 2003/11/26.

MAHANT, P.R.; STACY J. Movement disorders and normal aging. Neurol Clin. 2001 Aug; 19(3):553-63

MARTINS WR et. al .Arch Gerontol Geriatr. Mechanical evaluation of elastic tubes used in physical therapy. Physiother Theory Pract, Early Online: 1-5 2013

MARTINS WR et. al. Elastic resistance training to Increase Muscle Strength in Elderly: A systematic review with metaanalysis. Archives of biochemistry and biophysics. No prelo 2013.;Arch Gerontol Geriatr.

MATSUDO, S. M. Avaliação do idoso: física e funcional. Londrina: Midiograf; 2000.

MATSUDO, S.M.M. Avaliação do Idoso: Física \& Funcional. $3^{\text {a }}$ Ed. 2010. 261p. 
MCGREGOR et al. It is not just muscle mass: a review of muscle quality, composition and metabolism during ageing as determinants of muscle function and mobility in later life. Longevity \& Healthspan 2014, 3:9

MIKESKY A.E, et al. Efficacy of a home-based training program for older adults using elastic tubing. European journal of applied physiology and occupational physiology. 1994;69(4):316-20. Epub 1994/01/01.

MORLEY JE. Sarcopenia: diagnosis and treatment. J Nutr Health Aging. 2008;12:452-6.

MORSE C.I, et. al. Muscle strength, volume and activation following 12-month resistance training in 70-year-old males. European journal of applied physiology. 2005;95(2-3):197-204. Epub 2005/07/09.

MS - Ministério da Saúde. VIGITEL - Vigilância de Fatores de Risco e Proteção para Doenças Crônicas por Inquérito Telefônico - Estimativas sobre frequência e distribuição sociodemográfica de fatores de risco e proteção para doenças crônicas nas capitais dos 26 estados brasileiros e no Distrito Federal em 2014. Brasil, 2015.

OLSSON M.U, et. al.. Prevalence and predictors of falls and dizziness in people younger and older than 80 years of age-A longitudinal cohort study. Archives of gerontology and geriatrics. 2012. Epub 2012/09/25.

OMS - Organização Mundial da Saúde. Good Health adds life to years: Global brief for World Health Day, 2012.

ORR R, et al.Power training improves balance in healthy older adults. J Gerontol A Biol Sci Med Sci, v.61ª, n.1, p.78-85, 2006.

PATERSON D. H. et. al. Ageing and physical activity: evidence to develop exercise recomendations for older adults. Appl. Physiol. Nutr. Metab. 32.S6S108 (2007)-

PETERSON M.D, et al. Resistance exercise for muscular strength in older adults: a meta-analysis. Ageing research reviews. 2010;9(3):226-37. Epub 2010/04/14.

PETERSON M.D, et. al. Influence of resistance exercise on lean body mass in aging adults: a meta-analysis. Medicine and science in sports and exercise. 2011;43(2):24958. Epub 2010/06/15.

PETERSON M.D, et. al. Influence of resistance exercise on lean body mass in aging adults: a meta-analysis. Medicine and science in sports and exercise. 2011;43(2):24958. Epub 2010/06/15.

PÍCOLI T. et al.. Sarcopenia e envelhecimento.Fisioter Mov. 2011 jul/set;24(3):45562. doi: 10.1590/S0103-51502011000300010

PILLARD F,et al. Physical activity and sarcopenia. Clinics in geriatric medicine. 2011;27(3):449-70. Epub 2011/08/10. 
RABELO, H. T.; OLIVEIRA, R. J.; BOTTARO, M. Effects of resistance training on activities of daily living in older women. Biology of Sports; vol. 21, p.325-336, 2004.

RAGUSO K.U, et al. A 3-year longitudinal study on body composition changes in the elderly: role of physical exercise. Clin Nutr. 2006;25(4).

RAMOS,E. M. C., et .al. The effects of elastic tubing-based resistance training compared with conventional resistance training in patients with moderate chronic obstructive pulmonary disease: a randomized clinical trial. Clinical Rehabilitation 2014, Vol. 28(11) 1096-1106. DOI: 10.1177/0269215514527842

RIBEIRO, F, et. al.. Impact of low cost strength training of dorsi- and plantar flexors on balance and functional mobility in institutionalized elderly people. Geriatrics \& Gerontology International, (2009) 9, 75-80 http://dx.doi.org/10.1111/j.14470594.2008.00500.x.

RIBOM, E. L. et al. Population-based reference values of handgrip strength and functional tests of muscle strength and balance in men aged 70-80 years. Arch Gerontol Geriatr, v. 53, n. 2, p. 114-117, 2011.

RIKLI, R. E.; JONES, C. J .Development and Validation of Criterion- Referenced Clinically Relevant Fitness Standards for Maintaining Physical Independence in Later Years. The Gerontologist Vol. 53, No. 2, 255-267 doi:10.1093/geront/gns071

RIKLI, R. E.; JONES, C. J. Teste de Aptidão Física para Idosos. Ed. Manole, 2008, $183 p$.

ROSENBERG, I. Epidemiologic and methodologic problems in determining nutritional status of older persons. Proceedings of a conference. Albuquerque, New Mexico, October 19-21, 1988. Am J Clin Nutr, vol. 50(5 Suppl), p.1121-235, 1989.

ROSENBERG, I.H. Summary comments. The American Journal of Clinical Nutrition, v.50, p.1231-1233, 1989.

ROSENBERG, I.H. Summary comments. The American Journal of Clinical Nutrition, v.50, p.1231-1233, 1989.

SAKANOUE N. K.K. The resistance quantity in knee extension movement of exercise banda (Thera-Band®). J Phys Ther Sci. 2007;19(4):287-91.

SANTILLI, V.et. al. Clinical definition of sarcopenia. Clinical Cases in Mineral and Bone Metabolism 2014; 11(3): 177-180

SCOTT D, et. al, Jones G. The epidemiology of sarcopenia in community living older adults: what role does lifestyle play? Journal of cachexia, sarcopenia and muscle. 2011;2(3):125-34. Epub 2011/10/04.

SILVA, L.A et al. Influence of strength training variables on strength gains in adults over 55 years-old: A meta-analysis of dose-response relationships Journal of Science and Medicine in Sport 17 (2014) 337-344 
SO, W. Y, et al. Body composition, fitness level, anabolic hormones, and inflammatory cytokines in the elderly: a randomized controlled trial.Aging Clin Exp Res (2013) 25:167-174 DOI 10.1007/s40520-013-0032-y

STEIB S, et. al. Dose-response relationship of resistance training in older adults: a meta-analysis. Medicine and science in sports and exercise. 2010;42(5):902 14. Epub 2009/12/10.

TOOMBS R.J, Ducher G, Shepherd JA, De Souza MJ. The impact of recentvtechnological advances on the trueness and precision of DXA to assess bodyvcomposition. Obesity (Silver Spring). 2012;20(1):30-9.

TOPP et al. Effect of resistance training on strength, postural control, and gait velocity among older adults. Clinical nursing research. 1996;5(4):407-27. Epub 1996/11/01

VALENTE, M. Sarcopenia. In: FREITAS, E. V.; CANÇADO, F. A. X.; DOLL, J.; GORZONI, M. L. Tratado de Geriatria e Gerontologia. p.1019-1029, 2011.

VANDERVOORT A.A. Aging of the human neuromuscular system. Muscle Nerve. 2002;25(1):17-25.

VERAS, R. Em busca de uma assistência adequada à saúde do idoso: revisão da literatura e aplicação de um instrumento de detecção precoce e de previsibilidade de agravos. Caderno de Saúde Pública, Rio de Janeiro, vol. 19, n. 3, p. 705-715, 2003.

VISSER, M.; SCHAAP, L. A. Consequences of Sarcopenia, Clin Geriatr. Med, v. 27, 387-399, 2011.

WALRAND, S. et al. Physiopathological Mechanism of Sarcopenia. Clin Geriatr Med, v.27, p.365-385, 2011.

WEBBER, S. C., \& PORTER, M. M. Effects of ankle power training on movement time in mobility-impaired older women. [Randomized Controlled Trial Research Support, Non-U. S. Gov’t]. Med Sci Sports Exerc, 2010.42(7), 1233-1240

WHO-World Health Organization. Global recommendations on physical activity for health, 2010. 
ANEXOS

ANEXO A

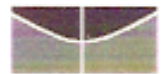

Universidade de Brasilia

Faculdade de Ciências da Saúde

Comitê de Ética em Pesquisa - CTP/FS

\section{PROCESSO DE ANÁLISE DE PROJETO DE PESQUISA}

Registro do Projeto no CEP: 081/11

Titulo do Projeto: "Efeitos do treinamento resistido com máquinas de peso versus dispositivos elásticos sobre a força muscular de idosos".

l'esquisadora Responsável: Wagner Rodrigues Martins

D)ata de Fntrada: 10/05/11

Com hase na Resoluçăo 196/96. do CNS/MS. que regulamenta a ética em pesquisa com seres humanos, o Comitê de Ética em Pesquisa con Seres Ilumanos da Faculdade de (iêneias da Saủde da Universidade de Brasília. após análise dos aspectos éticos e do contexto técnico-cientílico, resolveu APROVAR o projeto 081/11 com o título: "Efeitos do treinamento resistido com máquinas de peso versus dispositives clásticos sobre a força muscular de idosos". analisado na $1^{3}$ reuniào extraordinária realizadia no dia 28 de junho de 2011

O pesquisador responsável lica. desde já, notilicado da obrigatoriedade da apresentaçầo de un relatório semestral e relatório final sucinto e objetivo sobre o desenvolvimento do Projelo, no prazo de I (um) ano a contar da presente data (item VII.13 da Resolução 196/96).

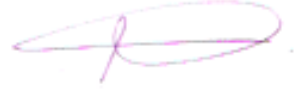

Thiago Rocha da Cunha Vice - coordenador do ClP-1S/ InB 


\section{ANEXO B}

\section{TERMO DE CONSENTIMENTO LIVRE E ESCLARECIDO}

Caro participante, você está sendo convidado a participar voluntariamente de uma pesquisa na Universidade de Brasília intitulada de "Efeitos do treinamento com resistência elástica progressiva na força, massa muscular e desempenho funcional de idosos sedentários".

Por favor, leia com atenção as informações contidas neste termo antes de tomar qualquer decisão sobre sua participação como voluntário. Todos os esclarecimentos que julgar necessário antes e durante a pesquisa poderão ser feitos diretamente para o pesquisador responsável. A sua participação é voluntária e você terá plena e total liberdade para desistir do estudo a qualquer momento, sem que isso acarrete em qualquer prejuízo para você. Da mesma forma, você terá direito de recusar a responder questões que lhe tragam constrangimentos. Todas as informações relacionadas a pesquisa são confidenciais e qualquer informação divulgada em relatório ou publicação será feita sob forma codificada, para que seu sigilo seja mantido. Os pesquisadores garantem que seu nome não será divulgado sob hipótese alguma em qualquer publicação.

O objetivo desta pesquisa é verificar se exercícios com dispositivos de resistência elástica podem aumentar a força e massa muscular em idosos sedentários. Espera-se que os exercícios elásticos possam aumentar a força e massa muscular dos membros superiores, inferioresde idosos, como ocorre nos exercícios com máquinas de musculação. Para prevenir possíveis dores musculares decorrente do início do treinamento, todos os voluntários realizarão 02 (duas) semanas de exercícios leves, em um período chamado de familiarização, com total de 04 dias de exercícios.

Em relação aos procedimentos da pesquisa, caso você não tenha um atestado médico próprio para a prática de exercícios resistidos, você deverá passar por uma consulta médica para avaliar sua saúde hoje e no passado. Caso seja necessário, podemos indicar um médico para tal avaliação, o qual poderá de acordo com a necessidade recomendar exames complementares para o coração com intuito de atestar sua aptidão física para participar de exercícios. No entanto, se for do seu interesse, essa avaliação poderá ser feita com seu cardiologista particular, que deverá lhe fornecer um atestado médico. A próxima etapa da pesquisa envolve a realização de 03 (três) testes: $\left(1^{\circ}\right)$ avaliação do nível de atividade física, $\left(2^{\circ}\right)$ avaliação da força muscular dos 
membros e coluna e $\left(3^{\circ}\right)$ avaliação da composição corporal. Essa etapa poderá durar de 01 (um) a 02 (dois) dias. Com o término dessa etapa de avaliação tem início a fase de exercícios com o chamado período de familiarização, que consistirá de duas semanas de exercícios leves. Depois dessas 02 (duas) semanas, você realizará mais 12 (dezesseis) semanas de exercícios com nível de esforço progressivo. A fase de exercícios será realizada sempre as segundas e quartas feiras, ou terças e quintas, no período matutino. A avaliação da força muscular dos membros e a avaliação da composição corporal serão novamente repetidas na $12^{\mathrm{a}}$ semana de exercícios. É importante ressaltar que os voluntários precisam ter no mínimo $75 \%$ (setenta e cinco por cento) de presença para um resultado significativo. Toda a pesquisa será realizada na Faculdade de Ceilândia Universidade de Brasília, Localizada na QNM 14, Ceilândia Sul, na sede do Centro de Ensino Médio número 4. Referência: Próximo à Escola Técnica de Ceilândia, Estação do metrô Guariroba fica ao lado da faculdade.

Os resultados do presente estudo serão divulgados em eventos e revistas científicas nacionais ou internacionais Esse termo de consentimento encontra-se redigido em duas vias, sendo uma para o participante e outra para o pesquisador.

Em caso de dúvidas utilize os contatos abaixo:

- Contatos do pesquisador responsável: (62) 9242-8111 (comercial). Email: gersonjunior1984@hotmail.com

- Contatos do Comitê de Ética em Pesquisa da Faculdade de Ciências da Saúde da Universidade de Brasília: (61) 3107-1947. Email: cepfs@unb.br

Diante do exposto acima eu, , declaro que

li e discuti com o pesquisador responsável pelo presente estudo os detalhes descritos neste documento e fui esclarecido(a) sobre os objetivos e procedimentos do presente estudo. Participo de livre e espontânea vontade do estudo em questão. Foi-me assegurado o direito de abandonar o estudo a qualquer momento, se eu assim o desejar. $\mathrm{Eu}$ entendi as informações apresentadas neste termo de consentimento e recebi uma cópia assinada e datada deste documento de consentimento informado.

Brasília, de de 


\section{ANEXO C \\ - QUESTIONÁRIO PARA IDENTIFICAÇÃO INICIAL DOS CRITÉRIOS DE SELEÇÃO DA AMOSTRA}

Nome: Data:

Telefone: Idade:

Código para preenchimento das perguntas: $\mathrm{S}=\operatorname{sim}$ ou $\mathrm{N}=$ Não.

Critérios de inclusão:

$\mathrm{O} \mathrm{Sr}^{\mathrm{a}}$

( ) Reside no distrito federal? Bairro?

( ) Tem idade igual ou superior a 60 anos?

( ) Tem atestado médico de liberação para exercícios resistidos?

Critérios de exclusão:

O Sr. (a)

( ) Possui algum problema de saúde (doença)?

Qual(s):

( ) Tem hipertensão arterial (>150/90 mmHg)?

Medicamento em uso:

Algum outro medicamento?

( ) Sofreu infarto do miocárdio nos últimos 6 meses?

( ) Tem marcapasso no coração?

( ) Já fez alguma cirurgia para colocação de prótese?

Local:

( ) Tem fez alguma cirurgia para colocação de placa e/ou parafuso?

Local:

( ) Fez alguma cirurgia nos últimos 6 meses?

Tipo/região:

( ) Sofreu fratura óssea ou lesão muscular nos últimos 6 meses?

Local:

( ) Faz algum tipo de treinamento resistido nos últimos 06 meses?

Qual(s):

( ) Faz uso de terapia hormonal? 
Questionário adaptado utilizado para medidas de Atinidade Física, a partir da versâo brasileira do Minnesota Leisure Tme Activity Queshionnaìe. FIBRA Campinas. Idoso, 2008-2009

Bloco 1 - Itens referentes à pritica de exercicios fisicos e esportes ativos

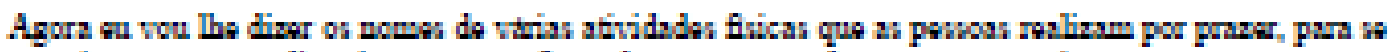

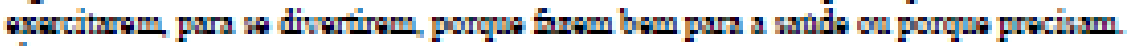

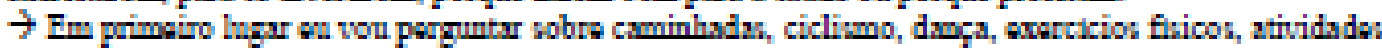

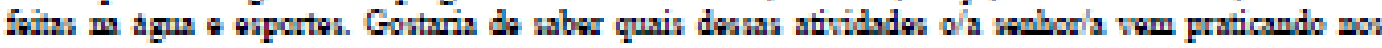
thimen 12 mons.

\begin{tabular}{|c|c|c|c|c|}
\hline Pergutar pun bomans o mulhare: & Rapont & $\begin{array}{l}\text { Qunitos } \\
\text { mengs as } \\
\text { ano? }\end{array}$ & $\begin{array}{l}\text { Quxntos } \\
\text { disingan } \\
\text { saman? }\end{array}$ & $\begin{array}{l}\text { Quniso } \\
\text { por dis? }\end{array}$ \\
\hline 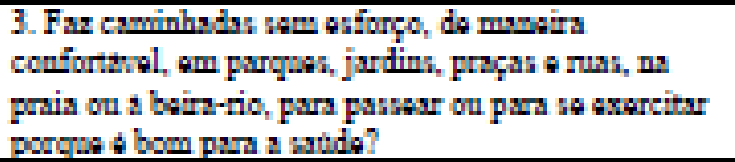 & $\begin{array}{l}1.5 \mathrm{mim} \\
2 \mathrm{NBo} \\
9 \mathrm{NR}\end{array}$ & & & \\
\hline 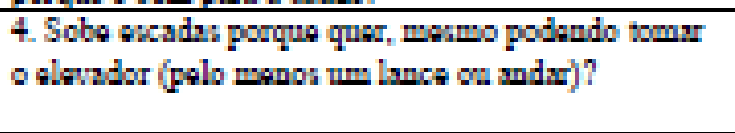 & $\begin{array}{l}1.5 \mathrm{im} \\
2 \mathrm{NAb} \\
9 \mathrm{NR}\end{array}$ & & & \\
\hline $\begin{array}{l}\text { 5. Pratica ciclines por prasar on vai tabalhar da } \\
\text { bicielaw? }\end{array}$ & $\begin{array}{l}1.5 \mathrm{~m} \\
2 \mathrm{NSh} \\
99 \mathrm{NR}\end{array}$ & & & \\
\hline 6. Fax danga de ralion? & $\begin{array}{l}1.5 \mathrm{~m} \\
2 \mathrm{NSo} \\
9 \mathrm{NR}\end{array}$ & & & \\
\hline 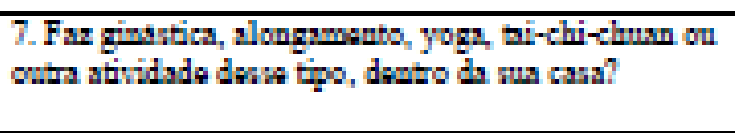 & $\begin{array}{l}1 . \operatorname{Sim} \\
2 \mathrm{Nan} \\
9 \mathrm{NR}\end{array}$ & & & \\
\hline 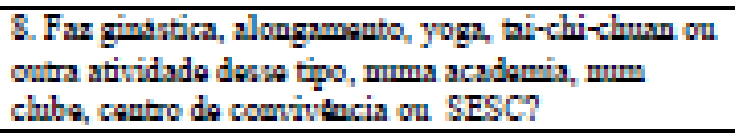 & $\begin{array}{l}1.3 \mathrm{~m} \\
2 \mathrm{Nio} \\
99 \mathrm{NR}\end{array}$ & & & \\
\hline $\begin{array}{l}\text { 9. Far hidroginastica nn acadamis, unm cluba, canto } \\
\text { do courivencis ou SESC? }\end{array}$ & $\begin{array}{l}1 \text { Sim } \\
2 \mathrm{NSi} \\
92 \mathrm{NR}\end{array}$ & & & \\
\hline 10. Pratica courids love on exminhs ds mais tigoron? & $\begin{array}{l}1.5 \mathrm{~min} \\
2 \mathrm{NSo} \\
9 \mathrm{NR}\end{array}$ & & & \\
\hline 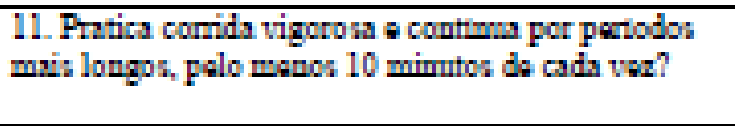 & $\begin{array}{l}1.5 \mathrm{~m} \\
2 \mathrm{~N} \\
99 \mathrm{NR}\end{array}$ & & & \\
\hline 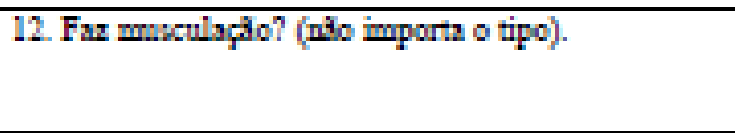 & $\begin{array}{l}1.5 \mathrm{mim} \\
2 \mathrm{N3o} \\
9 \mathrm{NR}\end{array}$ & & & \\
\hline 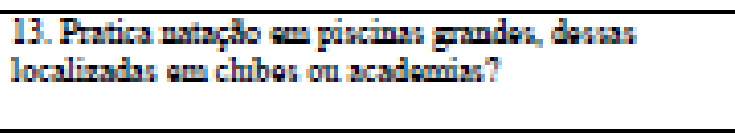 & $\begin{array}{l}1.5 \mathrm{~m} \\
2 \mathrm{NHo} \\
9 \mathrm{NR}\end{array}$ & & & \\
\hline 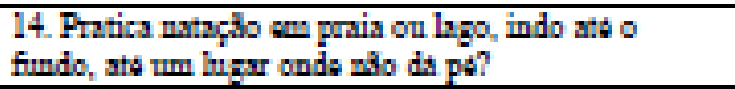 & $\frac{1.5 i m}{2 N a b}$ & & & \\
\hline
\end{tabular}




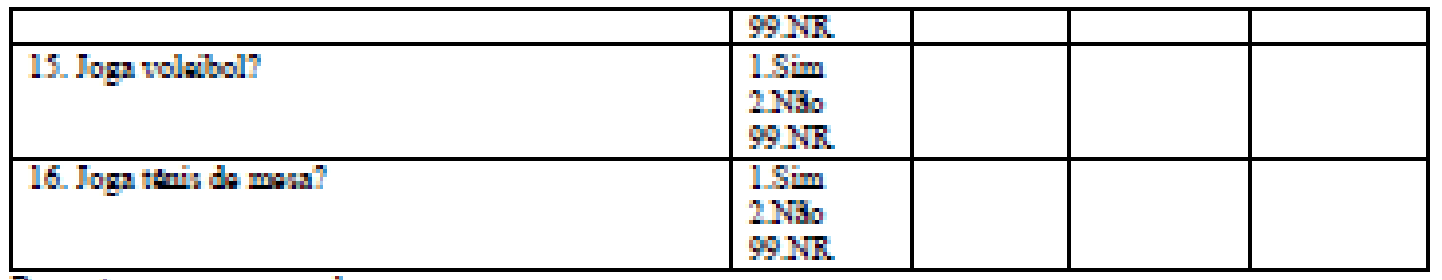

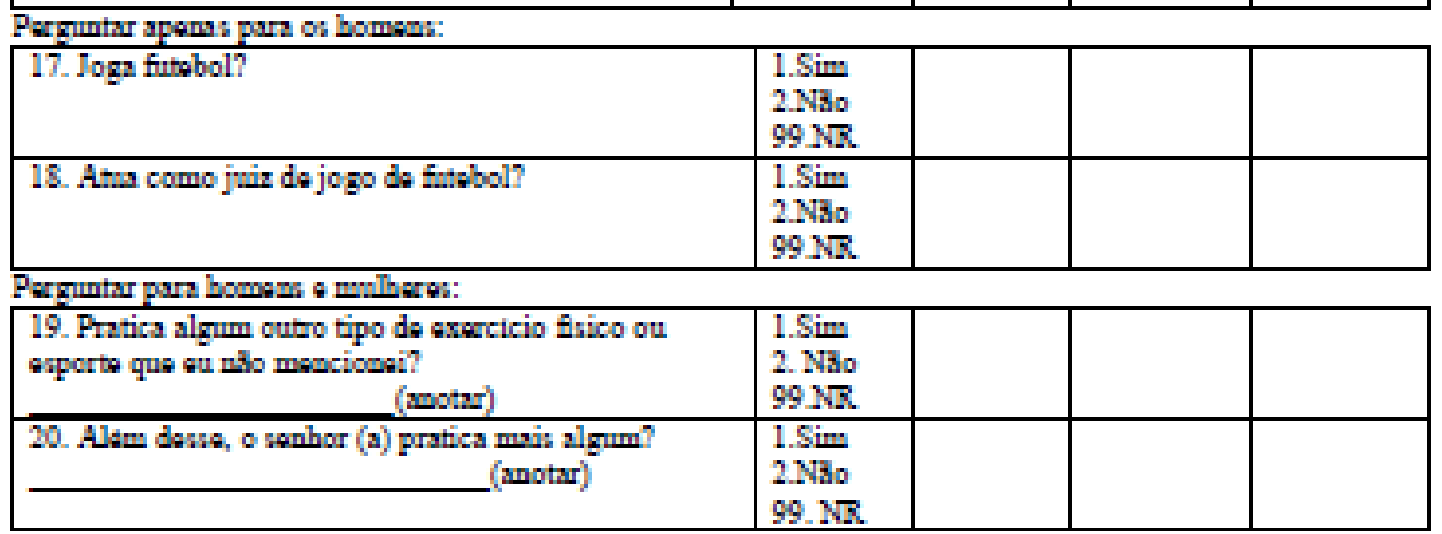

Voltar para o itom 3, pergantando wobre a frequatucia o a duraçało das atividados as quais o (a) idoso (a) rerponden sim

\section{Bloco 2-Itens referentes a tarefas domésticas}

Agora on vou the perguntar sobre stividades domssticas que o sembor vem praticando aos ultimos 12 meses. O (a) venbor(a) vai rerpoodando somaute sim on nde.

\begin{tabular}{|c|c|c|c|c|}
\hline Perguntar para homens e mulheres: & Rerposta & $\begin{array}{l}\text { Quantos } \\
\text { meses no } \\
\text { ano? }\end{array}$ & $\begin{array}{l}\text { Quantos } \\
\text { diss ux } \\
\text { semens? }\end{array}$ & $\begin{array}{l}\text { Quamto } \\
\text { tompo por } \\
\text { dis? }\end{array}$ \\
\hline 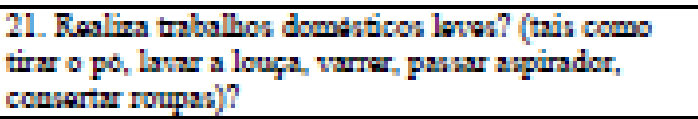 & $\begin{array}{l}1 . \mathrm{Sim} \\
2 \mathrm{N30} \\
99 \mathrm{NR}\end{array}$ & & & \\
\hline 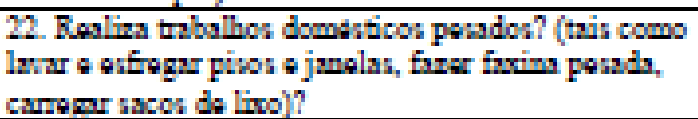 & $\begin{array}{l}1 . \mathrm{Sim} \\
2 \mathrm{N30} \\
99 \mathrm{NR}\end{array}$ & & & \\
\hline 23. Corinhs on ajods no propuro da courida? & $\begin{array}{l}1 . \operatorname{Sim} \\
2 \mathrm{NBo} \\
99 \mathrm{NR}\end{array}$ & & & \\
\hline 24. Corta grama com cortador alstrico? & $\begin{array}{l}1 . \mathrm{Sim} \\
2 \mathrm{N30} \\
99 \mathrm{NR}\end{array}$ & & & \\
\hline 25. Corta grama com cortador mamal? & $\begin{array}{l}1 . \mathrm{Sim} \\
2 \mathrm{N30} \\
99 \mathrm{NR}\end{array}$ & & & \\
\hline $\begin{array}{l}\text { 26. Tirs o mato o mantem um judim ou uma horth } \\
\text { que ja estaram formados? }\end{array}$ & $\begin{array}{l}1 . \operatorname{Sim} \\
2 \mathrm{N30} \\
99 \mathrm{NR}\end{array}$ & & & \\
\hline $\begin{array}{l}\text { 27. Capins, afofa a tema, aduba, cavz, planta on } \\
\text { samaia para former um jardim ou uma horta? }\end{array}$ & $\begin{array}{l}1 . \mathrm{Sim} \\
2 \mathrm{N3o} \\
99 \mathrm{NR}\end{array}$ & & & \\
\hline $\begin{array}{l}\text { 25. Constroi on conserta moveis ou outros utonstlios } \\
\text { domenticos, dentro de sua casa, usamdo martolo, serra } \\
\text { e outras farramontas? }\end{array}$ & $\begin{array}{l}1.5 \mathrm{im} \\
2 \mathrm{N30} \\
99 \mathrm{NR}\end{array}$ & & & \\
\hline 29. Pinh a casa por dautro, fas ou conserth & $1 . \operatorname{Sim}$ & & & \\
\hline
\end{tabular}




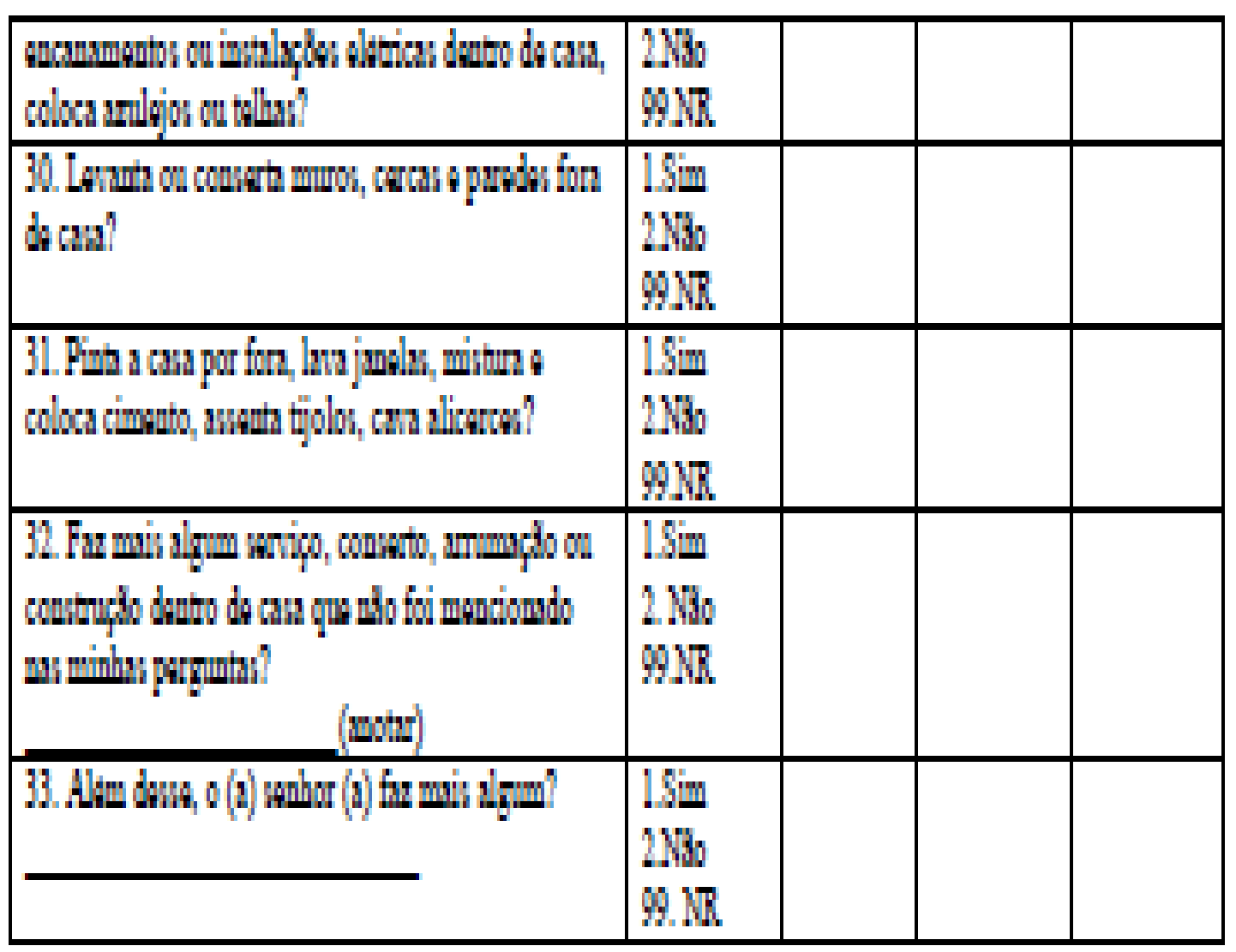

